March $2000 \quad$ • NREL/TP-520-28110

\title{
Optical Durability Testing of Candidate Solar Mirrors
}

G. Jorgensen, C. Kennedy, D. King, and $\mathrm{K}$. Terwilliger

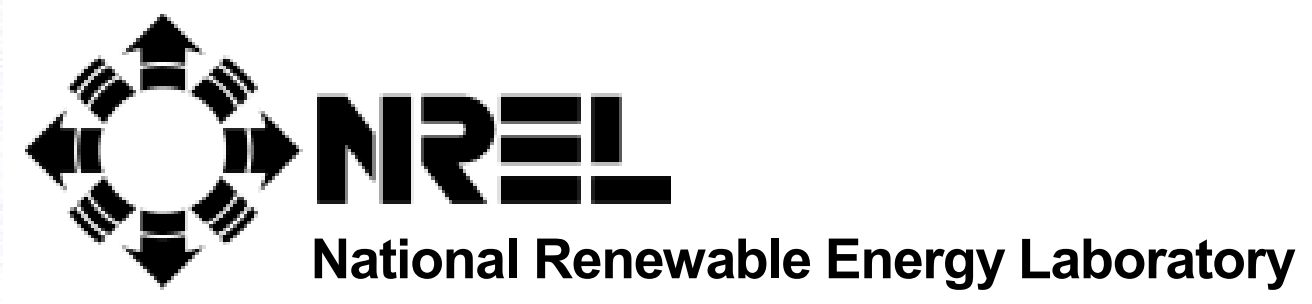

1617 Cole Boulevard

Golden, Colorado 80401-3393

NREL is a U.S. Department of Energy Laboratory

Operated by Midwest Research Institute $\bullet$ Battelle $\bullet$ Bechtel

Contract No. DE-AC36-99-G010337 


\section{Optical Durability Testing of Candidate Solar Mirrors}

\section{G. Jorgensen, C. Kennedy, D. King, and $\mathrm{K}$. Terwilliger}

Prepared under Task No. CP013200

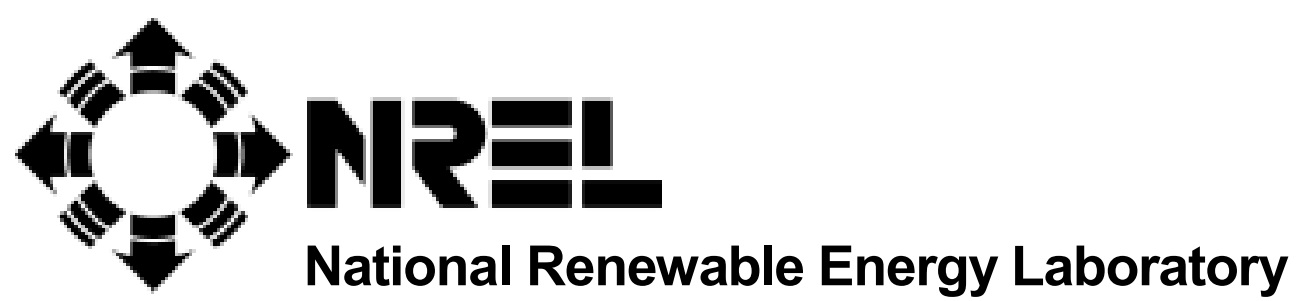

1617 Cole Boulevard

Golden, Colorado 80401-3393

NREL is a U.S. Department of Energy Laboratory

Operated by Midwest Research Institute $\bullet$ Battelle $\bullet$ Bechtel

Contract No. DE-AC36-99-G010337 


\section{NOTICE}

This report was prepared as an account of work sponsored by an agency of the United States government. Neither the United States government nor any agency thereof, nor any of their employees, makes any warranty, express or implied, or assumes any legal liability or responsibility for the accuracy, completeness, or usefulness of any information, apparatus, product, or process disclosed, or represents that its use would not infringe privately owned rights. Reference herein to any specific commercial product, process, or service by trade name, trademark, manufacturer, or otherwise does not necessarily constitute or imply its endorsement, recommendation, or favoring by the United States government or any agency thereof. The views and opinions of authors expressed herein do not necessarily state or reflect those of the United States government or any agency thereof.

Available electronically at http://www.doe.gov/bridge

Available for a processing fee to U.S. Department of Energy

and its contractors, in paper, from:

U.S. Department of Energy

Office of Scientific and Technical Information

P.O. Box 62

Oak Ridge, TN 37831-0062

phone: 865.576.8401

fax: 865.576.5728

email: reports@adonis.osti.gov

Available for sale to the public, in paper, from:

U.S. Department of Commerce

National Technical Information Service

5285 Port Royal Road

Springfield, VA 22161

phone: 800.553.6847

fax: 703.605.6900

email: orders@ntis.fedworld.gov

online ordering: http://www.ntis.gov/ordering.htm

Printed on paper containing at least $50 \%$ wastepaper, including $20 \%$ postconsumer waste 


\title{
Optical Durability Testing of Candidate Solar Mirrors
}

\author{
Gary Jorgensen, Cheryl Kennedy, David King, Kent Terwilliger
}

\begin{abstract}
Summary
Durability testing of a variety of candidate solar reflector materials at outdoor test sites and in laboratory accelerated weathering chambers is the main activity within the Advanced Materials task of the Concentrated Solar Power (CSP) Program. Outdoor exposure testing (OET) at up to eight outdoor, worldwide exposure sites has been underway for several years. This includes collaboration under the auspices of the International Energy Agency (IEA) Solar Power and Chemical Energy Systems (SolarPACES) agreement. Outdoor sites are fully instrumented in terms of monitoring meteorological conditions and solar irradiance. Candidate materials are optically characterized prior to being subjected to exposure in real and simulated weathering environments. Optical durability is quantified by periodically re-measuring hemispherical and specular reflectance as a function of exposure time. By closely monitoring the site- and time-dependent environmental stress conditions experienced by the material samples, site-dependent loss of performance may be quantified. In addition, accelerated exposure testing (AET) of these materials in parallel under laboratory-controlled conditions may permit correlating the outdoor results with AET, and subsequently predicting service lifetimes. Test results to date for a large number of candidate solar reflector materials are presented in this report. Acronyms are defined in Table 1.

Based upon OET and AET results to date, conclusions can be drawn about the optical durability of the candidate reflector materials. The optical durability of thin glass (from Naugatuck, Schlaich, Bergermann und Partner, or Steinmüller), thick glass (from ATS or Flagsol), and two metallized polymers (SA-85, ECP-305+) can be characterized as excellent. The all-polymeric construction, several of the aluminized reflectors (Alanod's improved product, materials from Metalloxyd), and a metallized polymer (ECP-305) can be characterized as having intermediate durability and require further improvement, testing and evaluation, or both. A metallized polymer (SS-95), metallized fluoropolymers (until specularity can be sufficiently improved), and constructions in which adhesives are in direct contact with a silver reflective layer can be characterized as poor and do not warrant further consideration for solar applications. Recently, a number of new promising constructions have been identified including: several front-surface mirrors under an ongoing Sun Lab subcontract and prepared by Sun Lab staff; a new all-polymeric construction using improved interlayer resins and incorporating UV screens; a newly available commercial solar reflector material called SolarBrite 95; and a novel commercial laminate construction co-invented by Sun Lab staff and industry collaborators.
\end{abstract}




\subsection{Introduction}

Potential investors in CSP systems demand confidence in the long-term durability of solar reflectors deployed in actual service conditions. The primary objective of Sun Lab's Solar Mirror Durability Testing activity is to quantify performance loss for a variety of candidate reflector materials as a function of exposure time at a number of outdoor locations. The exposure conditions are close to those sites of interest to utilities and industrial companies deploying CSP systems. The sites provide a way for utilities to gain direct experience with materials that may be used in prototype commercial power plants. Careful planning and proper execution of this research are intended to enable an understanding of why materials degrade differently at geographically diverse test sites. In addition, by complementing the outdoor test activities with parallel accelerated laboratory testing of the same materials, correlation of these results may allow quantitative prediction of the service lifetime of materials [1]. In this way, convincing estimates of optical durability can be made for materials deployed at locations other than those at which materials are actually tested (given the meteorological and radiometric characteristics of that site) and for new candidate solar mirrors, based upon accelerated test results only. This in turn will greatly facilitate and support commercialization of concentrating solar power technologies by providing greater confidence in life-cycle cost estimates and less uncertainty in warranty projections.

\subsection{Technical Approach}

Candidate reflector materials are identified based on their potential for low cost and high optical performance and durability. Samples are supplied by industry, fabricated by Sun Lab subcontractors, or prepared in-house by Sun Lab staff; all constructions are optically characterized prior to exposure testing. These mirrors are then subjected to outdoor weathering at a variety of geographically diverse exposure sites. At each location, radiometric and meteorological monitoring are performed to identify the important environmental exposure conditions (stresses) experienced by the materials being tested that can affect the material's performance and useful lifetime. Sites operational in the US have been augmented by collaborative efforts under the auspices of the IEA SolarPACES subtask 3.3.2 agreement [2]. Optical performance is periodically re-measured as a function of exposure time (stresses) to assess optical durability. Additionally, materials are subjected to laboratory-controlled AET. Sun $\downarrow$ Lab's exposure chambers are typically operated at $60^{\circ} \mathrm{C}$ and 60 $75 \%$ relative humidity $(\mathrm{RH})$ and have xenon-arc lamps appropriately filtered to replicate a terrestrial air-mass (AM) 1.5 solar spectrum.

\subsection{Optical Characterization}

Optical performance is characterized in terms of specular reflectance, the degree to which a mirror is capable of transferring directed radiation to a target receiver surface. Microroughness of a mirror surface, crazing of protective top coats, or both can result in scattering (loss) of light outside a specified acceptance angle, defined as the half angle $(\theta)$ subtended by the receiver as viewed from the reflector surface. Candidate reflector materials must exhibit very good specular reflectance. Depending on the CSP application, the system requirement is typically $90 \%$ reflectance into a half cone angle of 2-4 mrad [3]. At each wavelength $(\lambda)$, the level of specular 
reflectance $\left(\rho_{\mathrm{s}}\right)$ is a function of both the hemispherical reflectance $\left(\rho_{2 \pi}\right)$ and the half-width $(\sigma)$ of the (assumed Gaussian) distribution of scattered light, as defined in Equation 1:

$$
\rho_{\mathrm{s}}(\theta, \lambda)=\rho_{2 \pi}(\lambda)\left\{1-\exp \left[\frac{-\theta^{2}}{2 \sigma^{2}(\lambda)}\right]\right\}
$$

During weathering, loss in specular reflectance has generally been found to be proportional to loss in hemispherical reflectance. That is, weathering causes corrosion-induced loss in hemispherical reflectance of the reflective layer much sooner than loss of specularity (increase in $\sigma$ ) by surface effects (soiling, crazing, etc.) of the superstrate or a variety of other mechanisms. Because spectral hemispherical reflectance is relatively easier to measure compared to specular reflectance and because it is the predominant contributor to loss in specular reflectance during weathering, it is the performance parameter that is routinely used.

Initial spectral hemispherical reflectance of samples is measured using dual-beam UV-VIS-NIR spectrophotometers with integrating-sphere attachments. Use of such devices with a secondary reflectance standard (traceable to the National Institute of Standards and Technology) allows the absolute reflectance to be measured as per ASTM E903-82 [4]. Such spectral measurements can then be convoluted with an appropriate standard terrestrial spectrum [5] to compute a solar-weighted hemispherical reflectance, $\rho_{2 \pi}(\lambda=250 \mathrm{~nm}$ to $2500 \mathrm{~nm})$, as a meaningful single measure of optical performance. In addition, specular reflectance at $650 \mathrm{~nm}$ is also measured at Sun $\downarrow$ Lab for selected samples [6].

The time interval between successive characterizations is 6 months during the first year of exposure and 12 months thereafter. Field-weathered samples are typically measured both before and after appropriate cleaning to provide information about soiling and ease-of-cleaning properties of candidate materials.

\subsection{Outdoor Exposure Sites}

Six OET sites are presently operational in the United States. Their geographic locations and dates of activation are shown in Figure 1. A qualitative description of the average temperature/humidity conditions at the various sites (for example, "Hot/Humid" at Miami, Florida) is also provided in Figure 1. Many of these sites are operated in cooperation with public utilities. For example, Arizona Public Service (APS) and the Sacramento Municipal Utility District (SMUD) provide site support at Phoenix and Sacramento, respectively. The National Renewable Energy Laboratory (NREL) operates the site located in Golden at their outdoor test laboratory facility. The Texas exposure site was previously a joint undertaking between Sun Lab and a solar manufacturer in Abilene; this site was later moved to a "solar park" in Fort Davis, Texas in agreement with a group of cooperating utilities. The Barstow site near Daggett, California is at the Solar Two plant, a joint undertaking between the U.S. Department of Energy and a major consortium of public utilities. Exposure at the Miami site is subcontracted to a commercial organization (South Florida Test Services). 
The location of the two European sites, which participate under the IEA SolarPACES agreement, and their activation dates are shown in Figure 2. The site in Köln, Germany is operated by the Deutsches Zentrum für Luft- und Raumfahrt (DLR) at their local laboratory facility. An eighth site was activated at the Plataforma Solar de Almería by Centro de Investigaciones Energéticas Medioambientales y Tecnológicas (CIEMAT) in Spain in late February 1998. Interest in joining this collaborative testing activity has been expressed by other SolarPACES participants including Russia and Australia.

Precise and detailed knowledge of the specific environmental stress conditions experienced by weathered samples is needed to allow understanding of site-specific performance losses and to permit service-lifetime prediction of candidate solar mirrors. Consequently, operational exposure sites are fully equipped with appropriate meteorological and radiometric instrumentation and datalogging capability. Figure 3 shows an example of the hardware associated with a typical exposure site. Data channels are typically sampled at 10-s intervals and 5- to 10-min averages are recorded. ASTM specifications [7,8] for outdoor exposure were used to select the following minimum information that is routinely monitored [9]:

- Average global total solar radiation (Tot. Solar) in watts per square meter, measured with the instrument oriented due south and tilted relative to horizontal by an angle equal to the latitude of the site.

- $\quad$ Average global total ultraviolet (UV) solar radiation (Tot. UV) in watts per square meter, measured with the instrument oriented due south and tilted relative to horizontal by an angle equal to the latitude of the site.

- $\quad$ Average global narrow band UV-B solar radiation (Tot. UV-B) in watts per square meter, measured with the instrument (an EKO 210W) oriented due south and tilted relative to horizontal by an angle equal to the latitude of the site.

- $\quad$ Average ambient air temperature in degrees Celsius (Avg. $\mathrm{T}_{\mathrm{amb}}$ ).

- $\quad$ Average temperature measured on the backside of the sample exposure rack in degrees Celsius (Avg. $\mathrm{T}_{\text {rack}}$ ).

- $\quad$ Average temperature measured approximately $2.5 \mathrm{~cm}$ below the ground surface underneath the sample exposure rack in degrees Celsius (Avg. $\mathrm{T}_{\text {grnd.). }}$.

- $\quad$ Average relative humidity in percent (Avg. $\mathrm{RH})$.

- $\quad$ Precipitation (rain, snow, sleet, hail, or ice) measured in millimeters (Tot. Prec.).

- Average wind speed $(\mathrm{km} / \mathrm{h})$ and wind direction conforming to the "wind rose" convention used by DSET Laboratories, Inc. The "wind rose" convention is a way of resolving ambiguities associated with averaging $1^{\circ}$ with $359^{\circ}$ and calculating the correct result, $360^{\circ}$, instead of $180^{\circ}$ for wind direction. 
Real-time monitoring of atmospheric pollutants is extremely expensive. In some cases, pollution data are available from monitoring stations nearby the exposure sites. However, such data may be irregular or variable. To provide some consistent assessment of the pollutant stresses, $\mathrm{SO}_{2}$ levels are monitored using a sulfonation plate technique as specified in references 10 and 11. It is intended that correlations between parallel measurements (sulfonation plates versus nearby stations) will be performed to quantify the usefulness of the data.

\subsection{Laboratory Accelerated Exposure Chambers}

In addition to outdoor weathering, a variety of suitable accelerated weathering chambers and the instrumentation to allow characterization of exposure conditions in these chambers is also available to allow control and monitoring of light intensity, $\mathrm{RH}$, and temperature. Two exposure chambers have been primarily used, namely, an Atlas Ci65 WeatherOmeter (WOM) and an Heraeus (now Atlas) XENOTEST ${ }^{\circ} 1200 \mathrm{LM}$ (XENO). Typical conditions are $\mathrm{T}=60^{\circ} \mathrm{C}$ and $\mathrm{RH}=$ $60 \%$ (XENO) or $75 \%$ (WOM). Each chamber can accommodate a large number ( 200-300) of samples (roughly $67 \mathrm{~mm} \times 44 \mathrm{~mm}$ ) at the same time with simulated solar irradiance levels of roughly 1-2X. These units use a xenon-arc light source with filters designed to give a close match to the terrestrial AM 1.5 solar spectrum [12].

As outdoor weather conditions vary continuously, accelerated exposure conditions can also change as well, either purposely (by programming a desired weathering profile) or inadvertently (for example, loss of light intensity due to aging of the bulb). Consequently, all relevant weathering parameters must be known and measured as a function of time. A state-of-the-art spectral radiometer system is used to measure the spectral content and spatial uniformity of artificial light sources so that samples can be subjected to accelerated testing in known and controlled laboratory environments. Plots of the typical spectral irradiance associated with each of Sun Lab's exposure chambers versus a global AM 1.5 spectrum are shown in Figures 4 and 5.

\subsection{Reflector Material Samples}

Samples are exposed according to ASTM specifications for both outdoor exposure testing [7,8] and in the accelerated weathering chambers $[13,14]$. At the OET sites, the exposure racks are oriented due south and with the sample exposure plane tilted from horizontal by an angle equal to the latitude of the site. The standard size of material samples is $67 \mathrm{~mm} \times 44 \mathrm{~mm}$ (2-5/8" x 1-3/4”). For glass, metal, and all-polymeric mirrors, three replicates of each material are exposed at each site. Metallized polymer samples are tested as two replicates each on five separate substrates, i.e., bare aluminum, coil-coated aluminum, stainless steel, glass, and polyethylene terephthalate (PET) film at each site. Unexposed samples of each reflector are retained as "witness" or reference specimens.

Testing of candidate reflector samples was initiated as sets of materials became available. Samples were grouped according to sequentially numbered OET experiments. A list of what materials are being tested at which sites is provided in Table 2, and a discussion of these materials is given below for each OET experiment. 


\subsubsection{Samples in OET\#1}

OET experiment \#1 consists of using several candidate commercially available metallized polymer reflector materials. These include SA-85, SS-95, and ECP-305 from the 3M Company. The construction of these materials is given in Table 2. SA-85 and SS-95 were originally indoor lighting products and have basically the same construction. The reflectors have aluminum (SA-85) or silver (SS-95) evaporated onto a PET film substrate with a thin layer of a weatherable acrylic, polymethylmethacrylate (PMMA) flood coat over the silver. ECP-305 uses a silvered UV stabilized 3.5 mil PMMA, where the PMMA is the superstrate. The various outdoor sites at which these materials have been exposed are provided in Figures 1 and 2. Samples were laminated to five different substrate materials including $6061 \mathrm{~T} 6$ aluminum $(0.89 \mathrm{~mm}$ thick) (AL), coil-coated or "painted" aluminum $(0.89 \mathrm{~mm})(\mathrm{PAL})$, glass $(3.2 \mathrm{~mm}), 304$ stainless steel foil $(0.08 \mathrm{~mm})(\mathrm{SS})$, and PET (a polyester film) $(0.10 \mathrm{~mm})$.

\subsubsection{Samples in OET \#2}

OET \#2 includes thin glass ( $0.7 \mathrm{~mm}$ thick) mirrors from Naugatuck and laminated glass mirrors from Advanced Thermal Systems (ATS). The Naugatuck mirrors were prepared both with and without edge tape (Tedlar), and with the glass adhesively bonded to aluminum substrates or freestanding without an aluminum substrate. The ATS mirrors were prepared with and without edge tape.

\subsubsection{Samples in OET \#3}

An early prototype version of ECP-305+ produced by the $3 \mathrm{M}$ Company under a subcontract with Sun Lab comprises OET \#3. Protective back-layers of copper, $10 \mathrm{~nm}$ and $50 \mathrm{~nm}$ thick were used. Small coupon-sized samples were laminated to four of the five substrates used in OET \#1 (excluding the PAL).

\subsubsection{Samples in OET \#4}

Another candidate construction, developed by Industrial Solar Technology (IST) under a Sun $\downarrow$ Lab subcontract, constitutes OET \#4. These are silvered $(150 \mathrm{~nm})$ Teflon (fluorinated ethylene propylene, FEP) having a back protective layer of copper $(30 \mathrm{~nm})$. The Teflon film was $0.083 \mathrm{~mm}$ thick. Samples were laminated onto the five standard substrate materials, with and without an intervening layer of the PET film ( $0.05 \mathrm{~mm}$ thick).

\subsubsection{Samples in OET \#5}

Samples in OET \#5 were produced by the 3M Company under the same subcontract discussed above for OET \#3. The intent was to avoid the potential for delamination failures by silvering a PET substrate rather than a PMMA superstrate. Silver adheres much better to PET than to PMMA and PET absorbs less moisture than PMMA, thereby reducing the swelling and consequent weakening of the silver bond. To protect the silver reflective layer, 3M laminated UV-screening PMMA (the same film used as the ECP-305+ superstrate) to the silvered PET using a highly specular, transparent, UV-resistant adhesive. The adhesive between the PMMA and the silver was chosen based upon a number of candidates subjected to accelerated screening tests. Samples 
having the construction (PMMA / adhesive / silver / PET / adhesive / release Liner) were laminated to aluminum substrates and the edges were protected by Tedlar tape. The adhesive used to laminate samples to the substrate materials was the same used in ECP-305+. Unweathered samples were highly reflective, but upon exposure (particularly in the accelerated test chambers), the various candidate adhesives yellowed and the construction lost reflectance.

\subsubsection{Samples in OET \#6}

OET \#6 was identical to OET\#5 except that a candidate replaceable adhesive was substituted for the substrate-laminating adhesive layer. This permitted easy removal and replacement of metallized polymer reflector materials in the field. Unweathered samples were highly reflective, but upon exposure (particularly in the accelerated test chambers), the various candidate adhesives used to bond the PMMA superstrate to the silver reflective layer yellowed and the construction lost reflectance.

\subsubsection{Samples in OET \#7}

As a follow-up to OET \#3, OET \#7 was a pre-pilot plant version (small 6" wide rolls) of ECP305+ produced by 3M. Samples having the construction (PMMA / Silver / Copper / Adhesive) were included, with copper layer thicknesses of 0, 10, 30, 50, and $100 \mathrm{~nm}$. Samples were all laminated to each of the five standard substrate materials. The intent was to explore the effect of copper layer thickness upon optical durability.

\subsubsection{Samples in OET \#8}

Because Teflon films (used in OET \#4) are relatively expensive, for OET \#8, IST provided samples of silvered FEP using thinner $(0.051 \mathrm{~mm})$ film superstrates. In addition to a 30-nm protective back-layer of copper (as in OET \#4), protective back-layers with $30 \mathrm{~nm}$ of Inconel were deposited. IST's collaborator, Sheldahl, who has experience with Inconel-backed materials for the aerospace industry, prepared these materials. Samples were laminated to each of the five standard substrate materials.

\subsubsection{Samples in OET \#9}

The commercial version of ECP-305+, the metallized polymer construction developed under subcontract with Sun Lab by the 3M Company, was tested as OET \#9. This material has the construction PMMA / silver / copper / adhesive / release liner. To investigate uniformity across the roll, material was taken from the side and from the center of a 1.22-m-wide roll. Three replicate samples from each roll location were laminated to the five standard substrate materials.

\subsubsection{Samples in OET \#10}

In OET \#10, all-polymeric reflector materials that were developed by Dow Chemical Company under subcontract to Sun Lab were tested. This material used co-extruded layers of alternating polymeric resins to obtain high reflectance from the summation of multiple reflectances caused by mismatched refractive indices at each interlayer. This material was not optimized for the solar 
spectrum but was intended to demonstrate the concept and to begin providing weathering information of such a construction.

\subsubsection{Samples in OET \#11}

A number of samples prepared by German companies and provided by the DLR are incorporated into OET \#11. Two types of silvered glass mirrors include thin glass reflectors from Schlaich, Bergermann und Partner, and thick painted glass from Flagsol (used by the Solar Electric Generating System (SEGS) plants in California). Candidate front-surface aluminum solar mirrors include anodized aluminum from Regiolux and physical vacuum deposited (PVD) aluminized aluminum from Alanod. Germany is very interested in such aluminized reflectors because of their potential low cost and flexibility with regard to system design issues; the major concern has been poor durability of such materials in urban and industrialized locations.

\subsubsection{Samples in OET \#12}

An additional thin-glass mirror, provided by Steinmüller in Germany, comprises OET \#12.

\subsubsection{Samples in OET \#13}

OET\#13 consists of another anodized aluminum mirror material from Metalloxyd in Germany.

\subsubsection{Samples in OET \#14}

An improved anodized aluminum mirror from Alanod in Germany is being tested as OET \#14. This material incorporated a protective polymeric overcoat onto PVD aluminized aluminum.

\subsection{Test Results}

The optical durability (performance as a function of time) of candidate reflector materials is evaluated based on results from both real-time exposure at outdoor test sites and from accelerated weathering in controlled laboratory environments. Outdoor testing is important because the durability of optical materials in actual field environments is a critical issue for the success of CSP technologies. In general, for those samples that degrade, the most severe sites are Miami, Florida, Phoenix, Arizona, and Köln, Germany; Texas and Barstow, California are intermediate; and Sacramento, California and Golden, Colorado are the least aggressive environments. Sufficient data from Almería, Spain is not yet available. Accelerated testing is also being used to screen new candidate materials on the basis of their optical durability. In the following sections, meteorological and radiometric data from the various outdoor test sites are tabulated (tables 3-10), and durability data are presented in graphical form (figures 6-44).

\subsection{Environmental Exposure Conditions}

From outdoor and accelerated exposure tests, environmental stress factors that cause degradation have been identified [1]. For most solar mirrors, exposure during service to sunlight (particularly ultraviolet wavelengths), temperature, and moisture can result in a loss in reflectance. The relative 
severity of these stresses occurs generally in the order they were listed. Synergistic effects (photothermal and photohydrolytic for example) can also drive degradation mechanisms. To hypothesize and assess damage functions that relate loss in performance to environmental stresses, a quantified measure of the relevant stresses actually experienced by materials being tested must be known. In particular, because outdoor weather conditions are so variable, appropriately small timeincrements must be used to properly characterize the time-dependent nature of these stresses. As discussed in Section 2.2, such data are available. Unfortunately, the size of this database is hundreds of megabytes and cannot be adequately presented in this report. As an alternative, a summary of relevant meteorological and radiometric data is provided in Tables 3-10. These tables present monthly and yearly totals of precipitation, broadband solar irradiation (energy dose), total UV irradiation, and narrowband UV-B irradiation. Monthly and yearly averages of relative humidity, ambient temperature, rack temperature, and ground temperature are also tabulated. These data are intended to be representative of the various outdoor test sites only; such aggregated values are too crude to be used in analytical evaluation of damage functions.

Table 3 presents data for our exposure site at APS, located in Tempe (just outside Phoenix), Arizona. This site was activated in September 1993. Weather data for our site at SMUD, located at Rancho Seco (Sacramento), California is provided in Table 4. This site has also been active since September 1993 but was inactive for 6 months between 1995-96 because of construction. Our third site was activated in Abilene, Texas in May 1994. This site was deactivated in August 1996 and the test station was reactivated in Fort Davis, Texas in March 1997. Weather data for Abilene and Fort Davis are given in Tables 5 and 6, respectively. The site at NREL, in Golden, Colorado, was activated in March 1994; it was inactive between September 1993 and January 1994 because of construction. Table 7 summarizes the NREL weather data. The Barstow, California site was activated in March 1995; weather data are provided in Table 8. The site at Miami, Florida was activated in June 1995 and the associated weather data are given in Table 9. The Köln, Germany site was activated in December 1995; weather data are provided in Table 10. No weather data are yet available from Almería, Spain (activated in February 1998).

As is evident from Tables 3-9, a good deal of missing and erroneous data needs to be corrected for all six U.S. sites. Three types of problems have been identified: 1) data missing because of problems with the data logger, modem hardware, or both 2) erroneous or missing data caused by faulty sensors, and 3) data having calibration errors. Efforts are underway to repair the weather database to allow more meaningful comparisons of accelerated and outdoor exposure test results.

Table 11 lists the actual dates that samples associated with each of the OET experiments were exposed at each of the test sites. This information provides a mapping between the weather database and the measured reflectance values. Once the missing weather data have been corrected, use of Table 11 will permit degradation to be predicted from damage functions based on the timedependent stresses that the exposed materials experienced. These calculated results can then be directly compared with actual loss in optical performance to validate the postulated models.

\subsection{Optical Durability (Performance as a Function of Exposure)}

In figures (6-44), test results are presented graphically as plots of solar-weighted hemispherical reflectance (hereafter, "reflectance") as a function of exposure time. For each material, data for all 
available outdoor test sites are plotted on the same graph (for example, Figure 6). Whatever accelerated test results are available are also plotted on the same (separate) graph (for example, Figure 7). For the outdoor data, samples are measured as received from field exposure and then after cleaning. This gives rise to the sawtooth appearance indicative of two data points (the lower value before cleaning and the higher value after cleaning) at the same exposure time. The data (symbols) represent average values for whatever number of sample replicates are available; error bars are for \pm one standard deviation. The axis scales are the same for all data to allow ease of intercomparison of different materials. In addition, each location (outdoor test site or accelerated weathering chamber) is uniquely identified by consistent use of the same symbol/color/line-type throughout in all the figures.

\subsubsection{Results for OET \#1}

SA-85 has the construction PMMA overcoat / aluminum / PET / adhesive / release liner. Because this is an aluminum reflector, its reflectance values are below $90 \%$ even for unweathered $(\mathrm{t}=0)$ samples. However, excellent optical durability is demonstrated by SA85 out to 4 years outdoor exposure at all sites (Figure 6). Some loss in reflectance occurs after two years accelerated exposure in the WOM (unfilled circles in Figure 7).

SS-95 has the same construction as SA-85 except for the substitution of silver for the aluminum: (PMMA overcoat / silver / PET / adhesive / release liner). SS-95 maintained performance for up to one year in the WOM (unfilled squares in Figure 7). However, during outdoor exposure, reflectance remains above $90 \%$ for up to 18 months, then severely degrades at all sites, especially Miami, Florida and Texas (Figure 8).

ECP-305 (Figure 9) lasts outdoors for up to 4 years at Golden, Colorado and Sacramento, California. Unacceptable degradation occurs after 18-30 months in Miami, Florida, and Phoenix, Arizona; durability results for Texas, Barstow, California, and Köln are intermediate. ECP-305 maintains close to $90 \%$ reflectance for up to 4 years of WOM exposure; a more rapid loss (less than one year) is evident during XENO exposure (Figure 10). Although this effect is unexpected based on the generally greater spectral intensity levels measured for the WOM (Figure 4) compared with the XENO (Figure 5), greater damage may be caused by the XENO's higher intensity at very low wavelengths (300-305 nm). Most of the accelerated laboratory exposure history of sample results presented in this report occurred prior to the availability of our spectral radiometer characterization equipment and prior to an extended period of down-time associated with consolidation of our laboratory equipment; it is possible that different filters and intensitylevel settings were previously used.

\subsubsection{Results for OET \#2}

A slight loss in reflectance is experienced by samples of Naugatuck thin glass (Figure 11) exposed outdoors in Texas (from 95\% to 94\% after 3 years) and at NREL (from 95\% to 93\% after 4 years). Similar results can be seen after about 2.5 years accelerated exposure in the WOM (Figure 12). This may be caused by corrosion associated with the choice of adhesive used to bond the thin glass to a substrate material [15]. Negligible loss in reflectance has occurred (after cleaning) in Phoenix and Sacramento after 3.5-4 years exposure. A good deal of cracking of thin-glass samples has occurred at all sites, although it is not clear to what extent handling is responsible for this (great care is taken when removing samples from the test racks, shipping them back to the laboratories 
for measurements, and returning them to exposure). Some samples that have cracked (especially those at Miami, Florida) exhibit propagation of corrosion from the crack lines. Little degradation has occurred for ATS laminated glass samples after 3 years in the WOM (Figure 12) or at any of the outdoor sites (Figure 13).

\subsubsection{Results for OET \#3}

Excellent optical durability is demonstrated by the ECP-305+ precursor materials out to 4 years in Phoenix, Golden, and Sacramento for samples with back protection layers of either $10 \mathrm{~nm} \mathrm{Cu}$ (Figure 14) or $50 \mathrm{~nm} \mathrm{Cu}$ (Figure 15). No accelerated test results for these materials are available.

\subsubsection{Results for OET \#4}

For the silvered fluoropolymer samples prepared by IST, the addition of an intervening backside layer of adhesive, and PET film between the deposited metal layers and the five standard substrates appears to increase the level of degradation compared to samples without such a layer. Results for constructions without the additional PET film (Figure 16) indicate that samples exposed at Phoenix, Golden, and Sacramento all still have reflectance values above 90\% after 3.5-4 years. This is not true for samples with the PET (Figure 17); samples exposed in Sacramento and Golden had reflectance values below $90 \%$, even after cleaning. This trend is repeated for samples exposed in the WOM, where the reflectance of samples having the additional PET layer exhibits a precipitous $(\sim 8 \%)$ drop within the first 6 months of exposure that levels off thereafter (unfilled circle symbols in Figure 18), compared with the non-PET samples (unfilled square symbols in Figure 18). For all exposed samples, specular reflectance and visual appearance is poor. Low specular reflectance is an inherent drawback of metallized fluoropolymer reflectors in general (even for unweathered materials).

One hope for this construction was that the low surface energy property of the fluoropolymer film would make the construction less susceptible to dirt retention then other metallized polymer constructions. Based upon outdoor test results, this potential advantage has not been demonstrated.

\subsubsection{Results for OET \#5}

The 3M alternate construction fails between 1-2 years in Miami and Texas, after 2 years in Phoenix Barstow, Köln, and Sacramento, and begins to degrade after 3 years in Golden (Figure 19). Accelerated test results for this material are not available.

\subsubsection{Results for OET \#6}

The $3 \mathrm{M}$ alternate construction having a replaceable adhesive performs slightly better than the samples discussed above in OET\#5, however, the same general trends are evident (Figure 20). The slight improvement may be caused by an increased absorption in the PMK4545 adhesive construction relative to the $10 \mathrm{~B}$ pressure sensitive acrylic-based adhesive, resulting in fewer photons reflected back by the aluminum substrate. Accelerated test results for this material are not available. 


\subsubsection{Results for OET \#7}

These samples were prepared by the 3M Company and were precursor versions of their later commercialized product designated as ECP-305+. The same PMMA superstrate material used in their earlier ECP-305 product (X09105) was used as the superstrate. Copper-back protective layers of various thicknesses $(0,10,30,50$, and $100 \mathrm{~nm})$ were applied to the silvered PMMA. Finally, a new adhesive formulation (designated 10B) was substituted for the 10A adhesive used in ECP305. Preliminary results at $3 \mathrm{M}$ and Sun Lab indicated that the 10B adhesive offered improved resistance to delamination failure; unfortunately, these results were not substantiated by the production version of ECP-305+. Figure 21 shows that without any copper $(0 \mathrm{~nm})$, the construction degrades similar to ECP-305 at all sites (Figure 9). Any thickness of copper between 10-100 nm can be seen to provide outstanding protection against loss in reflectance although loss of reflectance was found at Miami and Barstow after 3 - 3.5 years (Figures 22-25). It is thought that the protective layer of copper improves durability by screening the backside adhesive from UV photons. Photons are transmitted through silver near $320 \mathrm{~nm}$ and might, without the copper, induce reactive species that could corrode the silver reflective layer. The copper may also act as a getter for deleterious compounds incorporated into the adhesive layer. Another possibility is that copper diffuses through the silver and passivates the reflective layer at the silver/PMMA interface (although analytical characterization does not detect the expected concentrations of copper at this interface [16]).

\subsubsection{Results for OET \#8}

These samples were very badly marked from excessive handling by the supplier; those with Inconel back protective layers (Figure 26) were much worse than those protected with copper (Figure 27), even though they were less wrinkled. This contributed to the large amount of scatter (error bars) associated with the measurements. The copper back-protection layer provided improved durability compared to back-protection by Inconel (although Inconel provided excellent protection at Miami for up to 3 years). Significant improvements $(3 \%-5 \%)$ with cleaning are evident. Copper protective-backed samples have reflectance values exceeding 90\% (after cleaning) after 3 years of weathering at Golden, Sacramento, Phoenix, and Texas. However, as with OET \#4 samples, the visual appearance and specular reflectance of weathered materials are poor.

\subsubsection{Results for OET \#9}

The commercial version of ECP-305+ exhibits excellent optical durability at all OET sites except Barstow and Miami, within the 4 years for which data are available (Figure 28). In Barstow and Miami, ECP-305+ begins to degrade after two years. Comparison of these results with those for ECP-305 (Figure 9) clearly demonstrates the significant improvements gained by incorporation of a backside protective layer of copper. Accelerated exposure test results are not as impressive (Figure 29). Optical durability during WOM exposure is slightly better than for ECP-305 (compare with Figure 10). The onset of degradation of ECP-305+ during XENO exposure is delayed by 2-3 months relative to ECP-305. However, once significant degradation does occur, ECP-305+ appears to lose 5\% more reflectance than ECP-305. Surface analytical studies were performed to try to correlate loss of reflectance with changes in interfacial chemistry as a function of accelerated XENO exposure for both ECP-305 and ECP-305+ [16]. No clear compositional information was evident to explain the nature of the different reflectance-loss profiles of the two materials. Time 
dependent X-ray photoelectron spectroscopy (XPS) data suggest that the main loss in reflectance in both constructions involves the loss of a distinct metallic silver layer and the accumulation of carbon species at the reflective interface.

\subsubsection{Results for OET \#10}

Because Dow's prototype all-polymeric reflector material was intended to demonstrate proof-ofconcept, it was not optimized for broadband solar reflectance. Therefore, its unweathered solarweighted reflectance is only about $80 \%$. However, at this level of performance, little degradation has occurred at any of the OET sites, except for Miami, for up to 3 years exposure (Figure 30). These results are even more impressive insofar as the needs for appropriate UV-screening skin layers were known but, because of funding limitations, were not incorporated into these constructions. Results from accelerated exposure testing are shown in Figure 31. Elevated temperatures (and perhaps relative humidity) appear to result in photo-induced degradation; samples have discolored visually and have a pink hue. This effect might be minimized by the addition of proper UV-screening layers.

A great deal of flexibility exists in engineering this material, and reflectance values tailored to be greater than 98\% are possible. Unfortunately, following Dow's subcontracted development activities with Sun $\downarrow$ Lab, a corporate decision was made to discontinue further work on this material. Dow has subsequently sold the licensing rights of this concept to another company. Sun $\downarrow$ Lab staff continue to interact with this new company to further the development of all-polymeric solar mirrors.

\subsubsection{Results for OET \#11}

Samples of Alanod PVD aluminized polished aluminum degrade most rapidly in Köln, presumably because of higher concentrations of pollutants and acid rain than at other OET sites (Figure 32). Exposure testing of this material in Köln was discontinued after one year. Many other candidate front-surface reflector materials degrade rapidly in Köln. The reflectance of these aluminized mirrors has been enhanced by multi-layer deposition processes so that the unweathered values are about $90 \%$. Measurable degradation has also occurred for these samples exposed in Miami after 1.5 years and in Golden after 2 years. Samples from Miami were visually poor and surface analysis was carried out to discover the cause of degradation. Unprotected anodized aluminum samples are typically porous and during weathering are likely loaded with water. XPS analyses [17] showed he surfaces of exposed samples were contaminated with $\mathrm{Si}$ and $\mathrm{Ca}$, indicative of insoluble salts such as carbonates and silicates being bound to the surface. These result in visual white-spotted areas that could not be removed with acid and mild abrasion. Auger analyses [18] suggest that the aluminum reflector degrades in two ways: an oxide layer grows on the surface of the sample from under the reflector layer, and pits form as material is lost. Both of these processes result in a nonreflective aluminum oxide surface. We intend to perform surface analysis on failed or discontinued samples from Köln as well. Samples survive fairly well in accelerated exposure chambers (Figure 33). Such AET generally provide poor simulation of outdoor results (deceleration) for aluminum reflectors, probably because salt or pollutants, which seem to be the most deleterious type of stresses for these types of materials, are not presently incorporated into our accelerated testing protocol. 
Another candidate front surface aluminized reflector, anodized aluminum, from Regiolux, exhibits better durability but has poorer initial reflectance $(<90 \%$, Figure 34$)$. Surface analytical results for failed samples from Florida have the same characteristics as those discussed above for the Alanod samples [17,18]; in addition, the surfaces of the Regiolux samples were found to be marred with many small stress cracks [18]. This material also has good optical durability during AET (Figure $35)$.

With cleaning, silvered glass mirrors from Flagsol are generally able to maintain excellent optical durability during outdoor exposure within the 2 years for which results are available (Figure 36). Little degradation is evident after 1.5 years of AET (Figure 37).

Silvered thin glass samples from Schlaich, Bergermann und Partner, also demonstrate excellent outdoor durability (Figure 38). Slight degradation has occurred for samples exposed for a year in the XENO chamber (Figure 39). As with the Naugatuck thin glass samples discussed above in the OET \#2 results, some of these samples have experienced problems with cracking.

\subsubsection{Results for OET \#12}

Silvered thin glass samples from Steinmüller demonstrate excellent outdoor durability (Figure 40). Slight degradation has occurred for samples exposed for a year in both the WOM and the XENO chamber (Figure 41). Some problems with cracking of these samples has also occurred.

\subsubsection{Results for OET \#13}

Anodized aluminum samples from Metalloxyd (another front-surface aluminum reflector) is being tested. The initial reflectance of these mirrors is under 90\% (Figure 42). As with similar samples discussed in OET \#11, these materials have not degraded after 1-2 years of outdoor exposure, except for in Köln. There, samples degraded after 2 years of OET. These materials have presently experienced only 6-12 months of AET (Figure 43).

\subsubsection{Results for OET \#14}

An improved version of PVD aluminized polished aluminum, onto which a protective polymeric overcoat is applied, has been prepared by Alanod and is being tested as OET \#14. The addition of the polymeric overcoat reduced the initial reflectance below 90\%. Outdoor (Figure 44) and accelerated (Figure 45) testing has experienced between $6-18$ months of exposure. In contrast to similar materials without the protective polymeric overcoat (OET\#11, Figure 32) this construction have demonstrated excellent optical durability in Köln.

\subsection{Conclusions and Future Activities}

Eight fully instrumented outdoor exposure sites have been or are presently being used in the United States and Europe. These sites form an international network that allows collaborative outdoor testing of candidate solar reflector materials. Based upon test results to date from these sites, as well as from accelerated exposure chambers for a wide variety of candidate solar mirror materials, a number of general conclusions can be made. These include: 
- The optical durability of the following candidate reflector materials tested to date can be characterized as excellent:

- Thin glass (from Naugatuck, Schlaich,; Bergermann und Partner; or Steinmüller)

- Thick glass (from ATS or Flagsol)

- Two metallized polymers (SA-85 and, at some sites, ECP-305+)

- The optical durability of the following candidate reflector materials tested to date can be characterized as intermediate and require further improvement, testing and evaluation, or both:

- The all-polymeric construction

- Several of the aluminized reflectors (Alanod's improved product, materials from Metalloxyd)

- A metallized polymer (ECP-305)

- The optical durability of the following candidate reflector materials tested to date can be characterized as poor and do not warrant further consideration for solar applications:

- A metallized polymer (SS-95)

- Metallized fluoropolymers (until specularity can be sufficiently improved)

- Constructions in which adhesives are in direct contact with a silver reflective-layer

- The severity of our outdoor exposure sites exhibit the following ranking:

- The most severe sites are Miami, Florida, Phoenix, Arizona, and Köln, Germany

- $\quad$ Texas and Barstow, California are intermediate

- $\quad$ Sacramento, California and Golden, Colorado are the least aggressive environments

- $\quad$ Sufficient data from Almería, Spain are not yet available

- The specular reflectance properties of metallized fluoropolymer materials are insufficient to allow their use in concentrated solar power technologies

- Accelerated exposure testing of some metallized polymer reflectors over-accelerate degradation of these materials compared to outdoor testing. A better means of isolating temperature effects (which are believed to strongly contribute to this problem) needs to be incorporated into our accelerated testing protocol.

- NREL's accelerated test chambers do not provide qualitative simulation of outdoor test results for front-surface aluminum reflectors. A means of including pollutants and acid rain (believed to be an important stress factor for these materials) needs to be incorporated into our accelerated test protocols.

In the future, as new and improved candidate reflector materials become available, durability testing will be continued. Materials will be initially subjected to accelerated screening tests. Based upon these results, samples will be sent to outdoor exposure sites for in-service weathering as appropriate. Recently, a number of promising constructions have been identified. These include:

- Several front-surface mirrors (in which transparent, dense, protective overcoats are deposited onto metal-reflective substrates) being developed under an ongoing Sun Lab subcontract and being prepared in parallel by Sun $\bullet$ Lab staff 
- A new all-polymeric construction using improved interlayer resins and incorporating UV screens

- A newly available commercial solar reflector material called SolarBrite 95 that evolved from a product used for less-demanding indoor lighting applications and is marketed by Alcoa Brite Products, Inc.

- A novel commercial laminate construction co-invented by Sun Lab staff and industry collaborators

These and other materials will be considered. The collaborative test program should be expanded to include a more formalized parallel accelerated testing component. Pollution-monitoring capabilities should be improved at the various exposure sites. Data exchange will be streamlined and expanded. The possibility of additional exposure sites associated with other prospective participants will be explored.

A more systematic approach is needed to understand and explain apparent inconsistencies in the various data sets acquired to date as described in Section 3.2. Errors that have been discovered with our outdoor weather database must be corrected. Significant gaps of missing data were found for all six U.S. sites. Three types of problems have been identified: 1) data missing because of problems with the data logger or modem hardware, 2) erroneous or missing data caused by faulty sensors, and 3) data having calibration errors. Activities are underway to correct these data. This will strengthen our confidence in correlations derived between outdoor and accelerated exposure test results.

\subsection{Acknowledgements}

The authors express their appreciation to the following coworkers for their contributions. Leif Casey wrote the performance data base program. Rita Goggin, Brian Schelenbacher, Dave Gorman, Mike Stringfield, and Micah Davidson provided assistance with optical measurements. The meteorological data acquisition program was written by Tim Wendelin. Tim Wendelin and Rita Goggin installed the OET site hardware. Robert Pearson, Andre Somogyl and Richard Hutyra carried out analysis of the weather database. Daryl Myers has coordinated the calibration of our spectral radiometer and the outdoor radiometer units. Rita Goggin made spectral measurements of our laboratory accelerated exposure chamber light sources, and was responsible for initiation of the early phases of our accelerated exposure testing program. Thomas Fend of the DLR has provided Germany optical measurements and weather data from Köln. The US Department of Energy (DOE) supported this work under Contract No. DE-AC36-99GO10337.

\subsection{References}

1. Jorgensen, G.J.; Kim, H.M.; and Wendelin, T.J. "Durability Studies of Solar Reflector Materials Exposed to Environmental Stresses." Durability Testing of Nonmetallic Materials, ASTM STP 1294. Robert J. Herling, Ed.; American Society for Testing and Materials; 1996.

2. Jorgensen, G.; Böhmer, M., Fend, T.; and Sánchez, M. "International Collaborative Testing of Solar Reflectors." Solar Thermal Concentrating Technologies; Proceedings of the 8th 
International Symposium, October 6-11, 1996, Köln, Germany. M. Becker and M. Böhmer, Eds., C. F. Müller Verlag, Heidelberg; 1997, pp. 443-462.

3. Short, W. D. “Optical Goals for Polymeric Film Reflectors” SERI/SP-253-3383. Golden, CO: National Renewable Energy Laboratory, October 1988.

4. ASTM Standard E903-82 (Reapproved 1992). "Standard Test Method for Solar Absorptance, Reflectance, and Transmittance of Materials Using Integrating Spheres." Annual Book of ASTM Standards 1993, Vol. 12.02. Philadelphia, PA: American Society for Testing and Materials; pp. 512-520.

5. ASTM Standard E891-87 (Reapproved 1992), "Standard Tables for Terrestrial Direct Normal Solar Spectral Irradiance for Air Mass 1.5," Annual Book of ASTM Standards 1993, Vol. 12.02. Philadelphia, PA: American Society for Testing and Materials, pp. 481-486.

6. Susemihl, I. and Schissel, P. "Specular Reflectance Properties of Silvered Polymer Materials." Sol. Energy Mate.; 16 (1987) 403-421.

7. ASTM Standard D1435-85. "Standard Practice for Outdoor Weathering of Plastics." Annual Book of ASTM Standards 1993, Vol. 8.01. Philadelphia, PA: American Society for Testing and Materials, pp. 430-434.

8. ASTM Standard G7-89. "Standard Practice for Atmospheric Environmental Exposure Testing of Nonmetallic Materials." Annual Book of ASTM Standards 1993, Vol. 6.01. Philadelphia, PA: American Society for Testing and Materials, pp. 1008-1013.

9. Wendelin, T. and Jorgensen, G. "An Outdoor Exposure Testing Program for Optical Materials Used in Solar Thermal Electric Technologies." Solar Engineering 1994, David E. Klett, Roy E. Hogan, and Tadayoshi Tanaka, Eds. New York: American Society of Mechanical Engineers, 1994.

10. ASTM Standard G91-92, "Standard Practice for Monitoring Atmospheric $\mathrm{SO}_{2}$ Using the Sulfation Plate Technique," Annual Book of ASTM Standards 1993, Vol. 3.02, American Society for Testing and Materials, Philadelphia, PA, pp. 374-378.

11. ISO 9225:1992(E), "Corrosion of Metals and Alloys - Corrosivity of Atmospheres Measurement of Pollution." Switzerland: Global Engineering Documents, 1992, pp. 1-10.

12. ASTM Standard E 892-87 (Reapproved 1992). "Standard Tables for Terrestrial Solar Spectral Irradiance at Air Mass 1.5 for a 37 Tilted Surface." Annual Book of ASTM Standards 1993, Vol. 12.02. Philadelphia, PA: American Society of Testing and Materials, pp. 487-494.

13. ASTM Standard D2565-92a. "Standard Practice for Operating Xenon Arc-Type Light Exposure Apparatus With and Without Water for Exposure of Plastics." Annual Book of ASTM Standards 1993, Vol. 8.02. Philadelphia, PA: American Society for Testing and Materials, pp. 64-68. 
14. ASTM Standard G26-92. "Standard Practice for Operating Light-Exposure Apparatus (XenonArc Type) with and without Water for Exposure of Nonmetallic Materials." Annual Book of ASTM Standards 1993, Vol. 6.01. Philadelphia, PA: American Society for Testing and Materials, pp. 1033-1041.

15. Kennedy, C. "Preliminary Results of Optical Durability Testing of Candidate Thin Glass Solar Mirror Constructions," NREL letter report to Science Applications International Corporation, Golden, CO, March 21, 1997.

16. King, D., and Jorgensen, G. "Interfacial Chemistry of Accelerated Weathered Metallized Polymer Materials." Service Life Prediction of Organic Coatings, A Systems Approach, ACS Symposium Series 722. D.R. Bauer and J.W. Martin, Eds. American Chemical Society, 1999, pp. 288-297.

17. King, D. "XPS Surface Analysis Results of Anodized Aluminum Samples Weathered Outdoors in Florida.” Internal Memorandum. NREL, Golden, CO, December 7-14, 1998.

18. King, D. "Auger Surface Analysis Results of Anodized Aluminum Samples Weathered Outdoors in Florida." Internal Memorandum. NREL, Golden, CO, December 17, 


\begin{tabular}{|c|c|}
\hline $\begin{array}{l}\text { Table } 1 . \\
\text { Acronym }\end{array}$ & $\begin{array}{l}\text { Definition of Acronyms used } \\
\text { Definition }\end{array}$ \\
\hline AET & Accelerated Exposure Test \\
\hline $\mathrm{AL}$ & 6061T6 aluminum (0.89 mm thick) \\
\hline AM & Air-mass \\
\hline APS & OET site at Arizona Public Service in Tempe, AZ near Phoenix, AZ \\
\hline ASTM & American Society for Testing and Materials \\
\hline ATS & Advanced Thermal Systems \\
\hline Avg. RH & Average relative humidity in percent \\
\hline Avg. $\mathrm{T}_{\mathrm{amb}}$ & Average ambient temperature in degrees Celsius \\
\hline Avg. $T_{\text {grnd. }}$ & $\begin{array}{l}\text { Average temperature measured approximately } 2.5 \mathrm{~cm} \text { below the ground surface underneath } \\
\text { the sample exposure rack in degrees Celsius }\end{array}$ \\
\hline Avg. $T_{\text {rack }}$ & $\begin{array}{l}\text { Average temperature measured on the back side of the sample exposure rack in degrees } \\
\text { Celsius }\end{array}$ \\
\hline BAR & OET site at Solar Two site in Barstow, CA near Daggett, CA \\
\hline CIEMAT & Centro de Investigaciones Energéticas Medioambientales y Tecnológicas \\
\hline CSP & Concentrated Solar Power \\
\hline DIRNOR15 & Direct normal AM 1.5 solar weighting \\
\hline DLR & Deutsches Zentrum für Luft- und Raumfahrt \\
\hline DOE & Department of Energy \\
\hline FEP & fluorinated ethylene propylene (Teflon) \\
\hline FLA & OET site at South Florida Test Services in Miami, FL \\
\hline GER & OET site at DLR in Köln, Germany \\
\hline IEA & International Energy Agency \\
\hline IST & Industrial Solar Technology \\
\hline NAUG & Naugatuck glass \\
\hline NREL & OET site at National Renewable Energy Laboratory in Golden, CO \\
\hline OET & Outdoor Exposure Test \\
\hline PAL & coil-coated or "painted" aluminum ( $0.89 \mathrm{~mm}$ thick $)$ \\
\hline PET & polyethylene terephthalate $(0.10 \mathrm{~mm}$ thick $)$ \\
\hline PMMA & polymethylmethacrylate \\
\hline PVD & physical vacuum deposited \\
\hline SEGS & Solar Electric Generating System \\
\hline SolarPACES & Solar Power and Chemical Energy Systems \\
\hline SMUD & OET site at Sacramento Municipal Utility District in Rancho Seco (Sacramento), CA \\
\hline SPA & OET site at CIEMAT in Almería, Spain \\
\hline SS & 304 stainless steel foil $(0.08 \mathrm{~mm})$ \\
\hline Sun Lab & NREL and Sandia National Laboratory virtual laboratory under the DOE CSP program \\
\hline Tot. Prec. & Total precipitation (rain, snow, sleet, hail, or ice) measured in millimeters \\
\hline Tot. Solar & Average global total solar radiation in watts per square meter \\
\hline Tot. UV & Average global total UV solar radiation in watts per square meter \\
\hline Tot. UV-B & Average global narrow band UV-B solar radiation in watts per square meter \\
\hline TX & OET site at Abilene, TX moved to Fort Davis, TX \\
\hline UV & ultraviolet \\
\hline WOM & Atlas Ci65 WeatherOmeter \\
\hline XENO & Heraeus (now Atlas) XENOTEST 1200 LM \\
\hline XPS & X-ray photoelectron spectroscopy \\
\hline YE & Year end \\
\hline YTD & Year to date \\
\hline
\end{tabular}




\begin{tabular}{|c|c|c|c|c|}
\hline $\begin{array}{c}\text { OET } \\
\#\end{array}$ & Material Designation & Material Construction $^{1-4}$ & Supplier & Sites of Exposure \\
\hline 1 & SA-85 & PMMA/Al/Adh/Sub & 3M Company & $\mathrm{A}, \mathrm{B}, \mathrm{F}, \mathrm{G}, \mathrm{K}, \mathrm{M}, \mathrm{P}, \mathrm{S}, \mathrm{W}, \mathrm{X}$ \\
\hline 1 & SS-95 & PMMA/Ag/Adh/Sub & 3M Company & $\mathrm{A}, \mathrm{B}, \mathrm{F}, \mathrm{G}, \mathrm{K}, \mathrm{M}, \mathrm{P}, \mathrm{S}, \mathrm{W}, \mathrm{X}$ \\
\hline 1 & ECP-305 & PMMA/Ag/Adh/Sub & 3M Company & $\mathrm{A}, \mathrm{B}, \mathrm{F}, \mathrm{G}, \mathrm{K}, \mathrm{M}, \mathrm{P}, \mathrm{S}, \mathrm{W}, \mathrm{X}$ \\
\hline 2 & Laminated Glass & $\begin{array}{l}\text { Thin Glass/Silvered Thick } \\
\text { Glass }\end{array}$ & $\begin{array}{l}\text { Advanced } \\
\text { Thermal Systems }\end{array}$ & $\mathrm{A}, \mathrm{B}, \mathrm{F}, \mathrm{G}, \mathrm{K}, \mathrm{M}, \mathrm{P}, \mathrm{S}, \mathrm{W}$ \\
\hline 2 & Thin Glass & $\begin{array}{l}\text { Silvered Thin } \\
\text { Glass/Adh/Sub }\end{array}$ & Naugatuck Glass & $\mathrm{A}, \mathrm{B}, \mathrm{F}, \mathrm{G}, \mathrm{K}, \mathrm{M}, \mathrm{P}, \mathrm{S}, \mathrm{W}$ \\
\hline 3 & ECP-305+ Precursor & $\mathrm{PMMA} / \mathrm{Ag} / \mathrm{Cu} / \mathrm{Adh} / \mathrm{Sub}$ & 3M Company & $\mathrm{G}, \mathrm{P}, \mathrm{S}$ \\
\hline 4 & $\begin{array}{l}\text { Experimental Silvered } \\
\text { Teflon }\end{array}$ & Teflon/Ag/Copper/Adh/Sub & $\begin{array}{l}\text { Industrial Solar } \\
\text { Technology }\end{array}$ & $\mathrm{G}, \mathrm{P}, \mathrm{S}, \mathrm{W}$ \\
\hline 5 & Experimental & PMMA/Adh/Ag/PET & 3M Company & $\mathrm{A}, \mathrm{B}, \mathrm{F}, \mathrm{G}, \mathrm{K}, \mathrm{M}, \mathrm{P}, \mathrm{S}$ \\
\hline 6 & $\begin{array}{l}\text { Experimental } \\
\text { Replaceable Reflector }\end{array}$ & $\begin{array}{l}\text { ECP-305/PET/Replaceable } \\
\text { Adh/Sub }\end{array}$ & 3M Company & $\mathrm{A}, \mathrm{B}, \mathrm{F}, \mathrm{G}, \mathrm{K}, \mathrm{M}, \mathrm{P}, \mathrm{S}$ \\
\hline 7 & $\begin{array}{l}\text { Pilot plant version of } \\
\text { ECP-305+ }\end{array}$ & PMMA/Ag/Cu/Adh/Sub & 3M Company & $\mathrm{B}, \mathrm{F}, \mathrm{G}, \mathrm{M}, \mathrm{P}, \mathrm{S}$ \\
\hline 8 & $\begin{array}{l}\text { Experimental Silvered } \\
\text { Teflon }\end{array}$ & $\begin{array}{l}\text { Teflon/Ag/Copper or } \\
\text { Inconel/Adh/Sub }\end{array}$ & $\begin{array}{l}\text { Industrial Solar } \\
\text { Technology }\end{array}$ & $\mathrm{A}, \mathrm{B}, \mathrm{F}, \mathrm{G}, \mathrm{K}, \mathrm{M}, \mathrm{P}, \mathrm{S}$ \\
\hline 9 & $\begin{array}{l}\text { Commercial version of } \\
\text { ECP-305+ }\end{array}$ & $\mathrm{PMMA} / \mathrm{Ag} / \mathrm{Cu} / \mathrm{Adh} / \mathrm{Sub}$ & 3M Company & $\mathrm{A}, \mathrm{B}, \mathrm{F}, \mathrm{G}, \mathrm{K}, \mathrm{M}, \mathrm{P}, \mathrm{S}, \mathrm{W}, \mathrm{X}$ \\
\hline 10 & Experimental & All Polymeric & $\begin{array}{l}\text { Dow Chemical } \\
\text { Company }\end{array}$ & $\mathrm{A}, \mathrm{B}, \mathrm{F}, \mathrm{G}, \mathrm{K}, \mathrm{M}, \mathrm{P}, \mathrm{S}, \mathrm{W}, \mathrm{X}$ \\
\hline 11 & PVD-coated Al & $\mathrm{Al} / \mathrm{Al}$ & Alanod & $\mathrm{A}, \mathrm{B}, \mathrm{F}, \mathrm{G}, \mathrm{K}, \mathrm{M}, \mathrm{P}, \mathrm{S}, \mathrm{W}, \mathrm{X}$ \\
\hline 11 & Anodized Al & $\mathrm{Al}_{2} \mathrm{O}_{3} / \mathrm{Al}$ & Regiolux & $\mathrm{A}, \mathrm{B}, \mathrm{F}, \mathrm{G}, \mathrm{K}, \mathrm{M}, \mathrm{P}, \mathrm{S}, \mathrm{W}, \mathrm{X}$ \\
\hline 11 & Thick Painted Glass & Thick Glass/Ag/Paint & Flagsol & $\mathrm{A}, \mathrm{B}, \mathrm{F}, \mathrm{G}, \mathrm{K}, \mathrm{M}, \mathrm{P}, \mathrm{S}, \mathrm{W}, \mathrm{X}$ \\
\hline 11 & Thin Glass & $\begin{array}{l}\text { Silvered Thin } \\
\text { Glass/Adh/Sub }\end{array}$ & $\begin{array}{l}\text { Schlaich Berg- } \\
\text { ermann \& Partner }\end{array}$ & $\mathrm{A}, \mathrm{B}, \mathrm{F}, \mathrm{G}, \mathrm{K}, \mathrm{M}, \mathrm{P}, \mathrm{S}, \mathrm{W}, \mathrm{X}$ \\
\hline 12 & Thin Glass & $\begin{array}{l}\text { Silvered Thin } \\
\text { Glass/Adh/Sub }\end{array}$ & Steinmüller & $\mathrm{A}, \mathrm{B}, \mathrm{F}, \mathrm{G}, \mathrm{K}, \mathrm{M}, \mathrm{P}, \mathrm{S}, \mathrm{W}, \mathrm{X}$ \\
\hline 13 & Anodized Al & $\mathrm{Al}_{2} \mathrm{O}_{3} / \mathrm{Al}$ & Metalloxyd & $\mathrm{A}, \mathrm{B}, \mathrm{F}, \mathrm{G}, \mathrm{K}, \mathrm{M}, \mathrm{P}, \mathrm{S}, \mathrm{W}, \mathrm{X}$ \\
\hline 14 & Improved PVD-coated Al & Polymer/Al/Al & Alanod & $\mathrm{A}, \mathrm{B}, \mathrm{F}, \mathrm{G}, \mathrm{K}, \mathrm{M}, \mathrm{P}, \mathrm{S}, \mathrm{W}, \mathrm{X}$ \\
\hline
\end{tabular}

${ }^{1}$ Adh $=$ Adhesive

${ }^{2}$ Sub $=$ Substrate

${ }^{3}$ PMMA = Polymethylmethacrylate

${ }^{4} \mathrm{PET}=$ Polyethylene terephthalate

$$
\begin{aligned}
& A=\text { Almería, Spain } \\
& B=\text { Barstow, CA } \\
& F=\text { Fort Davis, TX } \\
& G=\text { Golden, } C O \\
& K=\text { Köln, Germany }
\end{aligned}
$$

$\mathrm{M}=$ Miami, $\mathrm{FL}$

$\mathrm{P}=$ Phoenix, $\mathrm{AZ}$

$\mathrm{S}=$ Sacramento, $\mathrm{CA}$

$\mathrm{W}=$ Atlas Ci 65 WeatherOmeter

$\mathrm{X}=$ Xenotest $1200 \mathrm{LM}$ 
Table 3. Monthly summaries of meteorological and radiometric data at Tempe, Arizona OET site

\begin{tabular}{|c|c|c|c|c|c|c|c|c|c|}
\hline Year & Month & Tot. Prec. & Avg. RH & Avg. $\boldsymbol{T}_{\text {amb. }}$ & Avg. $\boldsymbol{T}_{\text {rack }}$ & Avg. $\boldsymbol{T}_{\text {grnd. }}$ & Tot. Solar & Tot. UV & Tot. UV-B \\
\hline & & $(\mathrm{mm})$ & $(\%)$ & (deg. C) & (deg. C) & (deg. C) & $\left(\mathrm{MJ} / \mathrm{m}^{2}\right)$ & $\left(\mathrm{MJ} / \mathrm{m}^{2}\right)$ & $\left(\mathrm{MJ} / \mathrm{m}^{2}\right)$ \\
\hline
\end{tabular}

\begin{tabular}{|c|c|c|c|c|c|c|c|c|c|}
\hline 1993 & 9 & 4.10 & 2071 & $* * *$ & 2031 & 2351 & $\star * *$ & 22250 & 0838 \\
\hline 1993 & 10 & 0.00 & 3.86 & $* \star *$ & $\star * *$ & 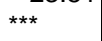 & *** & ${ }_{* \star \star}$ & $* \star * *$ \\
\hline 1993 & 11 & 77.50 & 13.98 & $\star \star * *$ & 13.73 & 16.91 & 508.482 & 16.703 & 0.404 \\
\hline 1993 & 12 & 1.00 & 11.14 & *** & 10.97 & 14.23 & 539.387 & 15.966 & 0.309 \\
\hline 1993 & YTD* & 82.60 & 12.42 & 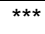 & 15.00 & 18.22 & 1047.869 & 54.928 & 1.551 \\
\hline
\end{tabular}

\begin{tabular}{|c|c|c|c|c|c|c|c|c|c|}
\hline 1994 & 1 & 200 & 1176 & $\star \star * \star$ & 1176 & 15.36 & 588330 & 17340 & 0347 \\
\hline 1994 & 2 & 28.50 & 13.22 & *** & 13.38 & 15.76 & 604.817 & 21.413 & 0.486 \\
\hline 1994 & 3 & 18.10 & 13.08 & *** & 12.99 & 15.01 & 509.958 & 20.102 & 0.529 \\
\hline 1994 & 4 & 0.00 & 22.31 & *** & 22.65 & 25.44 & 727.761 & 30.842 & 0.945 \\
\hline 1994 & 5 & 2.80 & 17.48 & 16.53 & 17.46 & 20.06 & 513.239 & 23.049 & 0.728 \\
\hline 1994 & 6 & 0.00 & 31.50 & 18.43 & 31.63 & 34.66 & 638.637 & 28.799 & 0.999 \\
\hline 1994 & 7 & 1.30 & 28.57 & 20.31 & 28.74 & 32.06 & 596.517 & 27.340 & 0.860 \\
\hline 1994 & 8 & 0.80 & 26.41 & 26.25 & 26.62 & 29.57 & 418.401 & $\star * \star \star$ & 0.764 \\
\hline 1994 & 9 & 21.10 & 29.61 & 35.72 & 29.77 & 33.40 & 764.747 & 24.924 & 0.768 \\
\hline 1994 & 10 & 13.20 & 22.65 & 35.78 & 22.69 & 27.14 & 728.941 & 26.693 & 0.584 \\
\hline 1994 & 11 & 16.00 & 14.08 & $\star \star \star *$ & 14.18 & 18.37 & 521.378 & 21.221 & 0.343 \\
\hline 1994 & 12 & 40.30 & 12.22 & *** & 12.18 & 14.57 & 419.506 & 18.297 & 0.241 \\
\hline 1994 & $Y E$ & 144.10 & 20.24 & 25.50 & 20.34 & 23.45 & 7032.234 & 260.021 & 7.593 \\
\hline
\end{tabular}

\begin{tabular}{|c|c|c|c|c|c|c|c|c|c|}
\hline \multicolumn{10}{|c|}{1995} \\
\hline 1995 & 1 & 39.90 & 11.71 & 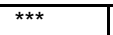 & $\begin{array}{ll}11.63 \\
\end{array}$ & 13.21 & 453.287 & 17.665 & 0.258 \\
\hline 1995 & 2 & 10.70 & 16.79 & $\star \star \star *$ & 16.93 & 19.42 & 614.078 & 22.417 & 0.438 \\
\hline 1995 & 3 & 26.00 & 17.69 & $\star * *$ & 18.12 & 20.80 & 830.318 & 27.295 & 0.674 \\
\hline 1995 & 4 & 5.40 & 17.34 & 26.00 & 17.65 & 20.18 & 800.091 & 24.553 & 0.696 \\
\hline 1995 & 5 & 0.80 & 22.85 & 23.82 & 23.39 & 26.72 & 986.510 & 28.085 & 0.882 \\
\hline 1995 & 6 & 0.00 & 30.25 & 16.61 & 30.77 & 34.15 & 1053.009 & 29.631 & 1.010 \\
\hline 1995 & 7 & 0.30 & 30.57 & 19.82 & 30.86 & 33.59 & 886.819 & 24.941 & 0.881 \\
\hline 1995 & 8 & 50.10 & 34.91 & 36.92 & 35.45 & 38.18 & 1056.423 & 28.181 & 0.919 \\
\hline 1995 & 9 & 38.10 & 31.82 & 34.13 & 32.10 & 36.24 & 997.926 & 27.558 & 0.777 \\
\hline 1995 & 10 & 0.00 & 24.33 & 26.32 & 24.24 & 29.03 & 891.050 & 27.599 & 0.585 \\
\hline 1995 & 11 & 56.80 & 18.43 & $\star * *$ & 18.47 & 22.10 & 478.126 & 21.970 & 0.378 \\
\hline 1995 & 12 & 0.00 & 12.99 & $\star * *$ & 13.13 & 17.51 & $\star * \star$ & 20.803 & 0.357 \\
\hline 1995 & $Y E$ & 228.10 & 22.47 & 26.23 & 22.73 & 25.93 & 9047.638 & 300.697 & 7.854 \\
\hline
\end{tabular}

\begin{tabular}{|c|c|c|c|c|c|c|c|c|c|}
\hline \multicolumn{10}{|c|}{1996} \\
\hline 1996 & 1 & 4.00 & 12.65 & *** & 12.77 & 16.45 & 144.876 & 18.466 & 0.400 \\
\hline 1996 & 2 & 21.90 & 16.29 & *** & 16.38 & 18.89 & 555.860 & $* * *$ & 0.498 \\
\hline 1996 & 3 & 15.40 & 17.08 & 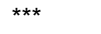 & 17.18 & 19.79 & 171.288 & 70.424 & 0.799 \\
\hline 1996 & 4 & 0.00 & 22.42 & *** & 22.72 & 25.64 & 808.850 & 21.724 & 1.074 \\
\hline 1996 & 5 & 0.00 & 28.74 & *** & 29.27 & 32.34 & 857.894 & 37.885 & 1.358 \\
\hline 1996 & 6 & 0.00 & 33.85 & *** & 34.28 & 37.21 & 788.565 & 36.122 & 1.317 \\
\hline 1996 & 7 & 26.70 & 35.43 & 33.33 & 36.12 & 39.02 & 775.741 & 35.815 & 1.307 \\
\hline 1996 & 8 & 25.90 & 34.76 & 32.18 & 35.41 & 38.99 & 831.118 & 36.005 & 1.277 \\
\hline 1996 & 9 & 16.20 & 28.88 & $* * *$ & 29.19 & 33.59 & 751.450 & 30.730 & 0.963 \\
\hline 1996 & 10 & 1.50 & 23.62 & *** & 23.74 & 28.83 & 746.222 & 26.725 & 0.673 \\
\hline 1996 & 11 & 14.20 & 17.65 & *** & 17.59 & 21.75 & 622.593 & 19.772 & 0.408 \\
\hline 1996 & 12 & 0.00 & 12.69 & *** & 12.87 & 16.99 & 601.189 & 17.278 & 0.297 \\
\hline 1996 & $Y E$ & 125.80 & 23.67 & 32.76 & 23.96 & 27.46 & 7655.646 & 350.946 & 10.371 \\
\hline
\end{tabular}




\begin{tabular}{|c|c|c|c|c|c|c|c|c|c|}
\hline Year & Month & Tot. Prec. & Avg. RH & Avg. $\boldsymbol{T}_{\text {amb. }}$ & Avg. $\boldsymbol{T}_{\text {rack }}$ & Avg. $\boldsymbol{T}_{\text {grnd. }}$ & Tot. Solar & Tot. UV & Tot. UV-B \\
\hline & & $(m m)$ & $(\%)$ & (deg. C) & (deg. C) & (deg. C) & $\left(\mathrm{MJ} / \mathrm{m}^{2}\right)$ & $\left(\mathrm{MJ} / \mathrm{m}^{2}\right)$ & $\left(\mathrm{MJ} / \mathrm{m}^{2}\right)$ \\
\hline
\end{tabular}

\begin{tabular}{|c|c|c|c|c|c|c|c|c|c|}
\hline \multicolumn{10}{|c|}{1997} \\
\hline 1997 & 1 & 27.40 & 12.54 & *** & 12.58 & 15.04 & 499.877 & 15.910 & 0.281 \\
\hline 1997 & 2 & 18.10 & 13.92 & *** & 14.09 & 17.61 & 587.059 & 19.501 & 0.394 \\
\hline 1997 & 3 & 0.00 & 20.23 & 24.54 & 20.39 & 22.88 & 734.074 & 26.564 & 0.730 \\
\hline 1997 & 4 & 7.60 & 21.02 & 27.85 & 21.56 & 24.82 & 758.221 & 30.875 & 0.840 \\
\hline 1997 & 5 & 1.30 & 30.33 & 19.20 & 30.83 & 33.61 & 815.883 & 34.794 & 1.118 \\
\hline 1997 & 6 & 1.00 & 30.59 & 20.07 & 31.02 & 34.71 & $\star \star \star *$ & $\star \star \star *$ & $* * *$ \\
\hline 1997 & 7 & 4.80 & 34.53 & 21.64 & 34.97 & 38.36 & 759.526 & 32.255 & 1.112 \\
\hline 1997 & $* * 8$ & $* * *$ & 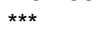 & $* * \star$ & *** & $* * \star$ & $\star \star * *$ & $\star \star \star *$ & *** \\
\hline 1997 & 9 & 2.40 & 39.03 & 31.91 & 32.21 & 36.15 & 641.192 & 24.697 & 0.745 \\
\hline 1997 & 10 & 2.10 & 29.49 & 23.26 & 23.25 & 28.47 & 703.630 & 23.297 & 0.554 \\
\hline 1997 & 11 & 1.80 & 38.98 & 17.13 & 17.15 & 21.97 & 582.972 & 17.156 & 0.326 \\
\hline 1997 & 12 & 41.00 & 55.76 & 10.58 & 10.62 & 13.53 & 524.083 & 14.023 & 0.206 \\
\hline 1997 & $Y E$ & 60.20 & 29.67 & 21.80 & 22.61 & 26.11 & 6606.517 & 239.074 & 6.306 \\
\hline
\end{tabular}

\begin{tabular}{|c|c|c|c|c|c|c|c|c|c|}
\hline 1998 & & & & & & & & & \\
\hline 1998 & 1 & 0.60 & 51.85 & $\begin{array}{l}12.82 \\
\end{array}$ & 13.05 & 15.89 & 596.760 & 16.695 & 0.265 \\
\hline 1998 & 2 & 1.40 & 65.93 & 11.30 & 11.51 & 13.44 & 462.536 & 14.999 & 0.276 \\
\hline 1998 & $* * 3$ & 27.60 & 49.81 & 15.96 & 16.23 & 18.76 & 586.338 & 21.429 & 0.514 \\
\hline 1998 & 4 & 7.90 & 35.69 & 18.61 & 19.22 & 21.53 & 734.102 & 28.032 & 0.675 \\
\hline 1998 & ** 5 & 1.60 & 26.81 & 23.74 & 24.49 & 27.79 & 785.008 & 32.291 & 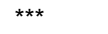 \\
\hline 1998 & 6 & 0.00 & 29.64 & 29.16 & 28.97 & 33.56 & $\star \star \star$ & $* * *$ & $* * *$ \\
\hline 1998 & $\star \star 7$ & 0.00 & 31.15 & 36.41 & 37.06 & 40.15 & $* * *$ & $* * *$ & $* * *$ \\
\hline 1998 & $Y T D^{*}$ & 39.10 & 41.56 & 21.14 & 21.50 & 24.44 & 3164.743 & 113.447 & 1.730 \\
\hline
\end{tabular}

* Figures reflect sums and averages for only the months shown, not yearly predictions or extrapolations.

** Data in the month column was calculated by calculating the average value for that

month and then multiplying by the total days in that month. Note also that prior to September 97 , all

values were calculated in this manner. Where there was a greater than $40 \%$ difference in this data, and known averages,

this data has been purposely omitted.

*** Unavailable due to incomplete data set. Also note that the ambient temp sensor shows erroneous readings in the winter months.

It is suspected that this is due to a malfunction the thermocouple. 
Table 4. Monthly summaries of meteorological and radiometric data at Sacramento, CA OET site

\begin{tabular}{|c|c|c|c|c|c|c|c|c|c|}
\hline Year & Month & Tot. Prec. & Avg. RH & Avg. Tamb & Avg. Track & Avg. Tgrnd & Tot. Solar & Tot. UV & Tot. UV-B \\
\hline & & $(\mathrm{mm})$ & $(\%)$ & (deg. C) & (deg. C) & (deg. C) & $\left(\mathrm{MJ} / \mathrm{m}^{2}\right)$ & $\left(\mathrm{MJ} / \mathrm{m}^{2}\right)$ & $\left(\mathrm{MJ} / \mathrm{m}^{2}\right)$ \\
\hline
\end{tabular}

\begin{tabular}{|r|r|r|r|r|r|r|r|r|r|}
\hline \multicolumn{10}{|c|}{1993} \\
\hline 1993 & 9 & 0.00 & 16.02 & $* * *$ & 15.99 & 20.73 & $* * *$ & 25.1297 & 0.8031 \\
1993 & 10 & 10.00 & 13.20 & $* * *$ & 12.85 & 16.84 & 436.8892 & 15.7800 & 0.4099 \\
1993 & 11 & 68.90 & 9.86 & $* * *$ & 9.48 & 14.03 & 506.3674 & 15.1293 & 0.3016 \\
1993 & 12 & 40.30 & 5.41 & $* * *$ & 5.24 & 8.30 & 256.3025 & 8.7982 & 0.1172 \\
\hline 1993 & YTD $^{*}$ & $\mathbf{1 1 9 . 2 0}$ & $\mathbf{1 1 . 1 2}$ & $* * *$ & $\mathbf{1 0 . 8 9}$ & $\mathbf{1 4 . 9 8}$ & $\mathbf{1 1 9 9 . 5 5 9}$ & $\mathbf{6 4 . 8 3 7}$ & $\mathbf{1 . 6 3 2}$ \\
\hline
\end{tabular}

\begin{tabular}{|c|c|c|c|c|c|c|c|c|c|}
\hline 1994 & 1 & 34.80 & 6.82 & 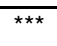 & 6.59 & 9.72 & 425.2719 & 13.0532 & 0.1913 \\
\hline 1994 & 2 & 68.80 & 8.16 & $* * *$ & 8.01 & 10.90 & 485.9374 & 18.2600 & 0.3230 \\
\hline 1994 & 3 & 2.30 & 12.39 & $* * *$ & 12.65 & 16.85 & 647.3166 & 27.4757 & 0.6342 \\
\hline 1994 & 4 & 18.80 & 13.76 & $* * *$ & 14.16 & 18.73 & 632.2480 & 28.6889 & 0.8092 \\
\hline 1994 & 5 & 19.50 & 16.80 & 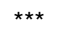 & 17.78 & 23.14 & 621.4349 & 30.3649 & 0.9466 \\
\hline 1994 & 6 & 0.00 & 21.67 & $* * *$ & 23.71 & 28.55 & 718.3451 & 35.3320 & 1.2761 \\
\hline 1994 & 7 & 0.00 & 18.50 & $* * *$ & 19.17 & 24.66 & 593.0726 & 28.6547 & 1.0127 \\
\hline 1994 & 8 & 0.00 & 15.66 & $* * *$ & 15.68 & 19.68 & 513.0497 & 24.7075 & 0.7968 \\
\hline 1994 & 9 & 11.70 & 21.11 & $\star \star \star *$ & 21.46 & 27.64 & 681.2810 & 30.4849 & 0.8193 \\
\hline 1994 & 10 & 25.10 & 15.85 & $* * *$ & 15.73 & 20.79 & 640.0257 & 25.3014 & 0.5614 \\
\hline 1994 & 11 & 54.70 & 7.66 & 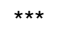 & 7.40 & 11.65 & 200.8963 & 14.2458 & 0.2252 \\
\hline 1994 & 12 & 33.50 & 5.69 & $* * *$ & 5.54 & 8.64 & 93.8716 & 8.3675 & 0.1115 \\
\hline 1994 & $Y E$ & 269.20 & 13.67 & *** & 13.99 & 18.41 & 6252.751 & 284.936 & 7.707 \\
\hline
\end{tabular}

\begin{tabular}{|c|c|c|c|c|c|c|c|c|c|}
\hline \multicolumn{10}{|c|}{1995} \\
\hline 1995 & 1 & 172.00 & 9.95 & $* \star *$ & 9.51 & 11.02 & $* * *$ & 8.9080 & 0.1253 \\
\hline 1995 & 2 & 20.30 & 9.56 & *** & 9.57 & 12.64 & *** & 13.9698 & 0.2491 \\
\hline 1995 & 3 & 126.00 & 5.73 & $\star \star \star *$ & 5.16 & 6.23 & $\star \star \star *$ & 8.5385 & 0.1360 \\
\hline 1995 & 4 & 89.10 & 10.89 & $* * *$ & 11.08 & 14.28 & $* * *$ & 23.2165 & 0.5920 \\
\hline 1995 & 5 & 41.00 & 62.28 & $* * *$ & 15.42 & 19.04 & 243.1276 & 30.2515 & 0.8360 \\
\hline 1995 & 6 & 2.60 & 21.11 & $* * *$ & 20.30 & 25.24 & 632.2880 & 32.9350 & 1.0094 \\
\hline 1995 & 7 & 0.00 & 24.70 & $* * *$ & 24.04 & 29.16 & 690.2825 & 37.7772 & 1.2216 \\
\hline 1995 & 8 & 0.00 & 25.19 & $* * *$ & 24.24 & 29.80 & 760.6769 & 40.1775 & 1.2377 \\
\hline 1995 & 9 & 0.50 & 22.57 & $* * \star$ & 21.20 & 27.82 & 730.4835 & 34.0948 & 0.9095 \\
\hline 1995 & 10 & 0.00 & 19.17 & $* * *$ & 18.81 & 22.72 & 332.7767 & 15.1238 & 0.3566 \\
\hline 1995 & 11 & 1.30 & 15.02 & *** & 15.23 & 18.63 & $* \star *$ & 4.6134 & 0.1018 \\
\hline 1995 & 12 & 100.70 & 9.70 & *** & 9.09 & 10.68 & $* * *$ & 2.8193 & 0.0453 \\
\hline 1995 & $Y E$ & 553.50 & 19.66 & *** & 15.30 & 18.94 & 3389.635 & 252.425 & 6.820 \\
\hline
\end{tabular}

\begin{tabular}{|c|c|c|c|c|c|c|c|c|c|}
\hline \multicolumn{10}{|c|}{1996} \\
\hline 1996 & 1 & 0.30 & $\overline{k \star \star}$ & $\overline{k \star \star}$ & $\begin{array}{l}\star \star * \\
\end{array}$ & $\overline{k \star \star}$ & $\overline{k \star * \star}$ & $\overline{k \star \star \star}$ & $\overline{k \star \star}$ \\
\hline 1996 & 2 & 0.00 & $* * *$ & $* \star *$ & $* * *$ & $* * *$ & $* * *$ & $* * *$ & $\star \star \star *$ \\
\hline 1996 & 3 & 0.00 & $\star * *$ & $* * *$ & $\star \star * *$ & $* * *$ & $* \star *$ & $* * *$ & $* * *$ \\
\hline 1996 & 4 & $* * \star$ & $\star * *$ & $* * *$ & $* * *$ & $* * *$ & $* * *$ & $* * *$ & $* * *$ \\
\hline 1996 & 5 & 59.60 & 39.44 & $* * *$ & 19.60 & 22.63 & 620.161 & 32.924 & 0.9443 \\
\hline 1996 & 6 & 0.00 & $\star * *$ & $* * *$ & $* * *$ & $* * *$ & $* * *$ & $\star * *$ & $* * *$ \\
\hline 1996 & 7 & 0.00 & 51.12 & $\star \star \star *$ & 27.28 & 31.88 & 713.242 & 7.881 & 1.1807 \\
\hline 1996 & 8 & 1.00 & 42.22 & $* * *$ & 27.47 & 30.14 & 763.629 & 27.141 & 1.0726 \\
\hline 1996 & 9 & 0.00 & $\star \star \star *$ & $* \star \star$ & $\star * *$ & $* \star \star$ & $\star \star \star$ & $* * *$ & $\star \star \star ~$ \\
\hline 1996 & 10 & 0.00 & $* * *$ & *** & $* * *$ & $* * *$ & $* * *$ & $* * *$ & $* * *$ \\
\hline 1996 & 11 & 77.30 & 12.32 & $\star \star \star *$ & 11.09 & 14.38 & 371.430 & 13.367 & 0.2031 \\
\hline 1996 & 12 & 158.60 & $* * *$ & *** & $* * *$ & $* * \star$ & $\star * *$ & $\star * *$ & $* * *$ \\
\hline 1996 & $Y E$ & 296.80 & 36.28 & *** & 21.36 & 24.76 & 2468.462 & 81.314 & 3.401 \\
\hline
\end{tabular}




\begin{tabular}{|c|c|c|c|c|c|c|c|c|c|}
\hline Year & Month & Tot. Prec. & Avg. RH & Avg. Tamb & Avg. Track & Avg. Tgrnd & Tot. Solar & Tot. UV & Tot. UV-B \\
\hline & & $(\mathrm{mm})$ & $(\%)$ & (deg. C) & (deg. C) & (deg. C) & $\left(\mathrm{MJ} / \mathrm{m}^{2}\right)$ & $\left(\mathrm{MJ} / \mathrm{m}^{2}\right)$ & $\left(\mathrm{MJ} / \mathrm{m}^{2}\right)$ \\
\hline
\end{tabular}

\begin{tabular}{|c|c|c|c|c|c|c|c|c|c|}
\hline \multicolumn{10}{|c|}{1997} \\
\hline 1997 & 1 & *** & 9.52 & *** & 8.45 & 10.38 & 204.282 & 8.298 & 0.104 \\
\hline 1997 & 2 & 10.30 & 10.33 & 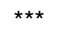 & 9.66 & 12.31 & 499.055 & 20.044 & 0.301 \\
\hline 1997 & 3 & 6.70 & 13.78 & $\star \star \star *$ & 13.70 & 17.52 & 696.635 & 31.726 & 0.637 \\
\hline 1997 & 4 & 9.40 & 16.29 & $\star \star \star *$ & 16.47 & 20.77 & 672.110 & 34.600 & 0.757 \\
\hline 1997 & 5 & 6.10 & 21.80 & $* * *$ & 22.46 & 27.59 & 717.897 & 42.274 & 1.057 \\
\hline 1997 & 6 & 12.90 & 22.61 & $* * *$ & 22.77 & 28.76 & 659.783 & 41.671 & 1.038 \\
\hline 1997 & 7 & 0.00 & 24.87 & $\star * \star *$ & 24.31 & 30.73 & 668.842 & 41.033 & 0.989 \\
\hline 1997 & 8 & 5.10 & 25.63 & $* * *$ & 23.48 & 29.83 & 704.359 & 36.124 & 4.625 \\
\hline 1997 & ${ }^{* *} 9$ & 0.00 & 46.38 & $\star \star \star *$ & 22.99 & 28.95 & 741.708 & 30.867 & 0.981 \\
\hline 1997 & $* * 10$ & 27.50 & 63.80 & $* * *$ & 16.01 & 21.40 & 624.553 & 9.186 & 0.049 \\
\hline 1997 & 11 & 80.10 & 82.09 & $* * *$ & 11.97 & 15.48 & 361.466 & 2.823 & 0.094 \\
\hline 1997 & 12 & 58.80 & 88.71 & $\star * *$ & 5.97 & 8.85 & 361.701 & 1.206 & 0.048 \\
\hline 1997 & YE & 216.90 & 35.48 & $\star \star \star *$ & 16.52 & 21.05 & 6912.391 & 299.852 & 10.681 \\
\hline
\end{tabular}

\begin{tabular}{|c|c|c|c|c|c|c|c|c|c|}
\hline \multicolumn{10}{|c|}{1998} \\
\hline 1998 & $* \star 1$ & 86.40 & 93.88 & 10.90 & 8.26 & 10.29 & 270.017 & 3.510 & 0.041 \\
\hline 1998 & 2 & 0.10 & 89.41 & 11.13 & 8.58 & 10.70 & 264.147 & 9.469 & 0.036 \\
\hline 1998 & 3 & 77.40 & 83.18 & 16.41 & 11.56 & 14.81 & 609.248 & 23.702 & 0.443 \\
\hline 1998 & ** 4 & 21.80 & 75.64 & 21.22 & 15.47 & 21.40 & 590.591 & 26.696 & 0.556 \\
\hline 1998 & 5 & $* * *$ & 81.30 & 27.33 & 13.50 & 17.96 & 497.129 & 24.883 & 0.543 \\
\hline 1998 & $\star * * 6$ & 3.90 & 73.04 & 25.44 & 18.71 & 23.38 & 484.723 & 25.430 & 0.624 \\
\hline 1998 & 7 & 0.00 & 56.84 & 32.05 & 24.86 & 31.22 & 737.451 & 36.109 & 0.990 \\
\hline 1998 & $\star \star 8$ & 0.00 & 45.22 & 37.41 & 30.80 & 34.37 & 771.886 & 35.164 & 1.069 \\
\hline 1998 & YTD* & 189.60 & 74.81 & 22.74 & 16.47 & 20.51 & 4225.191 & 184.962 & 4.302 \\
\hline
\end{tabular}

* Figures reflect sums and averages for only the months shown, not yearly predictions or extrapolations.

${ }^{* *}$ Data in the month column was calculated by calculating the average value for that

month, and then multiplying by the total days in that month. Note also that prior to September 97, all

values were calculated in this manner. Where there was a greater than $40 \%$ difference in this data, and known averages,

this data has been purposely omitted

*** Unavailable due to incomplete data set. Also note that the ambient temp sensor shows erroneous readings in the winter months. It is suspected that this is due to a malfunctioning thermocouple. 
Table 5. Monthly summaries of meteorological and radiometric data at Abilene, TX OET site

\begin{tabular}{|c|c|c|c|c|c|c|c|c|c|}
\hline Year & Month & $\begin{array}{c}\text { Tot. Prec. } \\
(\mathrm{mm})\end{array}$ & $\begin{array}{c}\text { Avg. RH } \\
(\%)\end{array}$ & $\begin{array}{c}\text { Avg. Tamb. } \\
(\text { deg. } \mathrm{C})\end{array}$ & $\begin{array}{c}\text { Avg. Track } \\
(\text { deg. C) }\end{array}$ & $\begin{array}{c}\text { Avg. Tgrnd. } \\
(\text { deg. } \mathrm{C})\end{array}$ & $\begin{array}{c}\text { Tot. Solar } \\
\left(\mathrm{MJ} / \mathrm{m}^{2}\right)\end{array}$ & $\begin{array}{c}\text { Tot. UV } \\
\left(\mathrm{MJ} / \mathrm{m}^{2}\right)\end{array}$ & $\begin{array}{c}\text { Tot. UV-B } \\
\left(\mathrm{MJ} / \mathrm{m}^{2}\right)\end{array}$ \\
\hline
\end{tabular}

\begin{tabular}{|r|r|r|r|r|r|r|r|r|r|}
\hline \multicolumn{10}{|c|}{1994} \\
\hline 1994 & 5 & 232.70 & 20.96 & 70.52 & 21.74 & 21.52 & 611.0906 & 5.3553 & 0.8353 \\
1994 & 6 & 0.00 & 18.18 & 31.10 & 18.36 & 19.28 & 477.8293 & 14.9836 & 0.6254 \\
1994 & 7 & 27.40 & 28.21 & 48.33 & 28.97 & 30.15 & 617.4898 & 18.7531 & 0.8545 \\
1994 & 8 & 12.70 & 28.03 & 48.98 & 29.08 & 29.70 & 741.9320 & 37.6247 & 0.7357 \\
1994 & 9 & 136.80 & 22.21 & 62.23 & 22.74 & 21.97 & 644.7306 & 32.1184 & 0.5124 \\
1994 & 10 & 95.20 & 18.00 & 67.86 & 18.44 & 18.58 & 563.4807 & 26.3289 & 0.7780 \\
1994 & 11 & 71.60 & 11.86 & 66.93 & 12.01 & 12.34 & 408.3733 & 17.7630 & 0.9277 \\
1994 & 12 & 20.40 & 7.91 & 72.51 & 8.36 & 9.30 & 432.3764 & 17.0580 & 0.3232 \\
\hline 1994 & YTD $^{*}$ & $\mathbf{5 9 6 . 8 0}$ & $\mathbf{1 9 . 4 2}$ & $\mathbf{5 8 . 5 6}$ & $\mathbf{1 9 . 9 6}$ & $\mathbf{2 0 . 3 5}$ & $\mathbf{4 4 9 7 . 3 0 3}$ & $\mathbf{1 6 9 . 9 8 5}$ & $\mathbf{5 . 5 9 2}$ \\
\hline
\end{tabular}

\begin{tabular}{|c|c|c|c|c|c|c|c|c|c|}
\hline \multicolumn{10}{|c|}{1995} \\
\hline 1995 & 1 & 22.40 & 7.34 & 57.02 & 7.54 & 7.45 & 469.2464 & 19.0995 & 0.3615 \\
\hline 1995 & 2 & 7.60 & 9.49 & 60.73 & 9.91 & 10.66 & 486.2907 & 21.4582 & 0.4829 \\
\hline 1995 & 3 & 32.30 & 11.30 & 67.74 & 11.85 & 11.47 & 540.8597 & 26.5121 & 0.7228 \\
\hline 1995 & 4 & 28.30 & 14.62 & 52.67 & 15.25 & 15.33 & 605.0968 & 30.6316 & 0.9269 \\
\hline 1995 & 5 & 116.30 & 16.72 & 47.71 & 17.05 & 16.42 & 496.3232 & 25.6340 & 0.8362 \\
\hline 1995 & 6 & 53.60 & 24.25 & 62.94 & 25.35 & 25.25 & 706.4722 & 38.0490 & 1.2550 \\
\hline 1995 & 7 & 56.50 & 28.19 & 55.32 & 29.29 & 28.90 & 723.3644 & 38.8279 & 1.3121 \\
\hline 1995 & 8 & 205.70 & 21.76 & 54.44 & 22.51 & 22.43 & 564.2141 & 30.0493 & 0.9383 \\
\hline 1995 & 9 & $\star \star \star *$ & 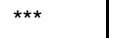 & 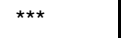 & $\star \star \star ~$ & & $\star \star \star *$ & $\star \star \star *$ & $\star \star \star$ \\
\hline 1995 & 10 & 5.10 & 17.17 & 43.55 & 18.08 & 18.46 & 674.2653 & 30.2306 & 0.7531 \\
\hline 1995 & 11 & 7.70 & 8.41 & 48.71 & 8.79 & 9.55 & 359.7436 & 15.4936 & 0.2933 \\
\hline 1995 & 12 & 5.30 & 4.89 & 47.49 & 5.32 & 5.78 & 346.5021 & 13.8125 & 0.2114 \\
\hline 1995 & YE & 540.80 & 14.92 & 54.39 & 15.54 & 15.61 & 5972.378 & 289.798 & 8.093 \\
\hline
\end{tabular}

\begin{tabular}{|c|c|c|c|c|c|c|c|c|c|}
\hline \multicolumn{10}{|c|}{1996} \\
\hline 1996 & 1 & 5.60 & 0.04 & 3.17 & -0.90 & -0.80 & 1.684 & 0.125 & 0.0017 \\
\hline 1996 & 2 & 0.00 & 0.00 & -1.00 & -1.00 & -1.00 & 0.000 & 0.000 & 0.0000 \\
\hline 1996 & 3 & 21.10 & 7.66 & 32.08 & 9.05 & 9.24 & 497.427 & 22.315 & 0.5016 \\
\hline 1996 & 4 & 59.90 & 15.58 & 38.91 & 16.93 & 17.45 & 754.183 & 30.139 & 0.7750 \\
\hline 1996 & 5 & 46.70 & 25.45 & 56.27 & 28.22 & 28.96 & 695.127 & 36.792 & 1.0720 \\
\hline 1996 & 6 & 67.80 & 26.69 & 59.25 & 30.62 & 30.69 & 681.536 & 38.386 & 1.1142 \\
\hline 1996 & 7 & 37.40 & 28.07 & 57.51 & 31.90 & 30.56 & 641.204 & 36.532 & 1.0338 \\
\hline 1996 & 8 & 21.40 & 27.12 & 58.45 & 30.16 & 29.40 & 611.154 & 33.454 & 0.9049 \\
\hline 1996 & $Y T D^{*}$ & 259.90 & 16.33 & 38.08 & 18.12 & 18.06 & 3882.314 & 197.744 & 5.403 \\
\hline
\end{tabular}

* Figures reflect sums and averages for only the months shown, not yearly predictions or extrapolations

*** Figures unavailable due to incomplete database 
Table 6. Monthly summaries of meteorological and radiometric data at Fort Davis, TX OET site

\begin{tabular}{|c|c|c|c|c|c|c|c|c|c|}
\hline Year & Month & Tot. Prec. & Avg. RH & Avg. $\boldsymbol{T}_{\text {amb. }}$ & Avg. $\boldsymbol{T}_{\text {rack }}$ & Avg. $\boldsymbol{T}_{\text {grnd. }}$ & Tot. Solar & Tot. UV & Tot. UV-B \\
\hline & & $(\mathrm{mm})$ & $(\%)$ & (deg. C) & (deg. C) & (deg. C) & $\left(\mathrm{MJ} / \mathrm{m}^{2}\right)$ & $\left(\mathrm{MJ} / \mathrm{m}^{2}\right)$ & $\left(\mathrm{MJ} / \mathrm{m}^{2}\right)$ \\
\hline
\end{tabular}

\begin{tabular}{|c|c|c|c|c|c|c|c|c|c|}
\hline \multicolumn{10}{|c|}{1997} \\
\hline 1997| & 3 & 7.10 & 11.36 & 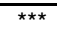 & \begin{tabular}{l|}
12.10 \\
\end{tabular} & 13.29 & 731.110 & \begin{tabular}{|l|}
1.096 \\
\end{tabular} & 0.856 \\
\hline 1997 & 4 & 28.20 & 12.20 & $\star \star \star \star ~$ & 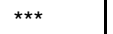 & 13.95 & 705.070 & 1.227 & 0.886 \\
\hline 1997 & 5 & 84.60 & 17.40 & $* * \star$ & $* \star \star$ & 18.28 & 634.293 & 3.052 & 0.950 \\
\hline 1997 & 6 & 54.30 & 21.08 & 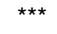 & $\star \star \star \star ~$ & 22.02 & 618.846 & 1.392 & 0.996 \\
\hline 1997 & 7 & 40.40 & 21.79 & 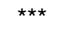 & 23.45 & 23.92 & 597.225 & 4.286 & 0.928 \\
\hline 1997 & 8 & 75.80 & 21.01 & $\star \star \star \star ~$ & 22.61 & 22.81 & 567.929 & 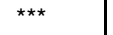 & 0.822 \\
\hline 1997 & $* * 9$ & $\star \star \star ~$ & 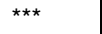 & $\star \star \star \star ~$ & 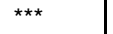 & 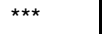 & $\star \star \star \star ~$ & 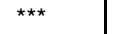 & $\star \star \star \star$ \\
\hline 1997 & $* * 10$ & *** & *** & $\star * \star$ & *** & *** & 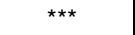 & $\star \star \star *$ & $\star \star \star$ \\
\hline 1997 & $* * 11$ & $* * *$ & $* * *$ & $* * *$ & $* * *$ & $\star * *$ & $* * *$ & $* \star \star$ & $\star \star \star *$ \\
\hline 1997 & ** 12 & $\star \star \star *$ & $\star * *$ & $* \star \star$ & $\star \star \star *$ & $* \star *$ & 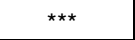 & 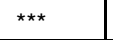 & $\star \star \star *$ \\
\hline 1997 & YTD* & 290.40 & 17.47 & 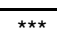 & 19.38 & 19.05 & 3854.472 & 11.053 & 5.438 \\
\hline
\end{tabular}

\begin{tabular}{|c|c|c|c|c|c|c|c|c|c|}
\hline \multicolumn{10}{|c|}{1998} \\
\hline 1998 & 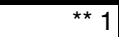 & 0.00 & 39.53 & 7.13 & 8.54 & 10.03 & 665.494 & 2.711 & 0.331 \\
\hline 1998 & $* * 2$ & 1.90 & 24.31 & 3.45 & 24.34 & 8.24 & 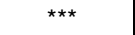 & $\star \star \star *$ & 0.966 \\
\hline 1998 & $* * 3$ & 0.00 & 22.15 & $\star \star \star *$ & 3.08 & 7.14 & 888.821 & 3.032 & 0.568 \\
\hline 1998 & ${ }^{* *} 4$ & $* \star \star$ & $\star * \star$ & $\star \star \star \star$ & 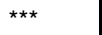 & $\star * *$ & 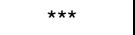 & $\star * \star$ & $\star \star \star *$ \\
\hline 1998 & ** 5 & $* * *$ & $\star * *$ & 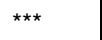 & $\star * \star *$ & $* * *$ & $\star \star \star *$ & $* \star *$ & $\star \star \star *$ \\
\hline 1998 & ** 6 & 6.80 & 33.63 & 25.82 & 32.27 & *** & 688.352 & 23.534 & 0.774 \\
\hline 1998 & 7 & 92.30 & $\star * *$ & 26.89 & 32.30 & 36.44 & 634.785 & 21.382 & 0.596 \\
\hline 1998 & ** 8 & 0.00 & $\star * \star$ & 26.15 & 31.93 & 25.62 & 683.085 & 19.496 & 0.642 \\
\hline 1998 & YTD* & 101.00 & 29.90 & 17.89 & 22.08 & 17.49 & 3560.538 & 70.155 & 3.877 \\
\hline
\end{tabular}

${ }^{*}$ Figures reflect sums and averages for only the months shown, not yearly predictions or extrapolations. ${ }^{* *}$ Data in the month column was calculated by calculating the average value for that

month, and then multiplying by the total days in that month. Note also that prior to September 97 , all

values were calculated in this manner. Where there was a greater than $40 \%$ difference in this data, and known averages, this data has been purposely omitted.

${ }^{* \star *}$ Unavailable due to incomplete data set. Also note that the ambient temp sensor shows erroneous readings in the winter months. 
Table 7. Monthly summaries of meteorological and radiometric data at Golden, Colorado OET site

\begin{tabular}{|c|c|c|c|c|c|c|c|c|c|}
\hline Year & Month & Tot. Prec. & Avg. RH & Avg. T $_{\text {amb }}$ & Avg. T $_{\text {rack }}$ & Ave. T grnd Tot. Solar & Tot. UV & Tot. UV-B \\
\hline & & $(\mathrm{mm})$ & $(\%)$ & (deg. C) & (deg. C) & (deg. C) & $\left(\mathrm{MJ} / \mathrm{m}^{2}\right)$ & $\left(\mathrm{MJ} / \mathrm{m}^{2}\right)$ & $\left(\mathrm{MJ} / \mathrm{m}^{2}\right)$ \\
\hline
\end{tabular}

\begin{tabular}{|c|c|c|c|c|c|c|c|c|c|}
\hline \multicolumn{10}{|c|}{1994} \\
\hline 1994 & 3 & 7.60 & 44.66 & 5.21 & 5.30 & 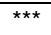 & 318.000 & 16.288 & 1.128 \\
\hline 1994 & 4 & 0.00 & 57.31 & 5.35 & 5.58 & $\star \star \star *$ & 503.780 & 28.450 & 0.000 \\
\hline 1994 & 5 & 9.40 & 50.05 & 13.84 & 14.27 & *** & 632.556 & 32.715 & 0.207 \\
\hline 1994 & 6 & 0.80 & 38.85 & 20.80 & 21.53 & *** & 691.855 & 34.347 & 0.578 \\
\hline 1994 & 7 & 10.40 & 40.47 & 21.33 & 21.84 & $\star * \star *$ & 608.939 & 31.399 & 0.529 \\
\hline 1994 & 8 & 40.10 & 43.68 & 22.21 & 22.31 & *** & 575.187 & 30.708 & 0.517 \\
\hline 1994 & 9 & 14.40 & 35.51 & 17.67 & 17.46 & $\star \star * *$ & 626.889 & 31.072 & 0.282 \\
\hline 1994 & 10 & 18.80 & 47.76 & 10.33 & 10.34 & $* \star *$ & 590.688 & 25.014 & 0.272 \\
\hline 1994 & 11 & 37.20 & 51.85 & 2.60 & 2.82 & *** & 466.610 & 18.417 & 0.136 \\
\hline 1994 & 12 & 1.30 & 41.35 & 2.06 & 2.18 & *** & 484.267 & 17.268 & 0.074 \\
\hline 1994 & YTD* & 140.00 & 45.15 & 12.14 & 12.36 & $* * *$ & 5498.773 & 265.677 & 3.723 \\
\hline
\end{tabular}

\begin{tabular}{|c|c|c|c|c|c|c|c|c|c|}
\hline \multicolumn{10}{|c|}{1995} \\
\hline 1995 & 1 & 0.30 & 41.32 & 0.71 & 0.95 & 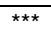 & 516.852 & 19.215 & 0.077 \\
\hline 1995 & 2 & 24.80 & 49.87 & 2.87 & 3.64 & *** & 560.617 & 21.718 & 0.193 \\
\hline 1995 & 3 & 18.30 & 50.50 & 3.88 & 4.59 & *** & 635.060 & 30.357 & 0.216 \\
\hline 1995 & 4 & 114.50 & 62.11 & 5.33 & 6.43 & 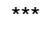 & 529.553 & 27.545 & 0.323 \\
\hline 1995 & 5 & 148.20 & 72.49 & 8.61 & 9.53 & 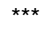 & 475.143 & 25.238 & 0.313 \\
\hline 1995 & 6 & 95.80 & 59.10 & 16.31 & 17.34 & *** & 571.119 & 28.972 & 0.455 \\
\hline 1995 & 7 & 24.10 & 42.93 & 21.40 & 22.24 & *** & 635.450 & 32.325 & 0.503 \\
\hline 1995 & 8 & 0.30 & 41.25 & 22.64 & 23.27 & *** & 642.068 & 29.225 & 0.368 \\
\hline 1995 & 9 & 56.80 & 54.37 & 15.20 & 15.68 & *** & 524.882 & 24.543 & 0.279 \\
\hline 1995 & 10 & 8.70 & 37.40 & 10.26 & 10.72 & *** & 675.421 & 26.798 & 0.239 \\
\hline 1995 & 11 & 14.00 & 44.92 & 6.81 & 7.07 & *** & 452.609 & 15.977 & 0.097 \\
\hline 1995 & 12 & 1.80 & 44.80 & 1.57 & 2.17 & *** & 490.401 & 14.978 & 0.066 \\
\hline 1995 & YE & 507.60 & 50.09 & 9.63 & 10.30 & *** & 6709.175 & 296.891 & 3.128 \\
\hline
\end{tabular}

\begin{tabular}{|c|c|c|c|c|c|c|c|c|c|}
\hline 1996 & 1 & 10.30 & 49.82 & \begin{tabular}{|l|}
-1.66 \\
\end{tabular} & $\mid-0.75$ & *** & 466.021 & 15.594 & 0.067 \\
\hline 1996 & 2 & 2.50 & 42.55 & 2.18 & 2.95 & $\star * *$ & 551.290 & 21.194 & 0.107 \\
\hline 1996 & 3 & 31.00 & 55.53 & 1.78 & 3.30 & *** & 619.381 & 26.738 & 0.177 \\
\hline 1996 & 4 & 27.20 & 44.74 & 8.56 & 9.77 & *** & 637.279 & 28.147 & 0.264 \\
\hline 1996 & 5 & 91.80 & 58.79 & 13.92 & 15.00 & *** & 629.871 & 28.622 & 0.365 \\
\hline 1996 & 6 & 42.90 & 46.90 & 19.23 & 20.09 & *** & 654.283 & 30.398 & 0.369 \\
\hline 1996 & 7 & 3.50 & 49.87 & 21.18 & 22.01 & $\star \star * *$ & 680.836 & 30.216 & 0.242 \\
\hline 1996 & 8 & 57.60 & 43.75 & 21.18 & 22.13 & *** & 676.253 & 8.445 & 0.363 \\
\hline 1996 & 9 & 78.60 & 51.79 & 15.31 & 15.91 & *** & 607.442 & 17.382 & 0.258 \\
\hline 1996 & 10 & 12.70 & 45.28 & 10.31 & 10.92 & *** & 622.987 & 21.134 & 0.187 \\
\hline 1996 & 11 & 15.00 & 53.72 & 3.99 & 4.69 & *** & 504.201 & 15.071 & 0.086 \\
\hline 1996 & 12 & 2.30 & 39.24 & 1.85 & 2.36 & $\star \star \star *$ & 466.326 & 13.689 & 0.050 \\
\hline 1996 & YE & 375.40 & 48.50 & 9.82 & 10.70 & $* * *$ & 7116.170 & 256.629 & 2.535 \\
\hline
\end{tabular}




\begin{tabular}{|c|c|c|c|c|c|c|c|c|c|}
\hline Year & Month & Tot. Prec. & Avg. RH & Avg. Tamb $_{\text {a }}$ & Avg. Track $_{\text {r }}$ & Ave. T grnd Tot. Solar & Tot. UV & Tot. UV-B \\
\hline & & $(\mathrm{mm})$ & $(\%)$ & (deg. C) & (deg. C) & (deg. C) & $\left(\mathrm{MJ} / \mathrm{m}^{2}\right)$ & $\left(\mathrm{MJ} / \mathrm{m}^{2}\right)$ & $\left(\mathrm{MJ} / \mathrm{m}^{2}\right)$ \\
\hline
\end{tabular}

\begin{tabular}{|c|c|c|c|c|c|c|c|c|c|}
\hline \multicolumn{10}{|c|}{1997} \\
\hline 1997 & 1 & 2.30 & 50.26 & -1.00 & 0.17 & $* * *$ & 467.673 & 13.874 & 0.060 \\
\hline 1997 & 2 & 22.20 & 60.91 & -1.41 & 0.08 & $* * *$ & 527.847 & 19.050 & 0.084 \\
\hline 1997 & 3 & 12.00 & 39.53 & 6.17 & 7.36 & $* * *$ & 701.564 & 26.406 & 0.223 \\
\hline 1997 & 4 & 109.20 & 59.17 & 3.97 & 5.56 & $* * *$ & 581.452 & 25.579 & 0.215 \\
\hline 1997 & 5 & 17.20 & 50.00 & 13.37 & 14.80 & $* * *$ & 661.978 & 27.807 & 0.332 \\
\hline 1997 & 6 & 47.60 & 53.08 & 19.18 & 20.26 & $* * *$ & 638.620 & 27.672 & 0.359 \\
\hline 1997 & 7 & 22.70 & 41.82 & 18.62 & 19.60 & $* * *$ & 631.597 & 27.039 & 0.289 \\
\hline 1997 & 8 & 69.50 & 56.67 & 20.23 & 20.97 & $* * *$ & 613.703 & 26.865 & 0.304 \\
\hline 1997 & $* * 9$ & 39.80 & 59.14 & 14.72 & 15.18 & 16.68 & 508.494 & 27.111 & 0.210 \\
\hline 1997 & 10 & 56.60 & 42.97 & 11.11 & 11.62 & 13.01 & 645.612 & 10.273 & 0.183 \\
\hline 1997 & 11 & 23.20 & 51.03 & 2.38 & 3.16 & 4.80 & 525.672 & 8.516 & 0.088 \\
\hline 1997 & 12 & 12.20 & 54.95 & -0.05 & 0.84 & 1.56 & 452.669 & 7.130 & 0.057 \\
\hline 1997 & YE & 434.50 & 51.63 & 8.94 & 9.97 & 9.02 & 6956.880 & 247.322 & 2.404 \\
\hline
\end{tabular}

\begin{tabular}{|c|c|c|c|c|c|c|c|c|c|}
\hline \multicolumn{10}{|c|}{1998} \\
\hline 1998 & $\begin{array}{ll}* * & 1\end{array}$ & 13.70 & 34.12 & 2.77 & 3.22 & 2.26 & 522.318 & 6.230 & 0.066 \\
\hline 1998 & 2 & $* \star *$ & 50.75 & 1.17 & 2.07 & 3.48 & 465.624 & 17.195 & 0.085 \\
\hline 1998 & ** 3 & 48.50 & 59.83 & 0.10 & 1.92 & 3.49 & 673.957 & 54.840 & 0.180 \\
\hline 1998 & ** 4 & 57.60 & 57.89 & 6.30 & 7.76 & 8.36 & 591.733 & 51.803 & 0.351 \\
\hline 1998 & 5 & 66.30 & 49.71 & 14.45 & 15.61 & $* * *$ & 641.222 & 56.556 & 0.598 \\
\hline 1998 & ${ }^{* *} 6$ & $* * *$ & 64.70 & 11.64 & 12.97 & $* * *$ & 369.120 & 34.449 & 0.384 \\
\hline 1998 & $\star * 7$ & 55.70 & 50.46 & 25.76 & 23.76 & 33.23 & 580.564 & 52.139 & 0.661 \\
\hline 1998 & ${ }^{\star *} 8$ & 0.03 & 64.70 & 17.94 & 18.60 & 18.78 & 497.790 & 46.830 & 0.539 \\
\hline 1998 & YTD* & 241.83 & 54.02 & 10.02 & 10.74 & 11.60 & 4342.329 & 320.044 & 2.864 \\
\hline
\end{tabular}

* Figures reflect sums and averages for only the months shown, not yearly predictions or extrapolations.

** Data in the month column was calculated by calculating the average value for that

month, and then multiplying by the total days in that month. Note also that prior to September 97 , all values were calculated in this manner.

*** Unavailable due to incomplete data set. Note the ground temperature sensor appears

to have an erroneous calibration factor. 
Table 8. Monthly summaries of meteorological and radiometric data at Barstow, California OET site

\begin{tabular}{|c|c|c|c|c|c|c|c|c|c|}
\hline Year & Month & Tot. Prec. & Avg. RH & Avg. Tamb & Avg. Track & Avg. Tgrnd & Tot. Solar & Tot. UV & Tot. UV-B \\
\hline & & $(\mathrm{mm})$ & $(\%)$ & (deg. C) & (deg. C) & (deg. C) & $\left(\mathrm{MJ} / \mathrm{m}^{2}\right)$ & $\left(\mathrm{MJ} / \mathrm{m}^{2}\right)$ & $\left(\mathrm{MJ} / \mathrm{m}^{2}\right)$ \\
\hline
\end{tabular}

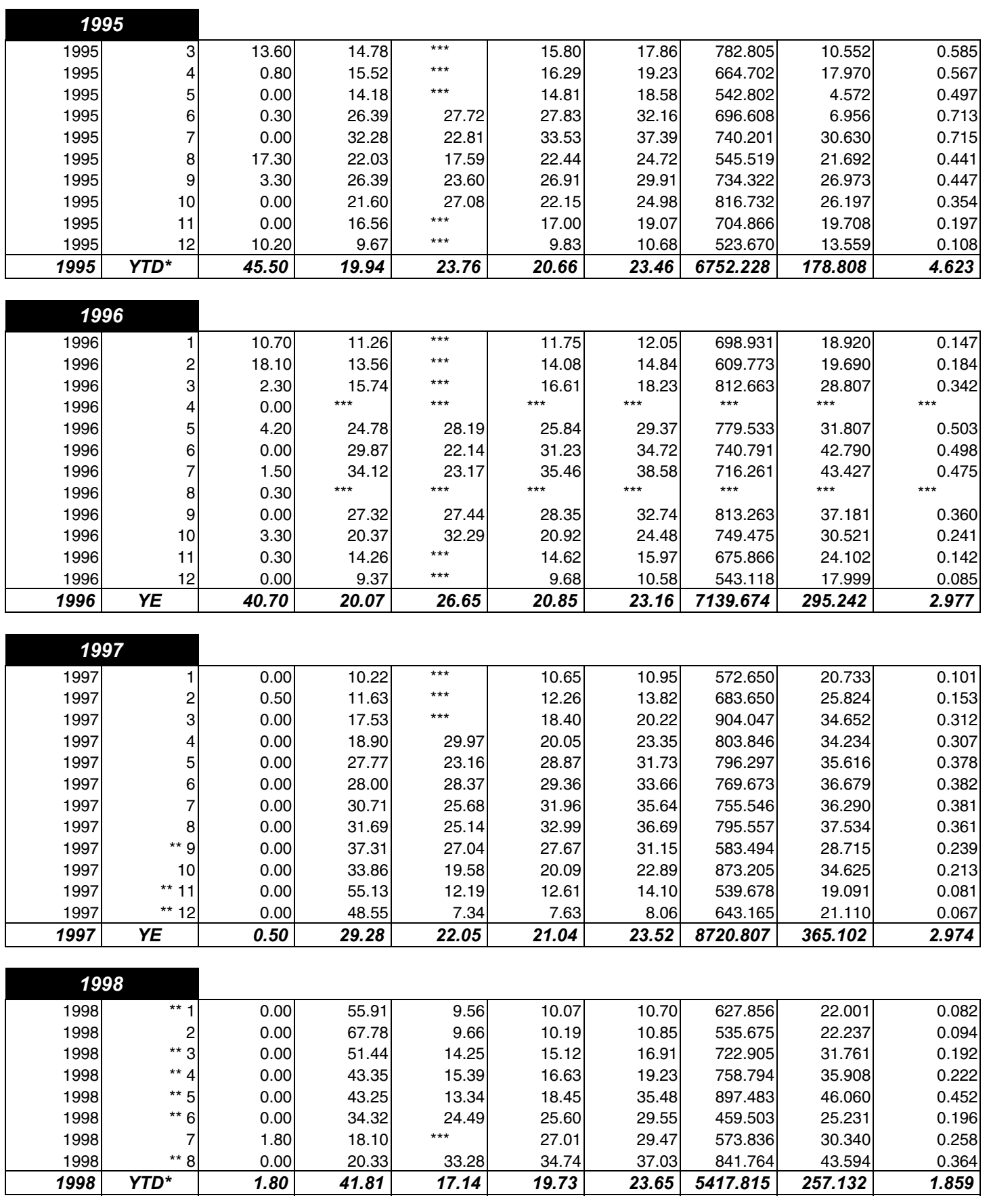

* Figures reflect sums and averages for only the months shown, not yearly predictions or extrapolations.

** Data in the month column was calculated by calculating the average value for that

month, and then multiplying by the total days in that month. Note also that prior to September 97, all

values were calculated in this manner. Where there was a greater than $40 \%$ difference in this data, and known averages,

this data has been purposely omitted.

*** Unavailable due to incomplete data set. Also note that the ambient temp sensor shows erroneous readings in the winter month. It is suspected that this is due to a malfunctioning thermocouple. 
Table 9. Monthly summaries of meteorological and radiometric data at Miami, Florida OET site

\begin{tabular}{|c|c|c|c|c|c|c|c|c|c|}
\hline Year & Month & Tot. Prec. & Avg. $R H$ & Avg. $T_{a m b}$ & Avg. $T_{\text {rack }}$ & Avg. $T_{\text {grnd }}$ & Tot. Solar & Tot. UV & Tot. UV-B \\
\hline & & $(\mathrm{mm})$ & $(\%)$ & (deg. C) & (deg. C) & (deg. C) & $\left(M J / m^{2}\right)$ & $\left(M J / m^{2}\right)$ & $\left(M J / m^{2}\right)$ \\
\hline \multicolumn{10}{|c|}{1995} \\
\hline 1995 & 6 & 414.30 & 26.98 & 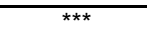 & 27.52 & 27.09 & 501.222 & 26.690 & 1.048 \\
\hline 1995 & 7 & 17.90 & 14.97 & *** & 14.94 & 14.71 & 317.621 & 15.779 & 0.666 \\
\hline 1995 & 8 & 0.00 & $\star \star \star ~$ & $* \star *$ & 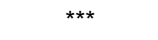 & 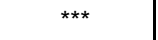 & $\star \star * \star$ & 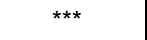 & 0.007 \\
\hline 1995 & 9 & $\star \star * *$ & 27.05 & $\star \star \star *$ & 27.58 & 27.78 & 480.905 & $* * *$ & 0.912 \\
\hline 1995 & 10 & $\star \star \star$ & 26.55 & $* \star \star$ & 26.87 & 26.87 & 410.030 & 22.929 & 0.787 \\
\hline 1995 & 11 & 243.60 & 20.61 & $* * *$ & 20.94 & 22.70 & 501.575 & 19.729 & 0.551 \\
\hline 1995 & 12 & 167.50 & $\star * \star$ & *** & $\star \star \star *$ & $* * *$ & $\star * *$ & $* * *$ & 0.063 \\
\hline 1995 & YTD* & 843.30 & 23.23 & $* * \star$ & 23.57 & 23.83 & 2211.352 & 85.126 & 4.033 \\
\hline \multicolumn{10}{|c|}{1996} \\
\hline 1996 & 1 & 269.20 & 18.16 & 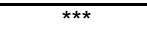 & 18.37 & 19.06 & 530.473 & 19.806 & 0.557 \\
\hline 1996 & 2 & 152.30 & 13.08 & *** & 13.08 & 13.87 & 479.726 & 17.850 & 0.491 \\
\hline 1996 & 3 & 4.90 & 14.61 & *** & 14.65 & 15.12 & 464.223 & 19.682 & 0.568 \\
\hline 1996 & 4 & *** & 21.00 & *** & 21.37 & 21.95 & 591.187 & 26.324 & 0.948 \\
\hline 1996 & 5 & *** & 26.00 & *** & 26.53 & 26.97 & 589.678 & 28.264 & 1.046 \\
\hline 1996 & 6 & *** & 26.80 & *** & 27.20 & 27.80 & 546.586 & 26.867 & 0.984 \\
\hline 1996 & 7 & *** & 28.66 & *** & 29.31 & 28.69 & 622.363 & 30.138 & 1.128 \\
\hline 1996 & 8 & *** & 27.47 & *** & 28.18 & 28.09 & 547.398 & 26.424 & 0.949 \\
\hline 1996 & 9 & *** & 27.05 & *** & 28.22 & 29.17 & 582.040 & 26.533 & 0.932 \\
\hline 1996 & 10 & *** & 24.62 & *** & 25.38 & 26.67 & 483.878 & 20.702 & 0.659 \\
\hline 1996 & 11 & 25.40 & $\star \star \star *$ & $* * *$ & 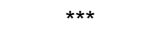 & 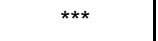 & $\star \star \star *$ & $\star \star \star *$ & $* \star *$ \\
\hline 1996 & 12 & 58.40 & 21.61 & $* * *$ & $\star * *$ & 22.12 & $\star \star * *$ & 13.753 & 0.161 \\
\hline 1996 & $Y E$ & 510.20 & 22.64 & *** & 23.23 & 23.59 & 5437.552 & 256.341 & 8.423 \\
\hline
\end{tabular}

\begin{tabular}{|c|c|c|c|c|c|c|c|c|c|}
\hline 1997 & 1 & 622.00 & 15.99 & *** & 16.56 & 17.76 & 423.951 & 15.963 & 0.000 \\
\hline 1997 & 2 & 693.00 & 19.78 & $\star \star \star \star ~$ & 20.42 & 22.56 & 462.102 & 19.652 & 0.000 \\
\hline 1997 & 3 & 487.40 & 12.39 & *** & 12.85 & 12.90 & 338.357 & 15.390 & 0.000 \\
\hline 1997 & 4 & 12.50 & 29.46 & 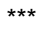 & 14.96 & 11.99 & 318.497 & 15.358 & 0.000 \\
\hline 1997 & 5 & 0.00 & 25.41 & *** & 26.10 & 24.85 & 631.589 & 31.042 & 0.826 \\
\hline 1997 & 6 & 0.00 & $\star \star \star *$ & *** & *** & $\star \star \star *$ & $\star \star \star *$ & $\star \star \star *$ & $\star \star \star *$ \\
\hline 1997 & 7 & 0.00 & *** & 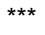 & *** & *** & *** & *** & $\star \star \star *$ \\
\hline 1997 & 8 & 0.00 & *** & *** & *** & *** & 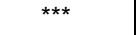 & *** & *** \\
\hline 1997 & ** 9 & 0.00 & 17.68 & *** & *** & 26.68 & 401.628 & 18.900 & 0.023 \\
\hline 1997 & ** 10 & 0.00 & 16.54 & *** & *** & 24.34 & 513.082 & 22.269 & 0.025 \\
\hline 1997 & 11 & 7.50 & 20.89 & *** & 19.89 & 19.07 & 305.030 & 13.864 & 0.029 \\
\hline 1997 & ${ }^{\star \star} 12$ & 35.40 & 10.97 & *** & 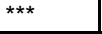 & 14.04 & 304.605 & 12.204 & 0.035 \\
\hline 1997 & $Y E$ & 1814.90 & 20.60 & 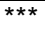 & 18.18 & 18.01 & 3698.841 & 164.641 & 0.938 \\
\hline
\end{tabular}

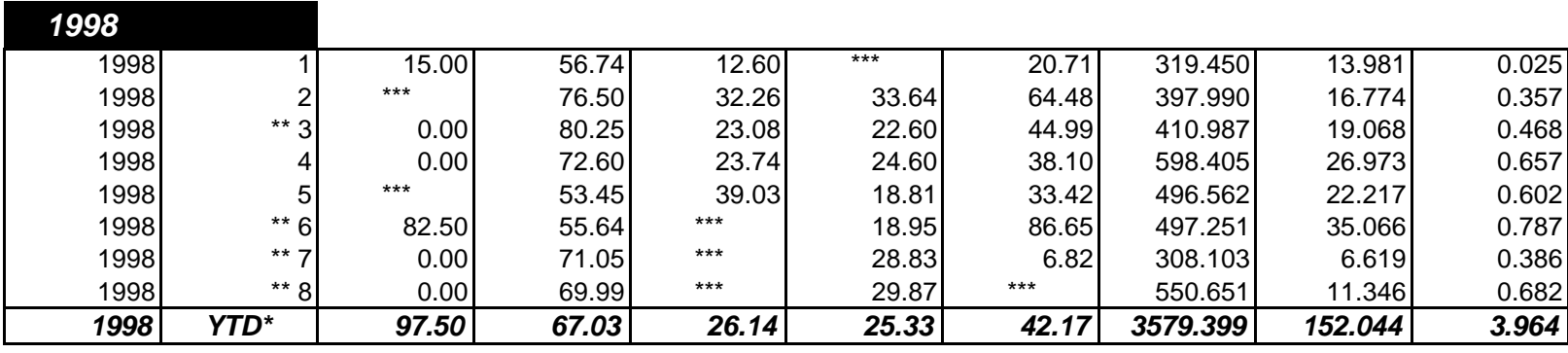

* Figures reflect sums and averages for only the months shown, not yearly predictions or extrapolations.

** Data in the month column was calculated by calculating the average value for that

month, and then multiplying by the total days in that month. Note also that prior to September 97 , all

values were calculated in this manner. Where there was a greater than $40 \%$ difference in this data, and known averages, this data has been purposely omitted.

*** Unavailable due to incomplete data set. Also note that the ambient temp sensor shows erroneous readings in the winter months. It is suspected that this is due to a thermocouple malfunction. 
Table 10. Monthly summaries of meteorological and radiometric data at Köln, Germany OET site

\begin{tabular}{|c|c|c|c|c|c|c|c|c|c|}
\hline Year & Month & Tot. Prec. & Avg. RH & Avg. $\boldsymbol{T}_{\text {amb }}$ & Avg. $\boldsymbol{T}_{\text {rack }}$ & Avg. $\boldsymbol{T}_{\text {grnd }}$ & Tot. Solar & Tot. UV & Tot. UV-B \\
\hline & & $(\mathrm{mm})$ & $(\%)$ & (deg. C) & (deg. C) & $($ deg. $\mathrm{C})$ & $\left(\mathrm{MJ} / \mathrm{m}^{2}\right)$ & $\left(\mathrm{MJ} / \mathrm{m}^{2}\right)$ & $\left(\mathrm{MJ} / \mathrm{m}^{2}\right)$ \\
\hline
\end{tabular}

\begin{tabular}{|c|c|c|c|c|c|c|c|c|c|}
\hline \multicolumn{10}{|c|}{1995} \\
\hline 1995 & 12 & 44 & 77.13 & -0.97 & $* \star *$ & 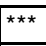 & 102.70 & 1.50 & 0.183384 \\
\hline 1995 & YTD* & 44 & 77.13 & -0.97 & $\star \star \star *$ & 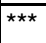 & 102.70 & 1.50 & 0.183384 \\
\hline
\end{tabular}

\begin{tabular}{|c|c|c|c|c|c|c|c|c|c|}
\hline \multicolumn{10}{|c|}{1996} \\
\hline 1996 & 1 & 11 & 70.93 & -0.54 & *** & 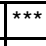 & 166.30 & 2.80 & 0.029568 \\
\hline 1996 & 2 & 27 & 72.03 & -0.32 & $\star \star \star \star ~$ & $\star \star \star \star ~$ & 191.50 & 4.30 & 0.051293 \\
\hline 1996 & 3 & 13 & 66.65 & 2.09 & *** & 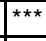 & 391.40 & 10.00 & 0.165325 \\
\hline 1996 & 4 & 15 & 56.22 & 8.60 & *** & 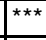 & 646.20 & 21.20 & 0.447504 \\
\hline 1996 & 5 & 60 & 66.13 & 10.81 & *** & *** & 439.00 & 17.90 & 0.419979 \\
\hline 1996 & 6 & 44 & 63.12 & 14.96 & 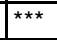 & 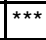 & 611.00 & 24.90 & 0.632064 \\
\hline 1996 & 7 & 88 & 72.81 & 15.60 & *** & 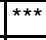 & 601.50 & 24.90 & 0.620012 \\
\hline 1996 & 8 & 157 & 76.93 & 16.14 & *** & 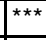 & 565.90 & 22.00 & 0.519116 \\
\hline 1996 & 9 & 48 & 82.14 & 10.80 & *** & *** & 453.60 & 15.30 & 0.322140 \\
\hline 1996 & 10 & 113 & 84.76 & 9.08 & *** & 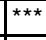 & 339.90 & 9.00 & 0.146559 \\
\hline 1996 & 11 & 66 & 86.56 & 4.38 & *** & 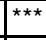 & 104.90 & 2.00 & 0.027233 \\
\hline 1996 & 12 & 36 & 86.00 & -1.84 & *** & 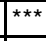 & 123.10 & 1.60 & 0.018472 \\
\hline 1996 & $Y E$ & 677 & 884.29 & 89.75 & $\star \star \star *$ & *** & 4634.30 & 155.90 & 3.399265 \\
\hline
\end{tabular}

\begin{tabular}{|c|c|c|c|c|c|c|c|c|c|}
\hline 1997 & 1 & 3 & 85.38 & -2.46 & 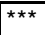 & 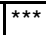 & 143.60 & 2.70 & 0.026970 \\
\hline 1997 & 2 & 72 & 76.52 & 5.22 & *** & 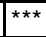 & 173.80 & 4.50 & 0.051707 \\
\hline 1997 & 3 & 36 & 79.75 & 6.66 & $* * *$ & $* * *$ & 331.80 & 9.60 & 0.161447 \\
\hline 1997 & 4 & 65 & 70.01 & 6.07 & *** & *** & 471.80 & 15.40 & 0.317163 \\
\hline 1997 & 5 & 112 & 71.81 & 12.06 & *** & *** & 502.30 & 19.50 & 0.454565 \\
\hline 1997 & 6 & 207 & 69.72 & 15.26 & *** & 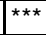 & 418.20 & 16.80 & 0.405228 \\
\hline 1997 & 7 & 127 & 76.32 & 16.55 & $* * *$ & $\star \star * *$ & 456.00 & 17.90 & 0.438991 \\
\hline 1997 & 8 & 47 & 74.61 & 18.94 & *** & *** & 570.80 & 20.50 & 0.496477 \\
\hline 1997 & 9 & 26 & 77.15 & 12.63 & *** & *** & 501.60 & 15.30 & 0.330488 \\
\hline 1997 & 10 & 74 & 80.51 & 7.71 & *** & *** & 336.60 & 8.00 & 0.127777 \\
\hline 1997 & 11 & 25 & 83.99 & 4.50 & $* \star *$ & 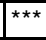 & 158.10 & 3.10 & 0.036509 \\
\hline 1997 & 12 & 69 & 79.58 & 3.35 & $\star \star *$ & *** & 28.60 & 1.90 & 0.018590 \\
\hline 1997 & $Y E$ & 862 & 925.34 & 106.49 & 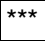 & 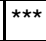 & 4093.20 & 135.20 & 2.865914 \\
\hline
\end{tabular}

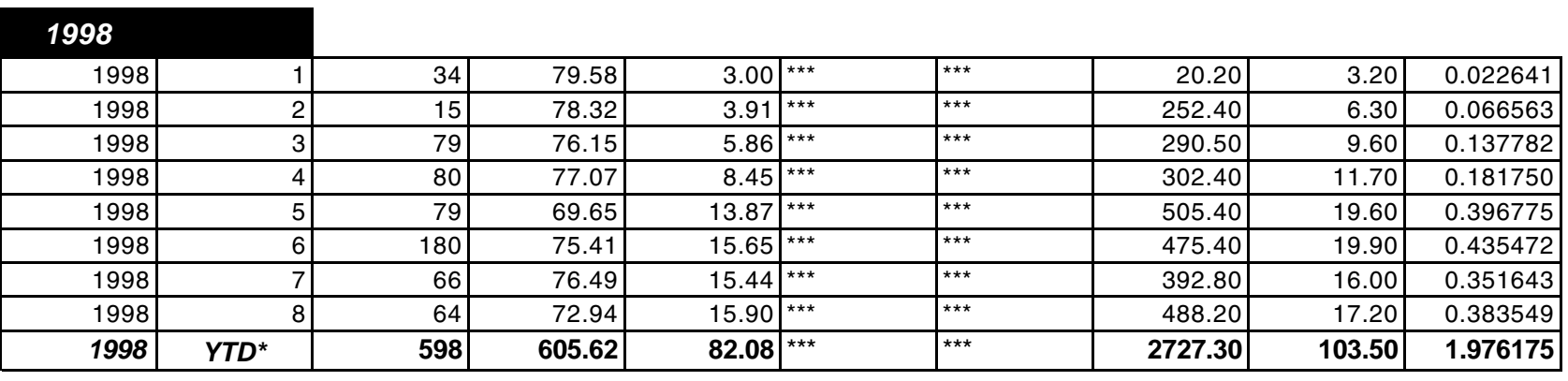

* Figures reflect sums and averages for only the months shown, not yearly predictions or extrapolations.

*** Unavailable due to incomplete data set. 
Table 11. OET Experiments Exposure Time

\begin{tabular}{|c|c|c|c|c|c|c|c|c|c|c|c|c|}
\hline & \begin{tabular}{|l|} 
APS \\
Out \\
\end{tabular} & In & \begin{tabular}{|l|} 
Time \\
(Months) \\
\end{tabular} & $\begin{array}{l}\text { BAR } \\
\text { Out } \\
\end{array}$ & In & \begin{tabular}{|l}
$\begin{array}{l}\text { Time } \\
\text { (Months) }\end{array}$ \\
\end{tabular} & \begin{tabular}{|l} 
FLA \\
Out \\
\end{tabular} & In & \begin{tabular}{|l|} 
Time \\
(Months)
\end{tabular} & \begin{tabular}{|l} 
GER \\
Out \\
\end{tabular} & In & \begin{tabular}{|l|} 
Time \\
(Months) \\
\end{tabular} \\
\hline \multirow[t]{8}{*}{ OET\#1 } & $\begin{array}{l}1 / 29 / 9312: 00 \\
5 / 13 / 9312: 00\end{array}$ & \begin{tabular}{|r|}
$4 / 29 / 93 ~ 12: 14$ \\
$11 / 29 / 9312: 37$
\end{tabular} & $\begin{array}{l}3.0 \\
9.7\end{array}$ & $\begin{array}{r}11 / 8 / 948: 45 \\
1 / 15 / 9612: 00\end{array}$ & $\begin{array}{l}1 / 15 / 9612: 00 \\
3 / 25 / 96\end{array}$ & \begin{tabular}{|l|l|}
0 & 14.4 \\
\end{tabular} & $\begin{array}{l}\text { 4/27/95 8:00 } \\
1 / 16 / 968: 00\end{array}$ & $\begin{array}{r}11 / 30 / 958: 00 \\
7 / 3 / 9613: 00\end{array}$ & \begin{tabular}{|r|}
7.2 \\
129 \\
\end{tabular} & 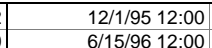 & $\begin{array}{l}5 / 29 / 9612: 00 \\
12 / 12 / 960: 00\end{array}$ & \begin{tabular}{|r|r|}
6.0 \\
\end{tabular} \\
\hline & $1 / 5 / 948: 15$ & $3 / 31 / 949: 45$ & 12.5 & 5/23/96 15:00 & 4/10/97 14:30 & 25.2 & 9/6/96 8:00 & 8/4/97 13:20 & 24.0 & 1/18/97 12:00 & 1/18/98 12:00 & 24.2 \\
\hline & 4/11/94 7:22 & 10/14/94 9:30 & 18.7 & 6/27/97 9:30 & Set\#1 7/9/98 14:15 & 37.8 & 9/9/97 8:00 & 9/9/98 8:00 & 36.1 & & & \\
\hline & $11 / 3 / 947: 20$ & $8 / 12 / 956: 10$ & 28.1 & & Set\#2 11/12/1998 16:00 & 42.0 & 2/9/99 8:00 & 10/4/99 8:00 & & & & \\
\hline & $9 / 21 / 956: 12$ & 4/15/96 10:00 & 35.0 & 2/16/99 11:00 & Archived 11/11/99 & & & & & & & \\
\hline & $5 / 30 / 968: 32$ & 6/30/97 9:30 & 48.1 & & & & & & & & & \\
\hline & 7/31/97 8:00 & 8/18/98 9:00 & 61.5 & & & & & & & & & \\
\hline & 10/18/98 16:00 & 8/18/99 8:00 & & & & & & & & & & \\
\hline & & & & & & & & & & & & \\
\hline \multirow[t]{9}{*}{ OET\#2 } & 8/2/936:10 & 11/29/93 12:37 & 4.0 & $11 / 8 / 948: 45$ & 1/15/96 12:00 & 14.4 & 4/27/95 8:00 & $11 / 30 / 958: 00$ & 7.2 & $12 / 1 / 9512: 00$ & 5/29/96 12:00 & 6.0 \\
\hline & $1 / 5 / 948: 15$ & $3 / 31 / 949: 45$ & 6.1 & 1/15/96 12:00 & $3 / 25 / 96$ & & 1/16/968:00 & 7/3/96 13:00 & 12.9 & 6/15/96 12:00 & 12/12/96 0:00 & 12.0 \\
\hline & 4/11/94 7:22 & 10/14/94 9:30 & 13.2 & $5 / 23 / 9615: 00$ & 4/10/97 14:30 & 25.2 & 9/6/96 8:00 & 8/4/97 13:20 & 24.0 & 1/18/97 12:00 & 1/18/98 12:00 & 24.2 \\
\hline & $11 / 3 / 947: 20$ & $8 / 12 / 956: 10$ & 22.6 & 6/27/97 9:30 & $7 / 9 / 9814: 15$ & 37.8 & 9/9/97 8:00 & 9/9/98 8:00 & 36.1 & & & \\
\hline & 9/21/95 6:12 & 4/15/96 10:00 & 29.5 & 2/16/99 11:00 & Archived 11/11/99 & & 2/9/99:8:00 & $10 / 4 / 998: 00$ & & & & \\
\hline & $5 / 30 / 968: 32$ & 6/30/979:30 & 42.7 & & & & & & & & & \\
\hline & $7 / 31 / 978: 00$ & 8/18/98 9:00 & 55.5 & & & & & & & & & \\
\hline & 10/18/98 16:00 & 8/18/99 8:00 & & & & & & & & & & \\
\hline & & & & & & & & & & & & \\
\hline & & & & & & & & & & & & \\
\hline \multirow[t]{10}{*}{ OET\#3 } & 3/15/93 9:35 & 11/29/93 12:37 & 8.6 & NO SAMPLES & & & NO SAMPLES & & & NO SAMPLES & & \\
\hline & 1/5/94 8:15 & $3 / 31 / 949: 45$ & 12.6 & & & & & & & & & \\
\hline & 4/11/94 7:22 & 10/14/94 9:30 & 20.3 & & & & & & & & & \\
\hline & $11 / 3 / 947: 20$ & 8/12/95 6:10 & 27.1 & & & & & & & & & \\
\hline & 9/21/95 6:12 & 4/15/96 10:00 & 34.0 & & & & & & & & & \\
\hline & $5 / 30 / 968: 32$ & $6 / 30 / 979: 30$ & 47.3 & & & & & & & & & \\
\hline & 7/31/97 8:00 & Set\#1 7/7/1998 9:00:0 & 58.6 & & & & & & & & & \\
\hline & & Set\#2 8/18/1998 9:00: & 60.0 & & & & & & & & & \\
\hline & 10/18/98 16:00 & $8 / 18 / 998: 00$ & & & & & & & & & & \\
\hline & & & & & & & & & & & & \\
\hline \multirow{9}{*}{ OET\#4 } & 9/20/93 6:25 & $3 / 31 / 949.45$ & 64 & NO SAMPLES & & & NO SAMPLES & & & NO SAMPLES & & \\
\hline & 4/11/94 7:25 & $\begin{array}{r}3 / 31 / 949: 45 \\
10 / 14 / 949: 30\end{array}$ & $\begin{array}{r}6.4 \\
12.6\end{array}$ & & & & & & & & & \\
\hline & $11 / 3 / 947: 20$ & 8/12/95 6:10 & 22.0 & & & & & & & & & \\
\hline & 9/21/95 6:12 & 4/15/96 10:00 & 28.9 & & & & & & & & & \\
\hline & 5/30/96 8:32 & 6/30/97 9:30 & 42.1 & & & & & & & & & \\
\hline & 7/31/97 8:00 & Set\#1 7/7/1998 9:00:00 & 53.5 & & & & & & & & & \\
\hline & & Set \#2 8/18/1998 9:00: & 54.9 & & & & & & & & & \\
\hline & 10/18/98 16:00 & $10 / 18 / 998: 00$ & & & & & & & & & & \\
\hline & & & & & & & & & & & & \\
\hline & & & & & & & & & & & & \\
\hline \multirow[t]{9}{*}{ OET\#5 } & 9/20/93 6:25 & $3 / 31 / 949: 45$ & 6.4 & $11 / 8 / 948: 45$ & 1/15/96 12:00 & 14.4 & 4/27/95 8:00 & $11 / 30 / 958: 00$ & 7.2 & 12/1/95 12:00 & $5 / 29 / 96$ 12:00 & 6.0 \\
\hline & 4/11/94 7:22 & 10/14/94 9:30 & 12.6 & 1/15/96 12:00 & $3 / 25 / 96$ & & 1/16/96 8:00 & 7/3/96 13:00 & 12.9 & 6/15/96 12:00 & $12 / 12 / 960: 00$ & 12.0 \\
\hline & $11 / 3 / 947: 20$ & $8 / 12 / 956: 10$ & 22.0 & 5/23/96 15:00 & 4/10/97 14:30 & 25.2 & 9/6/96 8:00 & 8/4/97 13:20 & 24.0 & 1/18/97 12:00 & 1/18/98 12:00 & 24.2 \\
\hline & 9/21/95 6:12 & 4/15/96 10:00 & 28.9 & 6/27/97 9:30 & $11 / 12 / 98 \quad 16: 00$ & 42.0 & 9///97 8:00 & 9/9/98 8:00 & 36.1 & & & \\
\hline & 5/30/96 8:32 & 6/30/97 9:30 & 42.1 & 2/16/99 11:00 & Archived 11/11/99 & & & ARCHIVED 12/21/98 & & & & \\
\hline & 7/31/97 8:00 & 8/18/98 9:00 & 54.9 & & & & & & & & & \\
\hline & 10/18/98 16:00 & 8/18/99 8:00 & & & & & & & & & & \\
\hline & & & & & & & & & & & & \\
\hline & & & & & & & & & & & & \\
\hline \multirow{10}{*}{ OET\#6 } & & & & & & & & & & & & \\
\hline & 9/20/93 6:25 & 3/31/94 9:45 & 6.4 & $11 / 8 / 948: 45$ & 1/15/96 12:00 & 14.4 & 4/27/95 8:00 & 11/30/95 8:00 & 7.2 & 12/1/95 12:00 & 5/29/96 12:00 & 6.0 \\
\hline & 4/11/94 7:22 & 10/14/94 9:30 & 12.6 & 1/15/96 12:00 & $\begin{array}{r}3 / 25 / 96 \\
\end{array}$ & & 1/16/96 8:00 & 7/3/96 13:00 & 12.9 & 6/15/96 12:00 & 12/12/96 0:00 & 12.0 \\
\hline & 11/3/94 7:20 & 8/12/95 6:10 & 22.0 & 5/23/96 15:00 & 4/10/97 14:30 & 25.2 & 9/6/96 8:00 & 8/4/97 13:20 & 24.0 & 1/18/97 12:00 & 1/18/98 12:00 & 24.2 \\
\hline & 9/21/95 6:12 & 4/15/96 10:00 & 28.9 & 6/27/979:30 & 11/12/98 16:00 & 42.0 & 9/9/97 8:00 & 0 9/9/98 8:00 & 36.1 & & & \\
\hline & 5/30/96 8:32 & 6/30/97 9:30 & 42.1 & 2/16/99 11:00 & Archived 11/11/99 & & & ARCHIVED 12/21/98 & & & & \\
\hline & $7 / 31 / 978: 00$ & 8/18/98 9:00 & 54.9 & & & & & & & & & \\
\hline & 10/18/98 16:00 & 8/18/99 8:00 & & & & & & & & & & \\
\hline & & & & & & & & & & & & \\
\hline & & & & & & & & & & & & \\
\hline
\end{tabular}


Table 11. OET Experiments Exposure Time

\begin{tabular}{|c|c|c|c|c|c|c|c|c|c|c|c|}
\hline & \begin{tabular}{|l|} 
NREL \\
Out
\end{tabular} & In & \begin{tabular}{|l|} 
Time \\
(Months)
\end{tabular} & \begin{tabular}{|l|} 
SMUDD \\
Out
\end{tabular} & In & $\begin{array}{l}\text { SPA } \\
\text { Out }\end{array}$ & \begin{tabular}{|l|l} 
Time \\
(Months)
\end{tabular} & \begin{tabular}{|l|} 
Time \\
(Months)
\end{tabular} & \begin{tabular}{|l|} 
TX \\
Out
\end{tabular} & $\ln$ & $\begin{array}{l}\text { Time } \\
\text { (Months) }\end{array}$ \\
\hline \multirow[t]{10}{*}{ OET\#1 } & 2/23/93 12:00 & 5/25/93 8:00 & 3.0 & 3/1/93 12:00 & 6/1/93 12:00 & Feb-98 & & 3.1 & 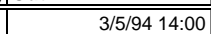 & $\mid$ & 6.4 \\
\hline & $5 / 26 / 938: 00$ & 9/29/93 10:00 & 7.0 & $6 / 30 / 934: 30$ & 11/16/93 12:00 & & & $\begin{array}{l}.1 .7 \\
\end{array}$ & 10/24/94 14:00 & 4/24/95 10:00 & 12.5 \\
\hline & 9/29/93 10:00 & $1 / 21 / 948: 00$ & & 11/29/93 8:30 & $4 / 19 / 948: 30$ & & & 12.4 & $5 / 24 / 9515: 45$ & $12 / 21 / 9511: 50$ & \\
\hline & $1 / 24 / 9413: 00$ & 6/26/94 8:30 & 12.0 & $5 / 18 / 94 \quad 10: 00$ & $11 / 2 / 948: 00$ & & & 18.0 & 3/14/96 15:00 & $8 / 19 / 96$ & 248 \\
\hline & 6/27/94 17:00 & $12 / 16 / 948: 00$ & 17.6 & $12 / 5 / 949: 30$ & $10 / 6 / 95 \quad 10: 45$ & & & 28.2 & 2/25/97 9:30 & 1/6/98 13:00 & 35.3 \\
\hline & $1 / 3 / 95 \quad 14: 00$ & 7/10/95 8:00 & 24.0 & $10 / 6 / 9510: 45$ & 4/11/96 14:30 & & & & 2/6/98 12:00 & 6/29/99 8:30 & 52.2 \\
\hline & 7/20/95 9:30 & 7/25/96 11:15 & 36.4 & 4/11/96 14:30 & 12/11/96 12:00 & & & 36.8 & 8/17/99 8:48 & $8 / 18 / 0012: 00$ & \\
\hline & 8/20/96 14:30 & 9/8/97 10:00 & 49.1 & $3 / 3 / 979: 00$ & 4/7/98 8:45 & & & 49.7 & & & \\
\hline & 9/15/97 14:15 & 12/16/98 11:00 & 64.4 & 6/12/98 12:00 & 9/29/99 13:30 & & & & & & \\
\hline & $1 / 8 / 9915: 00$ & 2/8/00 8:00 & & 12/16/99 15:00 & $12 / 17 / 0012: 00$ & & & & & & \\
\hline \multirow[t]{10}{*}{ OET\#2 } & & & 2.3 & $7 / 26 / 93$ 13:30 & 11/16/93 12:00 & Feb-98 & & 38 & & & 6.4 \\
\hline & $9 / 29 / 9310: 00$ & 1/21/94 8:00 & 2.3 & $11 / 29 / 938: 30$ & 2/19/93 13:00 & Fep-98 & & $\begin{array}{l}3.8 \\
6.2 \\
\end{array}$ & $\begin{array}{r}3 / 5 / 941400 \\
10 / 24 / 9414: 00\end{array}$ & | & $\begin{array}{r}6.4 \\
12.5\end{array}$ \\
\hline & 1/24/94 13:00 & 5/15/94 7:00 & 6.0 & 2/23/94 7:45 & 8/23/94 13:30 & & & $\begin{array}{l}0.4 \\
12.2 \\
\end{array}$ & 5/24/95 15:45 & 12/21/95 11:50 & \\
\hline & 5/18/94 11:00 & 12/12/94 8:00 & 13.1 & 9/19/94 13:00 & 3/30/95 7:35 & & & 18.6 & 3/14/96 15:00 & $8 / 19 / 96$ & 24.8 \\
\hline & $1 / 3 / 95 \quad 14: 00$ & 7/10/95 8:00 & 19.4 & 4/26/95 0:00 & 10/6/95 10:45 & & & 24.0 & 2/25/97 9:30 & 1/6/98 13:00 & 35.3 \\
\hline & 7/20/95 9:30 & 4/13/96 7:30 & 28.3 & $10 / 6 / 9510: 45$ & 4/11/96 14:30 & & & & 2/6/98 12:00 & 6/29/99 8:30 & 52.2 \\
\hline & 5/7/96 12:00 & 1/7/9711:00 & 36.4 & 4/11/96 14:30 & $12 / 11 / 9612: 00$ & & & 32.2 & 8/17/99 8:48 & 8/18/00 12:00 & \\
\hline & $3 / 3 / 978: 00$ & $3 / 3 / 98 \quad 10: 00$ & $\begin{array}{r}0.4 \\
48.6\end{array}$ & $3 / 3 / 979: 00$ & $4 / 7 / 988: 45$ & & & 45.6 & & & \\
\hline & $3 / 5 / 9814: 00$ & 12/16/98 11:00 & $\begin{array}{l}40.0 \\
58.1\end{array}$ & 6/12/98 12:00 & $\begin{array}{r}4 / 29 / 990.43: 30 \\
9 / 30\end{array}$ & & & & & & \\
\hline & 1/8/99 15:00 & 2/8/00 8:00 & 30.1 & 12/16/99 15:00 & 12/17/00 12:00 & & & & & & \\
\hline \multirow{10}{*}{ OET\#3 } & & & 67 & $3 / 15 / 937.52$ & $11 / 24 / 9312 \cdot 00$ & 0 NO SAMPLES & & 80 & & & \\
\hline & $\begin{array}{l}\text { 3/111193 12:00 } \\
\text { 9/29/93 10:00 }\end{array}$ & $\begin{array}{r}9 / 2 / 2 / 9310: 00 \\
1 / 21 / 948: 00\end{array}$ & 6.7 & $\begin{array}{l}3 / 1 / 15 / 937752 \\
12 / 6 / 93830\end{array}$ & $\begin{array}{r}11 / 24 / 9312: 00 \\
4 / 19 / 948: 30\end{array}$ & $\begin{array}{l}0 \text { NO SAMPLES } \\
0\end{array}$ & & $\begin{array}{r}8.0 \\
12.5\end{array}$ & & & \\
\hline & 1/24/94 13:00 & $7 / 8 / 9414: 30$ & 12.2 & $5 / 18 / 94 \quad 10: 00$ & $11 / 1 / 948: 00$ & & & $\begin{array}{l}12.0 \\
18.0 \\
\end{array}$ & & & \\
\hline & 7/18/94 11:30 & 1/18/95 8:00 & 18.3 & $12 / 5 / 949: 30$ & 10/6/95 10:45 & & & 28.0 & & & \\
\hline & 1/30/95 12:30 & 7/30/95 7:00 & 24.3 & 10/6/95 10:45 & 4/11/96 14:30 & & & & & & \\
\hline & 8/8/95 14:30 & 8/8/96 11:45 & 36.6 & 4/11/96 14:30 & 12/11/96 12:00 & & & 36.8 & & & \\
\hline & $8 / 20 / 9614: 30$ & 9/8/97 10:00 & 49.2 & 3/3/97 9:00 & $4 / 7 / 988: 45$ & & & 50.2 & & & \\
\hline & 9/15/97 14:15 & 12/16/98 11:00 & 64.5 & 6/12/98 12:00 & 9/29/99 13:30 & & & & & & \\
\hline & 1/8/99 15:00 & 2/8/00 8:00 & & 12/16/99 15:00 & $12 / 17 / 0012: 00$ & & & & & & \\
\hline & & & & & & & & & & & \\
\hline & & & & & & & & & & & \\
\hline \multirow[t]{10}{*}{ OET\#4 } & 9/10/93 8:30 & 9/29/93 10:00 & 0.6 & 9/21/93 12:00 & 4/19/94 8:30 & NO SAMPLES & & 7.0 & & & \\
\hline & 9/29/93 10:00 & $1 / 21 / 948: 00$ & & 5/18/94 10:00 & $11 / 1 / 948: 00$ & & & 12.6 & & & \\
\hline & 1/24/94 13:00 & 6/10/94 9:00 & 5.2 & $12 / 5 / 949: 30$ & $10 / 6 / 9510: 45$ & & & 22.8 & & & \\
\hline & 6/15/94 7:30 & $12 / 16 / 948: 00$ & 11.2 & $10 / 6 / 9510: 45$ & 4/11/96 14:30 & & & & & & \\
\hline & $1 / 3 / 9514: 00$ & $7 / 10 / 958: 00$ & 17.5 & 4/11/96 14:30 & $12 / 11 / 9612: 00$ & & & 30.9 & & & \\
\hline & $7 / 20 / 959: 30$ & 4/13/96 7:30 & 26.4 & $3 / 3 / 979: 00$ & 4/7/98 8:45 & & & 34.2 & & & \\
\hline & $5 / 7 / 9612: 00$ & $3 / 28 / 977: 30$ & $\begin{array}{r}20.4 \\
37.3\end{array}$ & $6 / 12 / 98 \quad 12 \cdot 00$ & 9/29/99 13:30 & & & & & & \\
\hline & $\begin{array}{r}5 / 1 / 19672.00 \\
4 / 11 / 9716.00\end{array}$ & $2 / 24 / 9810.30$ & $\begin{array}{l}3.3 .3 \\
47.9\end{array}$ & $12 / 16 / 9915.00$ & $\begin{array}{r}9 / 29 / 18 / 3.30 \\
\text { Archive } 11 / 189\end{array}$ & & & & & & \\
\hline & 2/27/98 17:00 & 12/16/98 11:00 & $\begin{array}{l}47.9 \\
57.7\end{array}$ & & & & & & & & \\
\hline & 1/8/99 15:00 & $2 / 8 / 008: 00$ & & & & & & & & & \\
\hline \multirow{11}{*}{ OET\#5 } & & & & & & & & & & & \\
\hline & 9/10/93 8:30 & 9/29/93 10:00 & 0.6 & 9/21/93 12:00 & 4/19/94 8:30 & Feb-98 & & 7.0 & $3 / 5 / 9414: 00$ & 10/3/94 14:00 & 6.4 \\
\hline & 9/29/93 10:00 & 1/21/948:00 & & $5 / 18 / 94 \quad 10: 00$ & 11/1/94 8:00 & & & 12.6 & 10/24/94 14:00 & $4 / 24 / 9510: 00$ & 12.5 \\
\hline & $1 / 24 / 9413: 00$ & 6/10/94 9:00 & 5.2 & $12 / 5 / 949: 30$ & $10 / 6 / 95 \quad 10: 45$ & & & 22.8 & $5 / 24 / 9515: 45$ & $12 / 21 / 9511: 50$ & \\
\hline & 6/15/94 7:30 & 12/16/94 8:00 & 11.2 & $10 / 6 / 9510: 45$ & 4/11/96 14:30 & & & & 3/14/96 15:00 & $8 / 19 / 96$ & 24.8 \\
\hline & $1 / 3 / 9514: 00$ & $7 / 10 / 958: 00$ & 17.5 & 4/11/96 14:30 & $12 / 11 / 9612: 00$ & & & 30.9 & $2 / 25 / 979: 30$ & 1/6/98 13:00 & 35.3 \\
\hline & $7120 / 959.30$ & $4 / 13 / 967.30$ & 264 & $3 / 3 / 979.00$ & $4 / 7988.45$ & & & 442 & 2 & $6 / 29 / 998.30$ & 552 \\
\hline & $5 / 7 / 9612: 00$ & $3 / 28 / 977: 30$ & $\begin{array}{l}20.4 \\
37.3 \\
\end{array}$ & $6 / 12 / 9812: 00$ & 9/29/99 13:30 & & & & & Archived & \\
\hline & 4/11/97 16:00 & $2 / 24 / 9810: 30$ & $\begin{array}{r}37.3 \\
47.9\end{array}$ & $12 / 16 / 9915: 00$ & Archived 11/18/99 & & & & & & \\
\hline & 2/27/98 17:00 & 12/16/98 11:00 & 57.7 & & & & & & & & \\
\hline & & ARCHIVED $1 / 8 / 99$ & & & & & & & & & \\
\hline \multirow{10}{*}{ OET\#6 } & $9 / 10 / 938.30$ & $9 / 29 / 9310.00$ & 06 & 9/21/9312.00 & $4 / 19 / 948.30$ & N SAMPIES & & 70 & & $10 / 3 / 9414 \cdot 00$ & 64 \\
\hline & 9/29/93 10:00 & 1/21/94 8:00 & 0.6 & $5 / 18 / 9410: 00$ & 4/1/1948.30 & f O OAVIFLEO & & 12.6 & $\begin{array}{r}3 / 24 / 9414: 00 \\
10 / 249414.00\end{array}$ & $\begin{array}{l}10 / 3 / 94 \quad 1400 \\
4 / 24 / 95 \quad 10.00\end{array}$ & $\begin{array}{r}6.4 \\
12.5 \\
\end{array}$ \\
\hline & 1/24/94 13:00 & 6/10/94 9:00 & 5.2 & 12/5/94 9:30 & $\begin{array}{l}10 / 6 / 9510: 45 \\
\end{array}$ & & & 22.8 & 5/24/95 15:45 & 12/21/95 11:50 & \\
\hline & $6 / 15 / 947: 30$ & 12/16/94 8:00 & 11.2 & $10 / 6 / 9510: 45$ & 4/11/96 14:30 & & & & $3 / 14 / 96$ 15:00 & $8 / 19 / 96$ & 24.8 \\
\hline & $1 / 3 / 9514: 00$ & 7/10/95 8:00 & 17.5 & 4/11/96 14:30 & 12/11/96 12:00 & & & 30.9 & 2/25/97 9:30 & 1/6/98 13:00 & 35.3 \\
\hline & 7/20/95 9:30 & 4/13/96 7:30 & 26.4 & 3/3/97 9:00 & 4/7/98 8:45 & & & 44.2 & $2 / 6 / 98$ 12:00 & 6/29/99 8:30 & 52.2 \\
\hline & 5/7/96 12:00 & $3 / 28 / 977: 30$ & 37.3 & 6/12/98 12:00 & 9/29/99 13:30 & & & & & Archived & \\
\hline & 4/11/97 16:00 & $2 / 24 / 9810: 30$ & 47.9 & $12 / 16 / 99$ 15:00 & Archived 11/18/99 & & & & & & \\
\hline & $2 / 27 / 98 \quad 17: 00$ & 12/16/98 11:00 & 57.7 & & & & & & & & \\
\hline & 1/8/99 15:00 & $2 / 8 / 008: 00$ & & & & & & & & & \\
\hline
\end{tabular}


Table 11. OET Experiments Exposure Time

\begin{tabular}{|c|c|c|c|c|c|c|c|c|c|c|c|c|}
\hline & \begin{tabular}{|l|} 
APS \\
Out
\end{tabular} & In & \begin{tabular}{|l|l} 
Time \\
(Months)
\end{tabular} & \begin{tabular}{|l} 
BAR \\
Out
\end{tabular} & In & \begin{tabular}{|l|} 
Time \\
(Months)
\end{tabular} & \begin{tabular}{|l|} 
FLA \\
Out
\end{tabular} & In & \begin{tabular}{|l|} 
Time \\
(Months)
\end{tabular} & \begin{tabular}{|l} 
GER \\
Out
\end{tabular} & In & $\begin{array}{l}\text { Time } \\
\text { (Months) }\end{array}$ \\
\hline \multirow[t]{8}{*}{ OET\#7 } & 1/19/94 12:42 & $\begin{array}{l}7 / 19 / 947: 40 \\
\end{array}$ & 6.0 & 11/8/94 8:45 & \begin{tabular}{ll|} 
1/15/96 12:00 \\
\end{tabular} & 14.4 & 4/27/95 8:00 & 11/30/95 8:00 & 7.2 & NO SAMPLES & & \\
\hline & $8 / 3 / 946: 20$ & 8/12/95 6:10 & 18.3 & 1/15/96 12:00 & $3 / 25 / 96$ & & $1 / 16 / 968: 00$ & $7 / 3 / 9613: 00$ & 12.9 & & & \\
\hline & 9/21/956-12 & $4 / 15 / 9610.00$ & 251 & $5 / 23 / 9615 \cdot 00$ & $4 / 10 / 9714 \cdot 30$ & 252 & $9 / 6 / 968.00$ & $8 / 4 / 9713 \cdot 20$ & 240 & & & \\
\hline & 5/30/96 8:32 & 6/30/97 9:30 & 38.5 & 6/27/97 9:30 & Set\#1 7/9/98 14:15 & 37.8 & 9///978:00 & 9/9/98 8:00 & 36.1 & & & \\
\hline & 7/31/978:00 & Set\#1 7/7/1998 9:00:00 & 49.8 & & Set\#2 11/12/98 16:00 & 42.0 & 2/9/998:00 & 10/4/99 8:00 & & & & \\
\hline & & Set \#2 8/18/1998 9:00: & 51.2 & 2/16/99 11:00 & Archived 11/11/99 & & & & & & & \\
\hline & 10/18/98 16:00 & $8 / 18 / 998: 00$ & & & & & & & & & & \\
\hline & & & & & & & & & & & & \\
\hline \multirow[t]{7}{*}{ OET\#8 } & 6/20/94 9:16 & 1/3/95 7:50 & 6.6 & $11 / 8 / 948: 45$ & 1/15/96 12:00 & 14.4 & 4/27/958:00 & 11/30/95 8:00 & 7.2 & 12/1/95 12:00 & $5 / 29 / 9612: 00$ & 6.0 \\
\hline & 1/20/95 7:35 & 8/12/95 6:10 & 13.4 & 1/15/96 12:00 & $3 / 25 / 96$ & & 1/16/968:00 & $7 / 3 / 9613: 00$ & 12.9 & 6/15/96 12:00 & $12 / 12 / 960: 00$ & 12.0 \\
\hline & 9/21/95 6:12 & 4/15/96 10:00 & 20.4 & 5/23/96 15:00 & \begin{tabular}{|l|l|} 
& $4 / 10 / 9714: 30$ \\
\end{tabular} & 25.2 & 9/6/96 8:00 & 8/4/97 13:20 & 24.0 & 1/18/97 12:00 & 1/18/98 12:00 & 24.2 \\
\hline & 5/30/96 8:32 & 6/30/97 9:30 & 33.5 & 6/27/97 9:30 & Set\#1 7/9/98 14:15 & 37.8 & 9/9/97 8:00 & 9/9/98 8:00 & 36.1 & & & \\
\hline & $7 / 31 / 978: 00$ & 8/18/98 9:00 & 46.3 & & Set\#2 11/12/98 16:00 & 42.0 & & ARCHIVED 12/21/98 & & & & \\
\hline & 10/18/98 16:00 & 8/18/99 8:00 & & 2/16/9911:00 & Archived 11/11/99 & & & & & & & \\
\hline & & & & & & & & & & & & \\
\hline & & & & & & & & & & & & \\
\hline \multirow[t]{7}{*}{ OET\#9 } & 6/20/94 9:16 & $1 / 3 / 957: 50$ & 6.6 & $11 / 8 / 948: 45$ & 1/15/96 12:00 & 14.4 & 4/27/95 8:00 & 11/30/95 8:00 & 7.2 & 12/1/95 12:00 & $5 / 29 / 9612: 00$ & 6.0 \\
\hline & 1/20/95 7:35 & 8/12/95 6:10 & $\begin{array}{r}0.0 \\
13.4\end{array}$ & 1/15/96 12:00 & $3 / 25 / 96$ & & 1/16/96 8:00 & 7/3/96 13:00 & 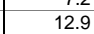 & 6/15/96 12:00 & $12 / 12 / 960: 00$ & $\begin{array}{l}0.0 \\
12.0\end{array}$ \\
\hline & 9/21/95 6:12 & 4/15/96 10:00 & 20.4 & 5/23/96 15:00 & 4/10/97 14:30 & 25.2 & 9/6/96 8:00 & 8/4/97 13:20 & 24.0 & 1/18/97 12:00 & 1/18/98 12:00 & 24.2 \\
\hline & 5/30/96 8:32 & 6/30/97 9:30 & 33.5 & 6/27/97 9:30 & 11/12/98 16:00 & 42.0 & 9/9/97 8:00 & 9/9/98 8:00 & 36.1 & & & \\
\hline & $7 / 31 / 978: 00$ & 8/18/98 9:00 & 46.3 & 2/16/99 11:00 & Archived 11/11/99 & & 2/9/998:00 & 10/4/99 8:00 & & & & \\
\hline & 10/18/98 16:00 & 8/18/99 8:00 & & & & & & & & & & \\
\hline & & & & & & & & & & & & \\
\hline \multirow{6}{*}{ OET\#10 } & $11 / 16 / 948: 00$ & $8 / 12 / 956: 10$ & 9.0 & & $1 / 15 / 9612 \cdot 00$ & 144 & $4 / 27 / 958.00$ & $11 / 30 / 958.00$ & 72 & $12 / 1 / 9512 \cdot 00$ & 5/29/96 12.00 & 600 \\
\hline & 9/21/95 6:12 & 8/15/96 6:10:00 & $\begin{array}{r}9.0 \\
15.9\end{array}$ & $\begin{array}{r}11 / 1 / 94648.45 \\
1 / 2: 00\end{array}$ & | & 14.4 & $\begin{array}{l}4 / 27 / 958: 00 \\
1 / 16 / 968: 00\end{array}$ & $\begin{array}{r}\text { r1/130/955 8:00 } \\
7 / 3 / 9613: 00\end{array}$ & $\begin{array}{r}7.2 \\
12.9\end{array}$ & $\begin{array}{l}\text { 1/2/1995 52:00 } \\
\text { 6/15/96 12:00 }\end{array}$ & $\begin{array}{l}\text { f/2/29/96 } 212: 00 \\
12 / 12 / 96000\end{array}$ & $\begin{array}{r}6.0 \\
12.0\end{array}$ \\
\hline & 5/30/96 8:32 & 6/30/97 9:30 & 29.1 & 5/23/96 15:00 & 4/10/97 14:30 & 25.2 & 9/6/96 8:00 & 8/4/97 13:20 & 24.0 & 1/18/97 12:00 & 1/1/18/98 12:00 & 24.2 \\
\hline & 7/31/97 8:00 & 8/18/98 9:00 & 41.9 & 6/27/97 9:30 & \begin{tabular}{|l|l|} 
& $7 / 9 / 9814: 15$
\end{tabular} & 37.8 & 9/9/97 8:00 & 9/9/98 8:00 & 36.1 & & & \\
\hline & 10/18/98 16:00 & 8/18/99 8:00 & & 2/16/99 11:00 & Archived 11/11/99 & & 2/9/99 8:00 & 10/4/99 8:00 & & & & \\
\hline & & & & & & & & & & & & \\
\hline & & & & & & & & & & & & \\
\hline \multirow[t]{7}{*}{ OET\#11 } & $11 / 1 / 9517: 45$ & $4 / 15 / 9610: 00$ & 5.5 & 12/22/95 13:30 & $1 / 15 / 9612: 00$ & & 11/7/95 9:45 & 7/3/96 13:00 & 8.0 & 12/1/95 12:00 & 5/29/96 12:00 & 6.0 \\
\hline & 5/30/96 8:32 & 6/30/97 9:30 & 18.7 & 5/23/96 15:00 & 4/10/97 14:30 & 15.8 & 9/6/96 8:00 & 8/4/97 13:20 & 19.1 & 6/15/96 12:00 & $12 / 12 / 960: 00$ & $\begin{array}{r}0.0 \\
12.0\end{array}$ \\
\hline & 7/31/97 8:00 & 8/18/98 9:00 & 31.5 & 6/27/97 9:30 & Set\#1 7/9/98 14:15 & 28.4 & 9/9/97 8:00 & 9/9/98 8:00 & 31.2 & 1/18/97 12:00 & 1/18/98 12:00 & 24.2 \\
\hline & 10/18/98 16:00 & 8/18/99 8:00 & & & Set\#2 11/12/98 16:00 & 42.0 & 2/9/99 8:00 & 10/4/99 8:00 & & & & \\
\hline & & & & 2/16/99 11:00 & Archived 11/11/99 & & & & & & & \\
\hline & & & & & & & & & & & & \\
\hline & & & & & & & & & & & & \\
\hline \multirow{5}{*}{ OET\#12 } & & & & $2 / 18 / 9614 \cdot 00$ & & & & & 50 & $12 / 1 / 9512 \cdot 00$ & & \\
\hline & 5/30/96 8:30 & $\begin{array}{r}\text { 4/15/96 60:00 } \\
\text { 6/30/97 9:30 }\end{array}$ & $\frac{2.1}{15.3}$ & $\begin{array}{l}\text { 2/178896 } 4: 2700 \\
6 / 9030\end{array}$ & $\begin{array}{l}\quad 4 / 70 / 9 / 148.30 \\
\end{array}$ & $\begin{array}{l}13.9 \\
26.5\end{array}$ & $\begin{array}{l}2 / 5 / 969: 00 \\
9 / 6 / 968: 00\end{array}$ & $\begin{array}{l}7 / 3 / 9613: 00 \\
8 / 4 / 9713: 20\end{array}$ & $\begin{array}{r}5.0 \\
15.1\end{array}$ & $\begin{array}{l}\text { 1/2/1995 52:2:00 } \\
\text { 6/15/96 12:00 }\end{array}$ & $\begin{array}{l}\text { 5/29/96 } 12: 00 \\
\text { 12/12/96 0:00 }\end{array}$ & $\begin{array}{r}6.0 \\
12.0\end{array}$ \\
\hline & 7/31/97 8:00 & 8/18/98 9:00 & 28.1 & $2 / 16 / 9911: 00$ & Archived 11/11/99 & & 9/9/97 8:00 & 9/9/98 8:00 & 28.2 & $1 / 18 / 9712: 00$ & 1/18/98 12:00 & 24.2 \\
\hline & 10/18/98 16:00 & 8/18/99 8:00 & & & & & 2/9/99 8:00 & 10/4/99 8:00 & & & & \\
\hline & & & & & & & & & & & & \\
\hline \multirow{4}{*}{ OET\#13 } & $2 / 25 / 978: 00$ & 8/18/98 9:00 & 18.0 & 4/11/97 8:30 & 11/12/98 16:00 & 19.3 & $4 / 1 / 978.00$ & $8 / 4 / 9713 \cdot 20$ & $42,2>3$ & $12 / 1 / 9512 \cdot 00$ & $5 / 29 / 9612.00$ & 60 \\
\hline & $\begin{array}{r}2 / 28 / 97800 \\
10 / 18 / 9816: 00\end{array}$ & 8/18/99 8:00 & 18.0 & 2/16/9911:00 & Archived 11/11/98 & 19.3 & 9//9/978:00 & 9/4/98 8:00 & $\begin{array}{r}4.2 \\
16.4\end{array}$ & $6 / 15 / 9612: 00$ & 5/2/1960 $2: 000$ & $\begin{array}{r}6.0 \\
12.0\end{array}$ \\
\hline & & & & & & & 2/9/998:00 & 10/4/99 8:00 & & 1/18/97 12:00 & 1/18/98 12:00 & 24.2 \\
\hline & & & & & & & & & & & & \\
\hline \multirow{10}{*}{ OET\#14 } & & & 8.1 & 12/27/97 12:00 & 11/12/98 16:00 & 10.7 & $12 / 18 / 978: 00$ & 9/9/98 8:00 & 8.8 & 3 NO SAMPLES & & \\
\hline & 10/18/98 16:00 & 10/18/99 8:00 & & 2/16/99 11:00 & 12/6/99 8:00 & & 2/9/99 8:00 & 10/4/99 8:00 & & & & \\
\hline & & & & $1 / 15 / 9612 \cdot 00$ & $3 / 25 / 96$ & & & & & & & \\
\hline & & & & Waited from $3 / 25 / 96$ tc & to $5 / 23 / 96$ & & Site Down & & & & & \\
\hline & & & & for samples to be plac & ced in rack & & $\sim 1$ week in ?97 & & & & & \\
\hline & & & & All experiments meas & sured except for & & Site moved to another & r location within & & & & \\
\hline & & & & OET-11 while site was & s down. & & South Florida Test Se & evice complex & & & & \\
\hline & & & & OET-11 not measured & & & No experiments meas & & & & & \\
\hline & & & & & & & while site was down. & & & & & \\
\hline & & & & Site decommisioned & $11 / 11 / 99 \&$ & & & & & & & \\
\hline
\end{tabular}


Table 11. OET Experiments Exposure Time

\begin{tabular}{|c|c|c|c|c|c|c|c|c|c|c|c|}
\hline & \begin{tabular}{|l|} 
NREL \\
Out
\end{tabular} & In & \begin{tabular}{|l|} 
Time \\
(Months)
\end{tabular} & \begin{tabular}{|l|} 
SMUD \\
Out
\end{tabular} & In & $\begin{array}{l}\text { SPA } \\
\text { Out } \\
\end{array}$ & \begin{tabular}{|l|}
$\begin{array}{l}\text { Time } \\
\text { (Months) }\end{array}$ \\
\end{tabular} & \begin{tabular}{|l|l|} 
Time \\
(Months) \\
\end{tabular} & \begin{tabular}{|l|} 
TX \\
Out \\
\end{tabular} & In & \begin{tabular}{|l|} 
Time \\
(Months) \\
\end{tabular} \\
\hline \multirow[t]{9}{*}{$\overline{\text { OETH7 }}$} & \begin{tabular}{ll|} 
1/24/94 13:00 \\
\end{tabular} & 7/25/94 8:00 & 6.1 & 1/20/94 9:30 & |8/23/94 13:30 & NO SAMPLES & & 7.2 & |3/5/94 14:00 & |10/3/94 14:00 & $\begin{array}{ll}6.4 \\
\end{array}$ \\
\hline & 8/1/94 8:20 & $2 / 1 / 957: 30$ & 12.2 & 9/19/94 13:00 & $3 / 30 / 957: 35$ & & & 13.6 & 10/24/94 14:00 & $4 / 24 / 95 \quad 10: 00$ & 12.5 \\
\hline & 2/15/95 15:00 & 7/30/95 7:00 & 17.7 & 4/26/95 15:45 & $10 / 6 / 95 \quad 10: 45$ & & & 19.0 & $5 / 24 / 9515: 45$ & $12 / 21 / 9511: 50$ & \\
\hline & 8/8/95 14:30 & 4/22/96 10:30 & 26.3 & $10 / 6 / 9510: 45$ & 4/11/96 14:30 & & & & $3 / 14 / 96$ 15:00 & $8 / 19 / 96$ & 24.8 \\
\hline & $5 / 23 / 967: 30$ & $3 / 28 / 977: 30$ & 36.6 & 4/11/96 14:30 & $12 / 11 / 9612: 00$ & & & 27.2 & $2 / 25 / 979: 30$ & 1/6/98 13:00 & $\begin{array}{c}24.0 \\
35.3 \\
\end{array}$ \\
\hline & 4/11/97 16:00 & 6/9/98 15:00 & $\begin{array}{l}30.0 \\
50.7\end{array}$ & 3/3/97 9:00 & 4/7/98 8:45 & & & 40.5 & $2 / 6 / 9812: 00$ & 6/29/99 8:30 & $\begin{array}{l}30.0 \\
52.2\end{array}$ \\
\hline & 6/15/98 8:30 & 12/16/98 11:00 & 56.9 & 6/12/98 12:00 & $\begin{array}{r}4 / 7 / 50 \\
9 / 29 / 99 \\
13: 30\end{array}$ & & & & $8 / 17 / 998: 48$ & $8 / 18 / 0012: 00$ & \\
\hline & 1/8/99 15:00 & 2/8/00 8:00 & & $12 / 16 / 9915: 00$ & $12 / 17 / 0012: 00$ & & & & & & \\
\hline & & & & & & & & & & & \\
\hline \multirow[t]{8}{*}{ OET\#8 } & 6/10/94 9:00 & 12/16/94 8:00 & 6.2 & 6/13/94 16:00 & $3 / 30 / 957: 35$ & Feb-98 & & 9.7 & 6/24/94 14:00 & 1/20/95 14:00 & 7.1 \\
\hline & 1/3/95 14:00 & 7/10/95 8:00 & 12.5 & 4/26/95 15:45 & 10/6/95 10:45 & & & 15.1 & 2/3/95 14:45 & 4/24/95 10:00 & 9.8 \\
\hline & 7/20/95 9:30 & 7/13/96 11:15 & 24.5 & 10/6/95 10:45 & 4/11/96 14:30 & & & & 5/24/95 15:45 & 12/21/95 11:50 & \\
\hline & $8 / 20 / 9614: 30$ & 9/8/97 10:00 & 37.2 & 4/11/96 14:30 & 12/11/96 12:00 & & & 23.2 & $3 / 14 / 96$ 15:00 & $8 / 19 / 96$ & 22.1 \\
\hline & 9/15/97 14:15 & $12 / 16 / 98$ 11:00 & 52.4 & $3 / 3 / 979: 00$ & $4 / 7 / 988: 45$ & & & 36.6 & $2 / 25 / 979: 30$ & 1/6/98 13:00 & 32.6 \\
\hline & & ARCHIVED 1/8/99 & & 6/12/98 12:00 & 9/29/99 13:30 & & & & $2 / 6 / 9812: 00$ & 6/29/99 8:30 & 49.5 \\
\hline & & & & 12/16/99 15:00 & Archived 11/18/99 & & & & & Archived & \\
\hline & & & & & & & & & & & \\
\hline & & & & & & & & & & & \\
\hline \multirow[t]{7}{*}{ OET\#9 } & 6/10/94 9:00 & 12/16/94 8:00 & 6.2 & 6/13/94 16:00 & $3 / 30 / 957: 35$ & Feb-98 & & 9.7 & 6/24/94 14:00 & 1/20/95 14:00 & 7.1 \\
\hline & 1/3/95 14:00 & 7/10/95 8:00 & 12.5 & 4/26/95 15:45 & $10 / 6 / 9510: 45$ & & & 15.1 & $2 / 3 / 95$ 14:45 & 4/24/95 10:00 & 9.8 \\
\hline & 7/20/95 9:30 & $7 / 13 / 9611: 15$ & 24.5 & $10 / 6 / 9510: 45$ & 4/11/96 14:30 & & & & 5/24/95 15:45 & $12 / 21 / 9511: 50$ & \\
\hline & 8/20/96 14:30 & 9/8/97 10:00 & 37.2 & 4/11/96 14:30 & 12/11/96 12:00 & & & 23.2 & 3/14/96 15:00 & $8 / 19 / 96$ & 221 \\
\hline & $9 / 15 / 9714: 15$ & 12/16/98 11:00 & 52.4 & 3/3/97 9:00 & $4 / 7 / 988: 45$ & & & 36.6 & $2 / 25 / 979 \cdot 30$ & $1 / 6 / 9813.00$ & 32.1 \\
\hline & 1/8/99 15:00 & $2 / 8 / 008: 00$ & & 6/12/98 12:00 & 9/29/99 13:40 & & & & $2 / 6 / 9812: 00$ & 6/29/99 8:30 & $\begin{array}{l}32.6 \\
49.5\end{array}$ \\
\hline & & & & 12/16/99 15:00 & $12 / 17 / 0012: 00$ & & & & 8/17/99 8:48 & $8 / 18 / 00 \quad 12: 00$ & 49.5 \\
\hline \multirow{8}{*}{ OET\#10 } & & & & & & & & & & & \\
\hline & 11/2/94 8:50 & $5 / 2 / 957: 30$ & 6.0 & 12/5/94 9:30 & $10 / 6 / 9510: 45$ & Feb-98 & & 10.2 & 11/18/94 9:00 & $4 / 24 / 9510: 00$ & 5.2 \\
\hline & 5/11/95 7:30 & 2/11/96 12:30 & 15.1 & $10 / 6 / 9510: 45$ & 4/11/96 14:30 & & & & 5/24/95 15:45 & 12/21/95 11:50 & \\
\hline & $4 / 1 / 967: 45$ & $7 / 1 / 968: 15$ & 18.1 & 4/11/96 14:30 & 12/11/96 12:00 & & & 18.3 & 3/14/96 15:00 & $8 / 19 / 96$ & 17.5 \\
\hline & $7 / 8 / 9610: 15$ & 1/8/97 11:00 & 21.2 & 3/3/97 9:00 & $4 / 7 / 988: 45$ & & & 31.7 & 2/25/97 9:30 & 1/6/98 13:00 & 28 \\
\hline & $3 / 3 / 978: 00$ & $3 / 3 / 98$ 10:00 & 36.4 & 6/12/98 12:00 & $12 / 17 / 0012: 00$ & & & & 2/6/98 12:00 & 6/29/99 8:30 & 45 \\
\hline & 3/5/98 14:00 & 12/16/98 11:00 & 46.0 & & & & & & $8 / 17 / 998: 48$ & 8/18/00 12:00 & \\
\hline & 1/8/99 15:00 & 2/8/00 8:00 & & & & & & & & & \\
\hline \multirow{7}{*}{ OET\#11 } & & & & & & & & & & & \\
\hline & $\begin{array}{r}10 / 26 / 959: 30 \\
5 / 20 / 6767: 30\end{array}$ & $\begin{array}{r}4 / 26 / 967: 45 \\
11 / 2019611.15\end{array}$ & \begin{tabular}{r|r}
6.1 \\
12.3
\end{tabular} & $\begin{array}{r}\text { 4/11/96 14:30 } \\
3 / 3 / 979 \cdot 0.0\end{array}$ & $\begin{array}{r}\text { 12/11/96 12:00 } \\
4471988.45\end{array}$ & & & $\begin{array}{r}8.1 \\
215\end{array}$ & $\begin{array}{l}10 / 27 / 9511: 00 \\
31 / 496 \\
\end{array}$ & $\begin{array}{r}12 / 21 / 9511: 50 \\
8 / 19 / 96\end{array}$ & 71 \\
\hline & $12 / 26 / 9614: 30$ & 3/28/97 7:30 & $\begin{array}{l}12.3 \\
15.3 \\
\end{array}$ & 6/12/98 12:00 & $\begin{array}{r}4 / 7 / 9000.45 \\
9 / 29 / 99130\end{array}$ & & & & $\begin{array}{r}3 / 74 / 9617500 \\
2 / 25 / 979: 30\end{array}$ & $\begin{array}{r}8 / 19996 \\
1 / 6 / 9813.00\end{array}$ & 1.1 \\
\hline & 4/11/97 16:00 & 2/24/98 10:30 & 26.0 & $12 / 16 / 9915: 00$ & 12/17/00 12:00 & & & & 2/6/98 12:00 & 6/29/99 8:30 & 34.5 \\
\hline & 2/27/98 17:00 & 12/16/98 11:00 & 35.7 & & & & & & 8/17/99 8:48 & 8/18/00 12:00 & \\
\hline & 1/8/99 15:00 & $2 / 8 / 008: 00$ & & & & & & & & & \\
\hline & & & & & & & & & & & \\
\hline \multirow{5}{*}{ OET\#12 } & & & & $4 / 11 / 9614: 30$ & $12 / 11 / 9612 \cdot 0$ & NAMPIES & & 81 & $3 / 14 / 9615 \cdot 00$ & $8 / 1906$ & 52 \\
\hline & $\begin{array}{l}\text { 2/2/2/96 14:00 } \\
\text { 8/30/30 }\end{array}$ & $\begin{array}{r}\text { 8/6696/37:30 } \\
3 / 28 / 97730\end{array}$ & $\begin{array}{r}6.1 \\
13.4\end{array}$ & $\begin{array}{r}\text { 4/17/96 14:30 } \\
3 / 3 / 979: 00\end{array}$ & $\begin{array}{r}12 / 71 / 961200 \\
4 / 7 / 988: 45\end{array}$ & 5 & & $\begin{array}{r}8.1 \\
21.5\end{array}$ & $\begin{array}{r}\text { 3/4/966 15:00 } \\
\text { 2/25/97 9:30 }\end{array}$ & $\begin{array}{r}8,1996 \\
1 / 6 / 9813: 00\end{array}$ & $\begin{array}{r}5.2 \\
15.8\end{array}$ \\
\hline & 4/11/97 16:00 & $3 / 3 / 98$ 10:00 & 25.6 & 6/12/98 12:00 & 9/29/99 13:30 & & & & 2/6/98 12:00 & 6/29/99 8:30 & 32.7 \\
\hline & $3 / 5 / 9814: 00$ & 12/16/98 11:00 & 35.1 & 12/16/99 15:00 & $12 / 17 / 0012: 00$ & & & & $8 / 17 / 998: 48$ & 8/18/00 12:00 & \\
\hline & 1/8/99 15:00 & $2 / 8 / 008: 00$ & & & & & & & & & \\
\hline \multirow{4}{*}{ OET\#13 } & & & & & & & & & & & \\
\hline & $\begin{array}{r}3 / 3 / 977: 45 \\
9 / 15 / 9714: 15\end{array}$ & 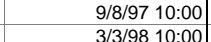 & $\begin{array}{r}6.3 \\
11.9 \\
\end{array}$ & $\begin{array}{r}3 / 3 / 979: 00 \\
6 / 12 / 9812: 00\end{array}$ & $\begin{array}{r}4 / 7 / 988: 45 \\
9 / 29 / 9913: 30\end{array}$ & 5 NO SAMPLES & & 13.3 & $\begin{array}{l}2 / 25 / 979: 30 \\
2 / 6 / 9812 \cdot 00\end{array}$ & \begin{tabular}{|r|}
$1 / 6 / 9813: 00$ \\
$6 / 29 / 998 \cdot 30$ \\
\end{tabular} & $\begin{array}{l}10.5 \\
27.4\end{array}$ \\
\hline & 3/5/98 14:00 & 12/16/98 11:00 & 21.5 & 12/16/99 15:00 & $\begin{array}{l}12 / 17 / 0012: 00 \\
\end{array}$ & & & & 8/17/98 8:48 & $\begin{array}{l}6 / 18 / 0012: 00 \\
8 / 12: 00\end{array}$ & \\
\hline & 1/8/99 15:00 & $2 / 8 / 008: 00$ & & & & & & & & & \\
\hline \multirow{10}{*}{ OET\#14 } & 12/5/97 12:15 & 6/9/98 15:00 & 6.2 & 12/7/97 9:00 & 4/7/98 8:45 & 5 NO SAMPLES & & 4.0 & 2/6/98 12:00 & 6/29/99 8:30 & 16.9 \\
\hline & 6/15/98 8:30 & 12/16/98 11:00 & & 6/12/98 12:00 & 9/29/99 13:40 & & & & 8/17/99 8:48 & 8/18/00 12:00 & \\
\hline & 1/8/99 15:00 & $2 / 8 / 008: 00$ & & 12/16/99 15:00 & $12 / 17 / 00 \quad 12: 00$ & & & & & & \\
\hline & & & & & & & & & & & \\
\hline & Site Down & & & Site Down & & & & & Site Down & & \\
\hline & 9/29/93 10:00 & 1/21/94 8:00 & & $10 / 6 / 95 \quad 10: 45$ & 4/11/96 14:30 & & & & $12 / 21 / 9511: 50$ & $3 / 14 / 9615: 00$ & \\
\hline & Due to construction o & of OTF & & Placed back in same I & location but & & & & Cummins out of busin & ness moved & \\
\hline & All experiments meas & sured & & now get $0.5 \mathrm{hr}$ of shad & de per day. & & & & site from Abiliene, $T X$ & to Ft.Davis, TX. & \\
\hline & while site was down. & & & All experiments meas & sured & & & & No experiments meas & sured & \\
\hline & & & & while site was down. & & & & & while site was down. & & \\
\hline
\end{tabular}




\section{Figures 1 \& 2. International OET Sites}

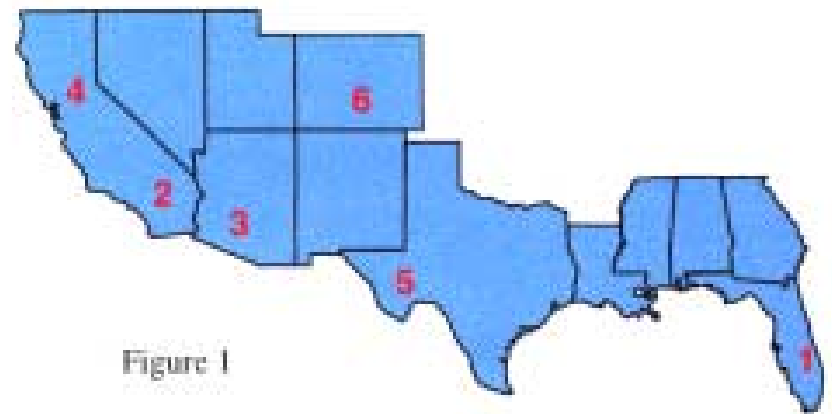

\begin{tabular}{|c|c|c|}
\hline Site & Abbreviation & Stress Conditions \\
\hline $\begin{array}{l}\text { 1. Mianni, FL. } \\
\text { 2. Daggett, CA } \\
\text { 3. Poocenix, AZ } \\
\text { 4. Sacramerno, CA } \\
\text { 5. Fort Davis, TX } \\
\text { 6. Golden, CO } \\
\text { 7. Köln, Germany } \\
\text { 8. Almeria, Spain }\end{array}$ & $\begin{array}{l}\text { FLA } \\
\text { BAR } \\
\text { APS } \\
\text { SMUD } \\
\text { TX } \\
\text { NREL. } \\
\text { GER } \\
\text { SPA }\end{array}$ & $\begin{array}{l}\text { Hos / Hamid } \\
\text { Hos / Dry } \\
\text { Hot / Dry } \\
\text { Warm / Humid } \\
\text { Warm / Mild } \\
\text { Cool/ Mild } \\
\text { Warn / Humid } \\
\text { Hot / Mild }\end{array}$ \\
\hline
\end{tabular}

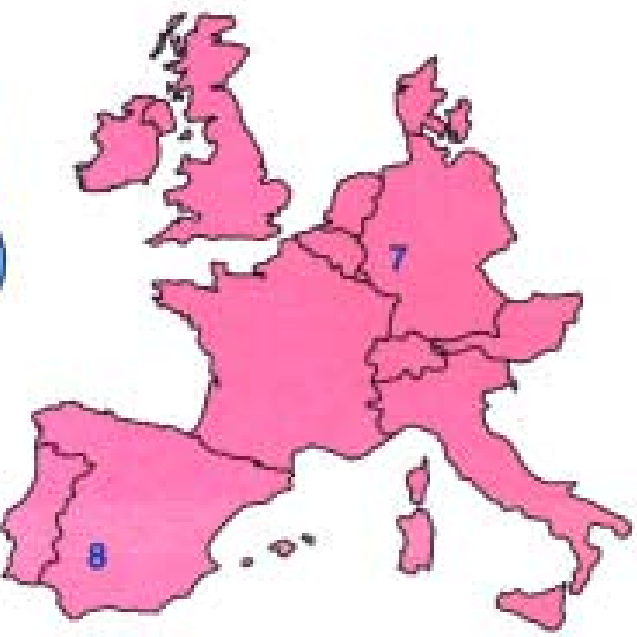

Figure 2

\section{Figure 3. Typical Outdoor Exposure Test Site}

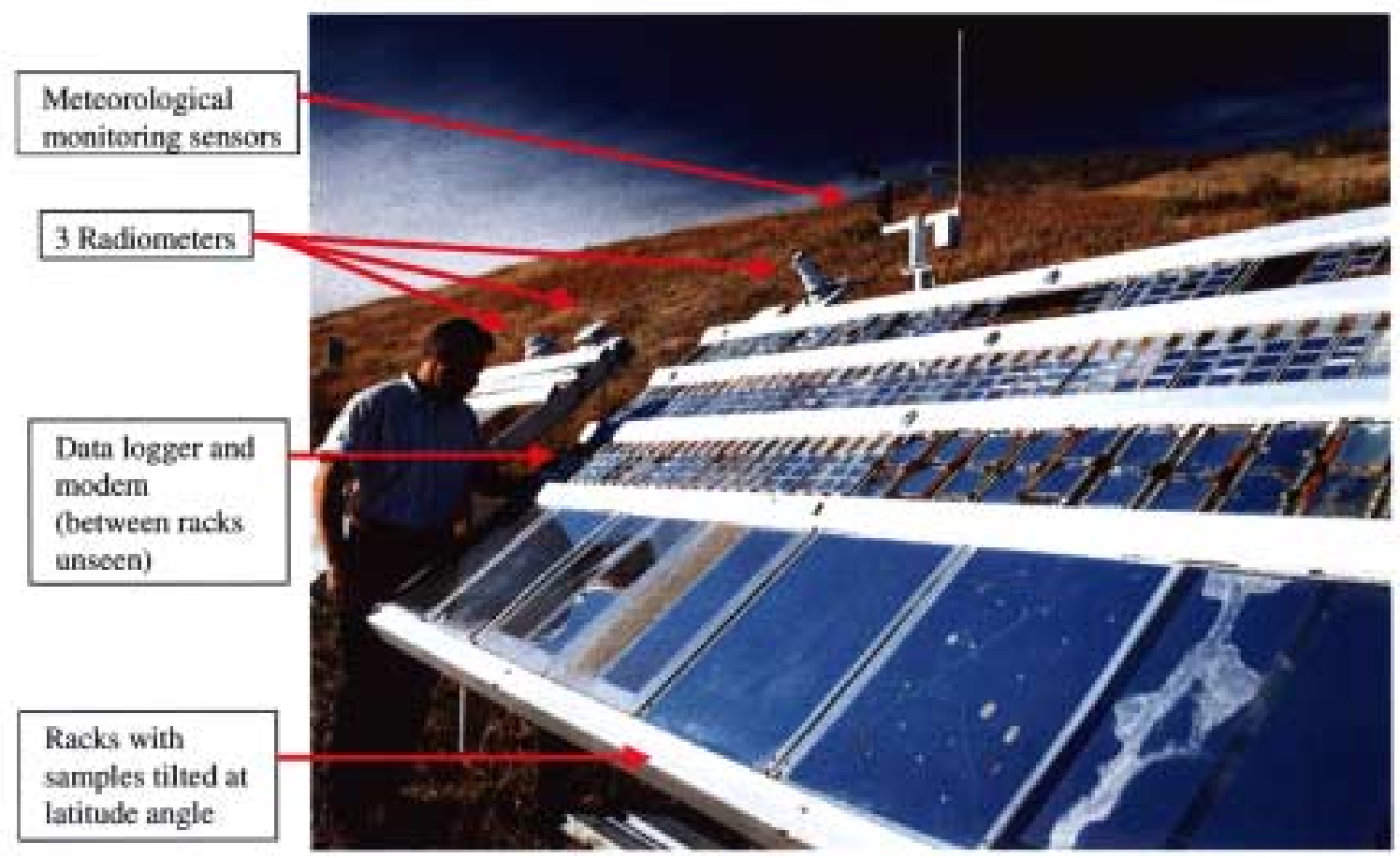


Figure 4. Spectral Irradiance of Atlas $\mathrm{Ci} 65$ WOM vs. Global Air Mass 1.5 Solar Spectrum

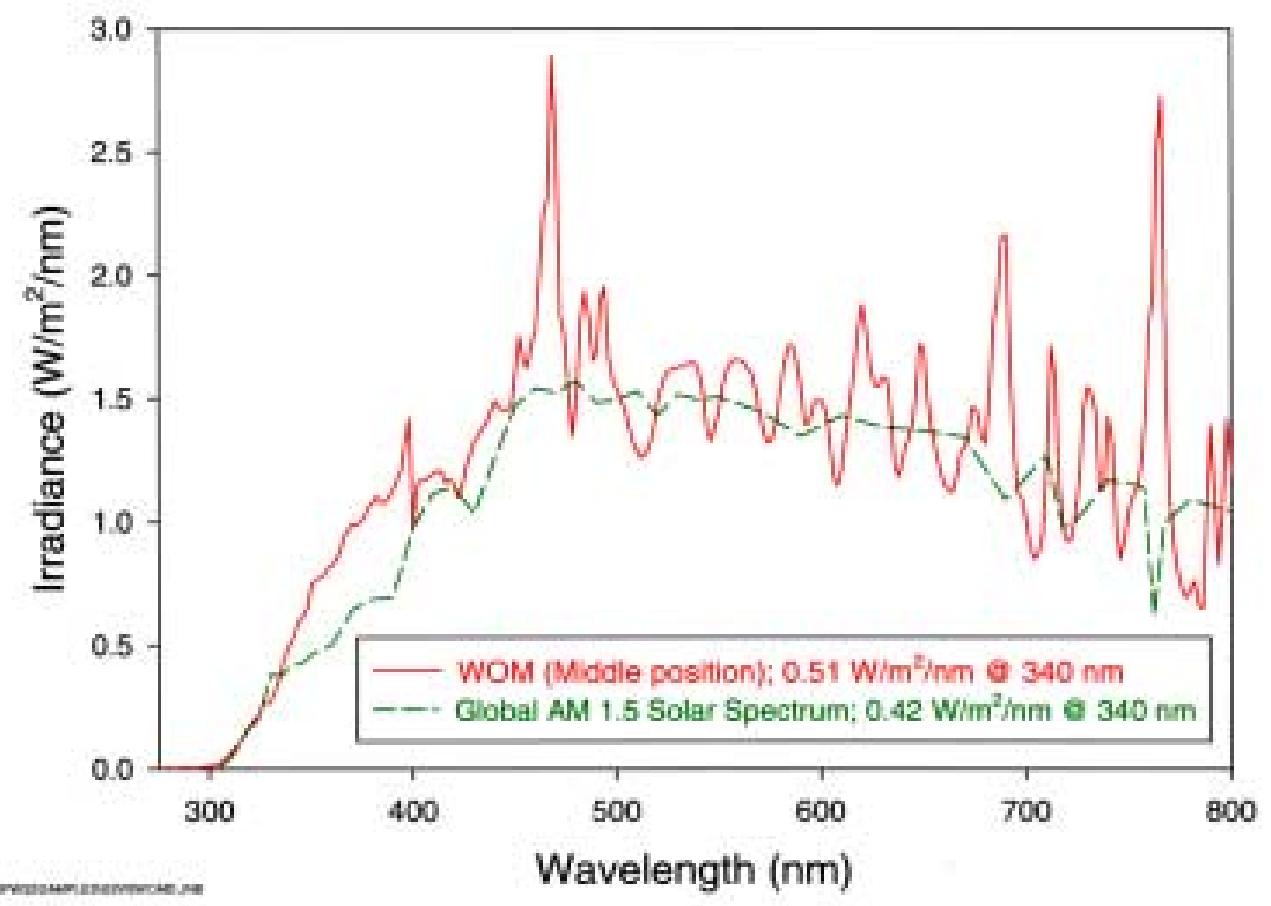

Figure 5. Spectral Irradiance of XENOTEST 1200 LM vs. Global Air Mass 1.5 Solar Spectrum

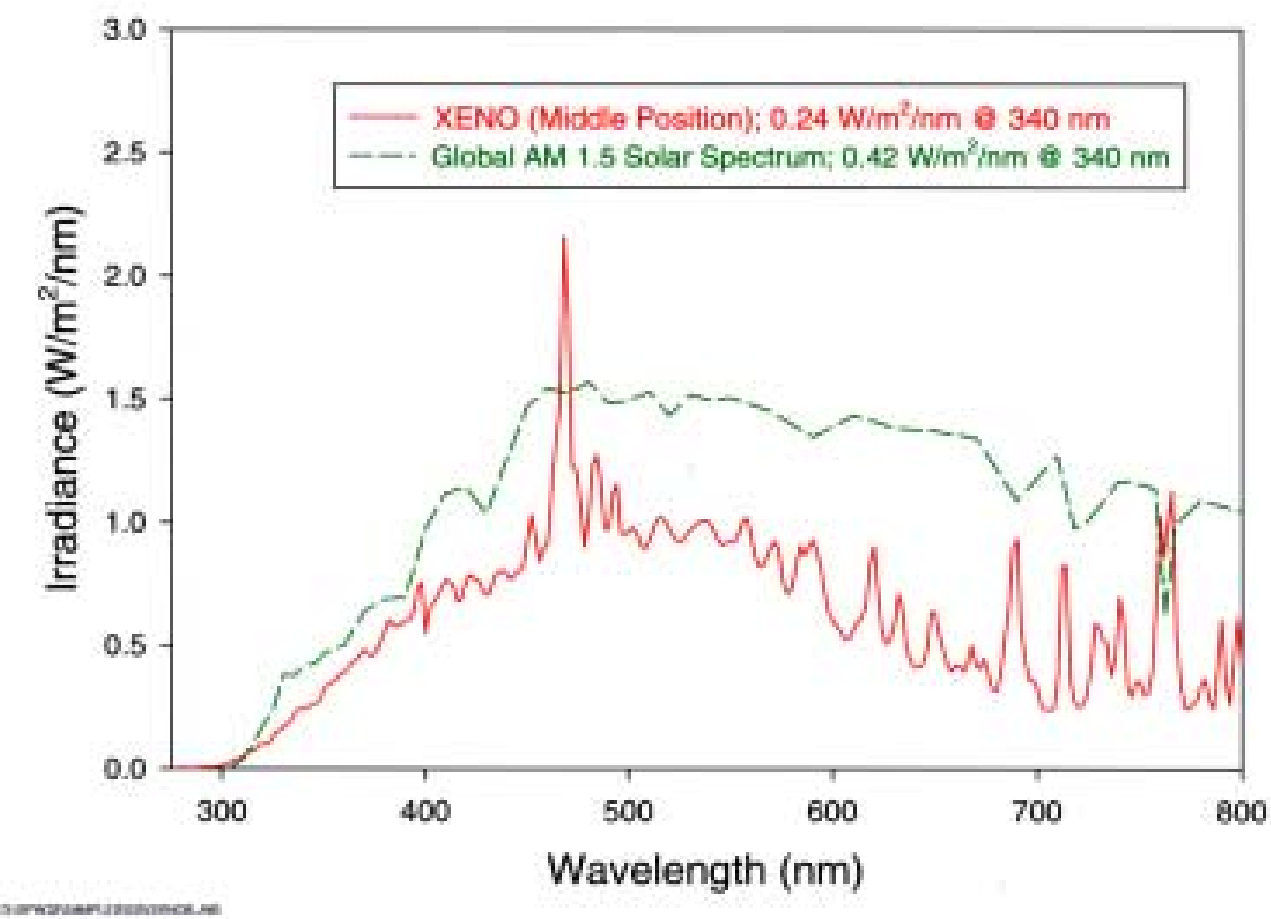




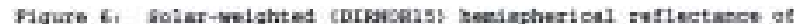

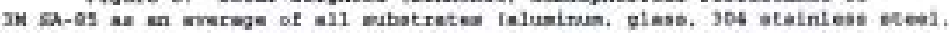

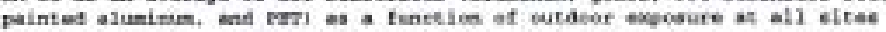

before and after eleasing. imperiment okroi?
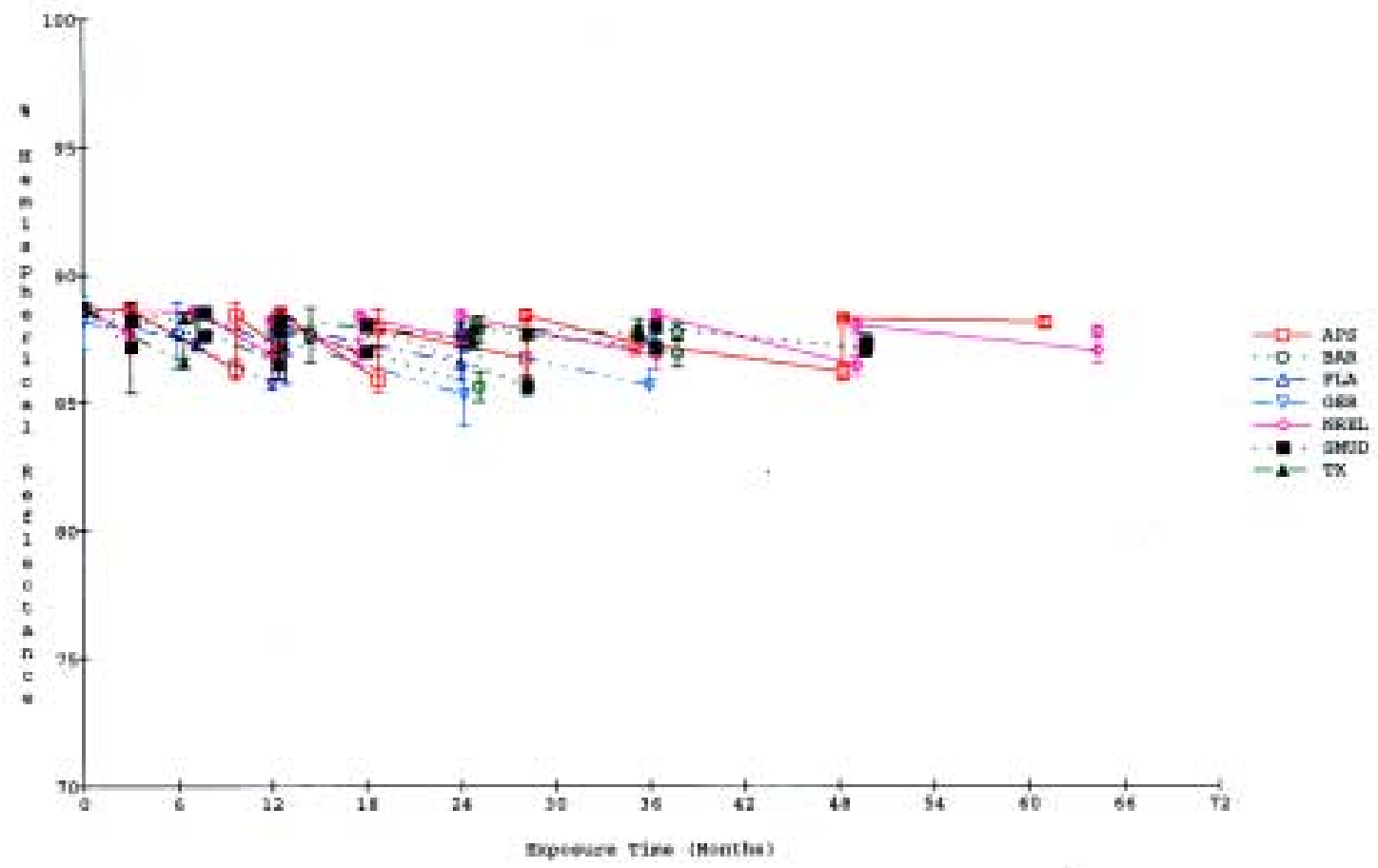

Fipurs 7t soler weighted cormonss) kedapheriesl reflecranse of

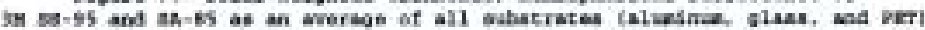

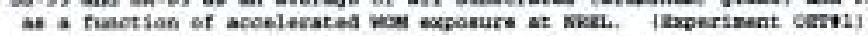

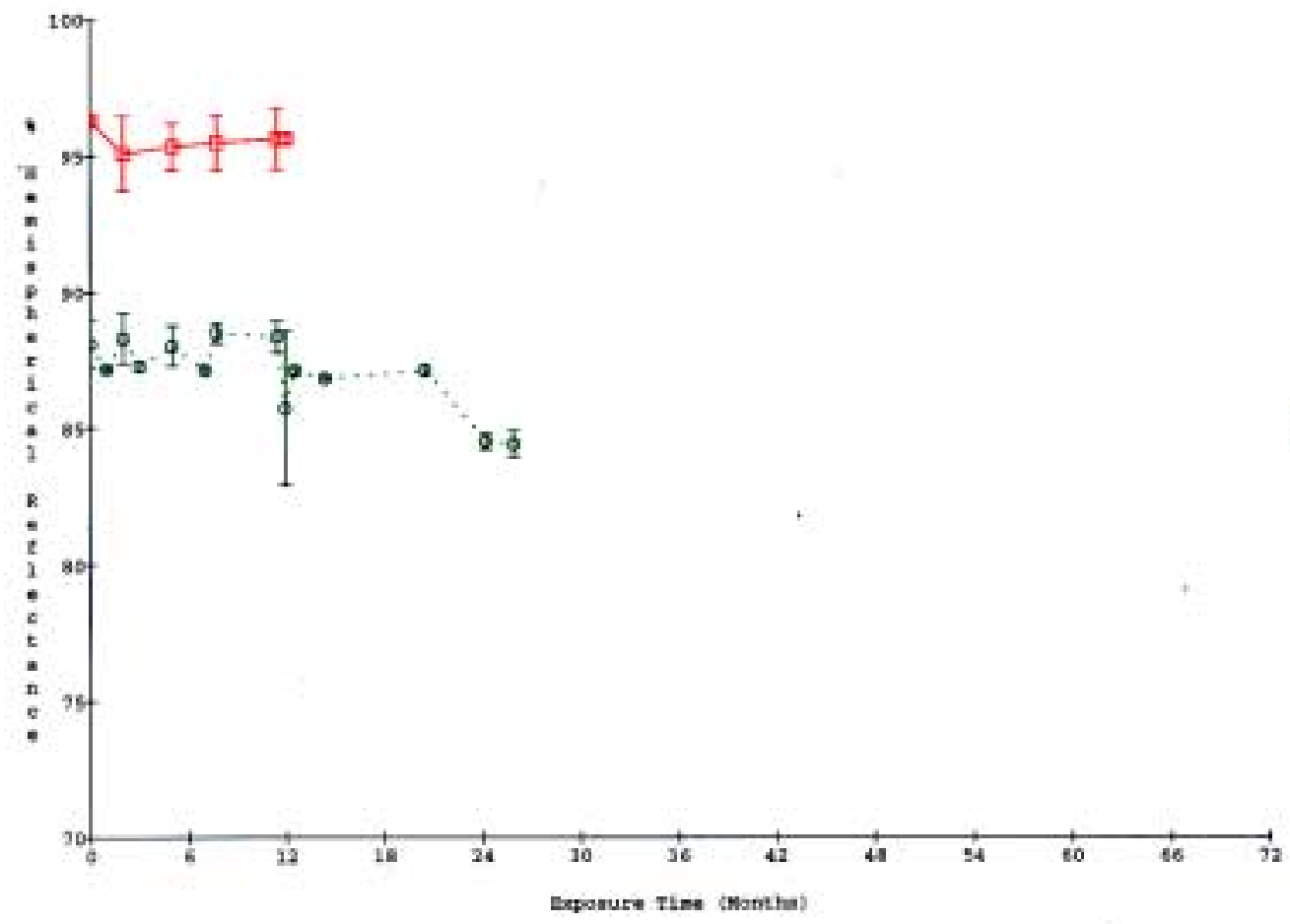




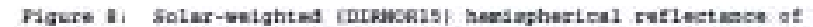

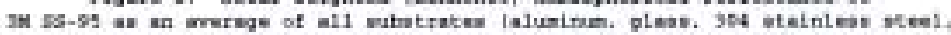

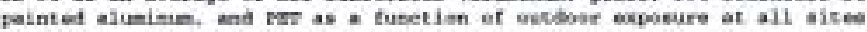

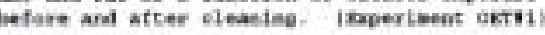
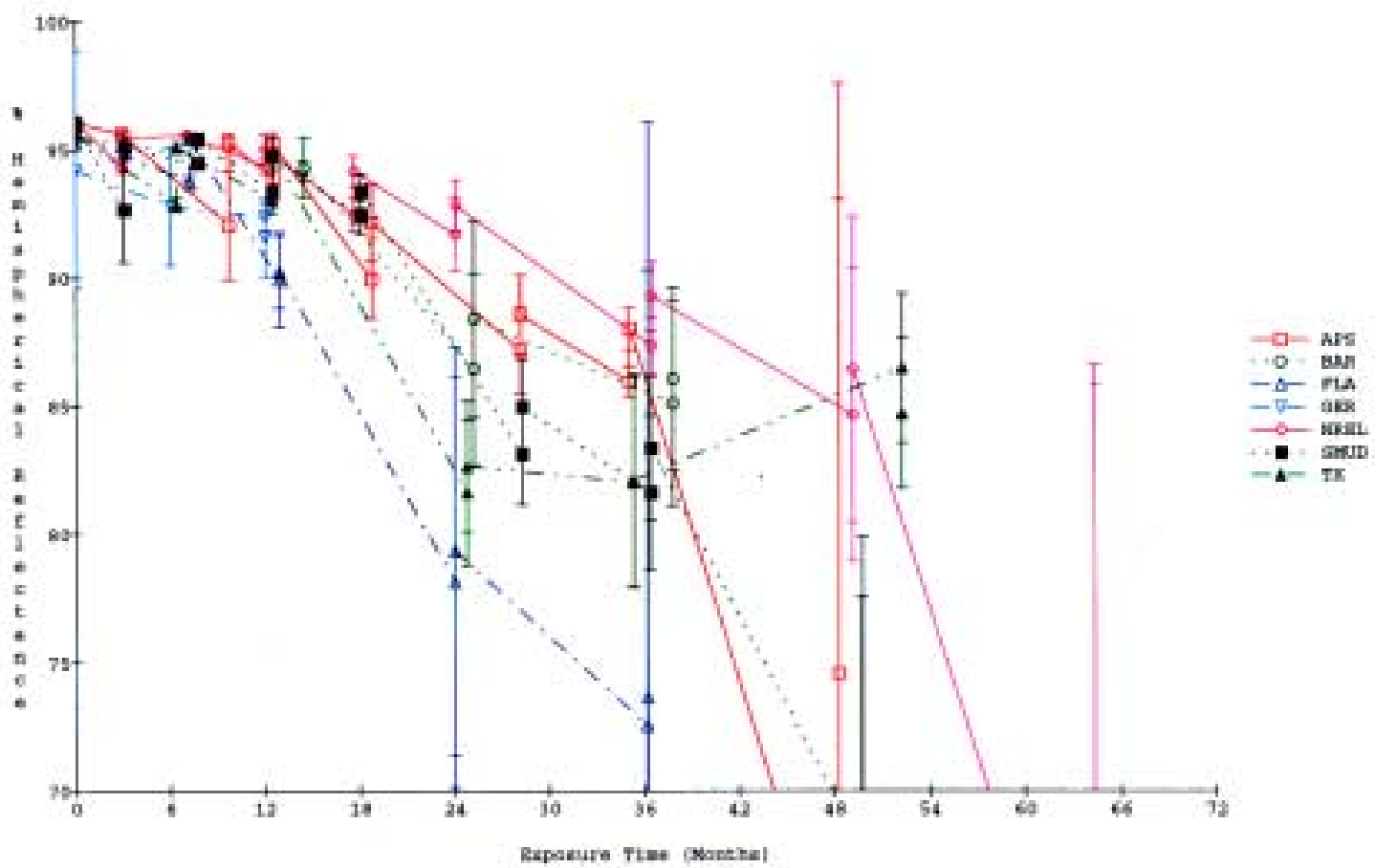

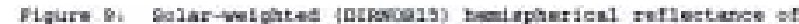

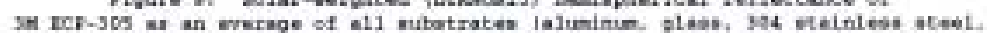

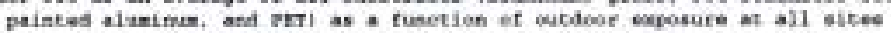

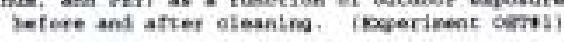
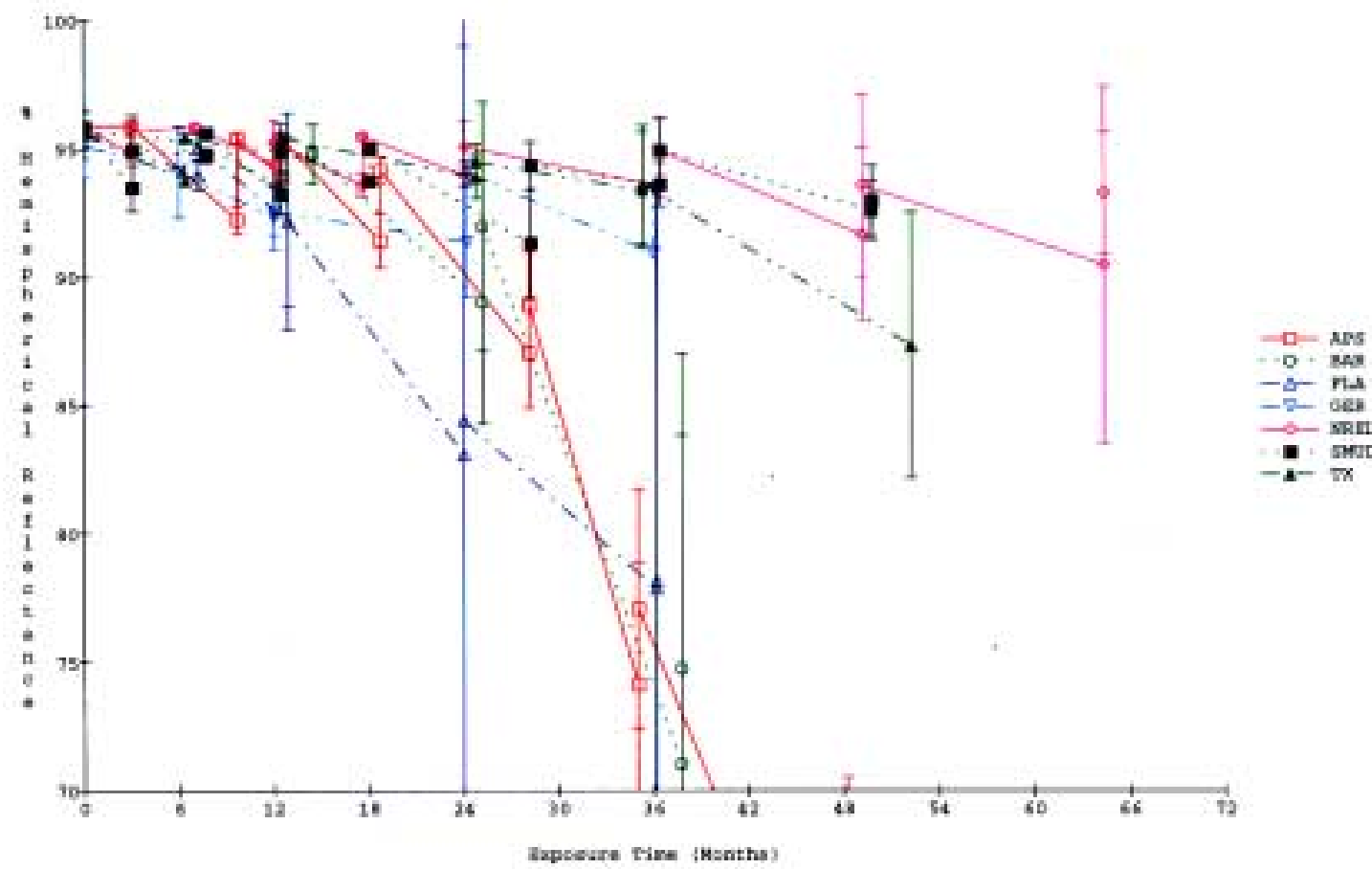


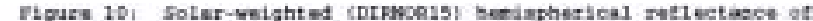

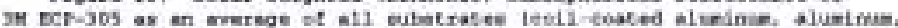

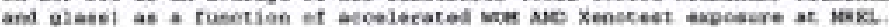
imeariment ostat?

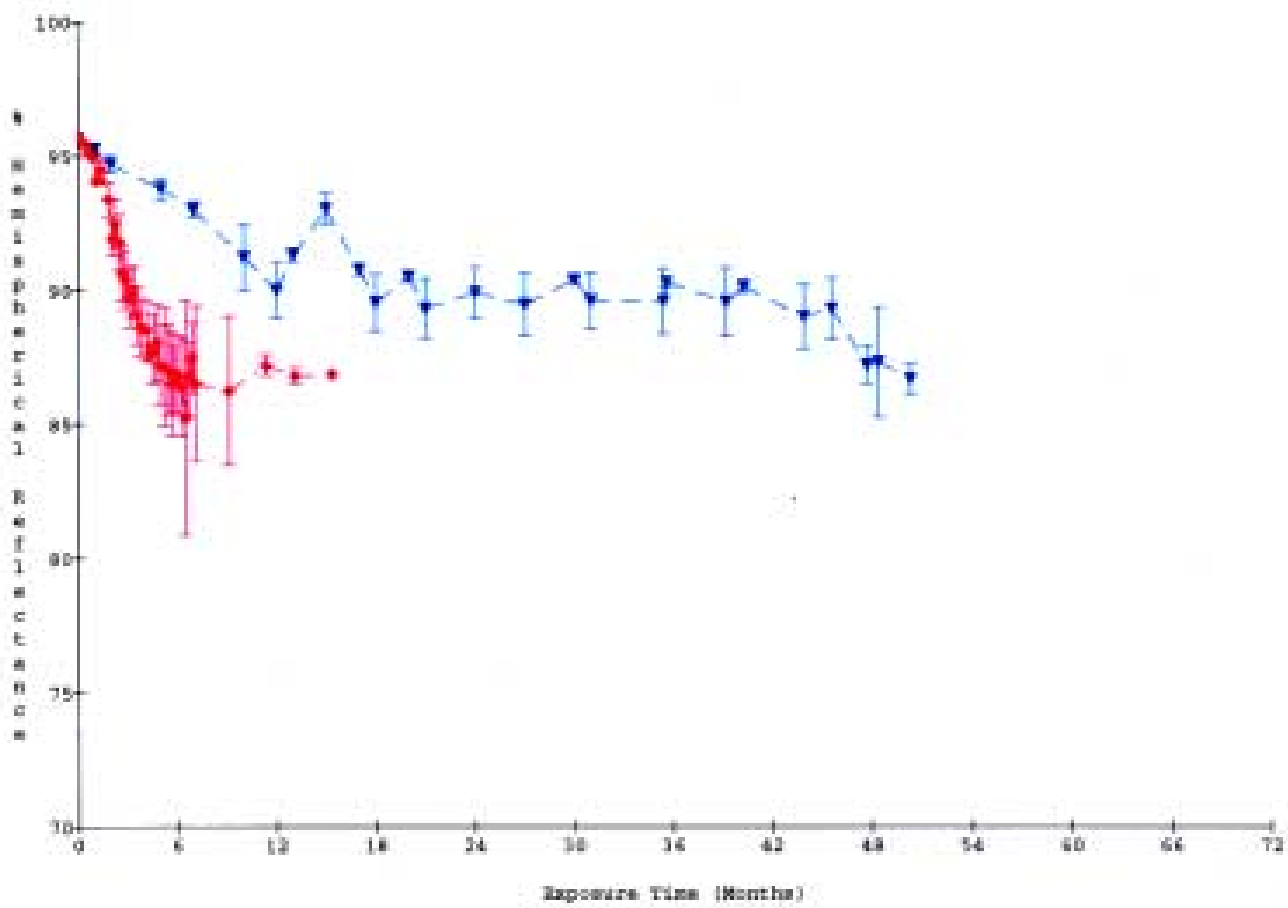

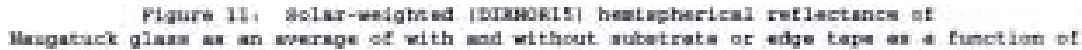

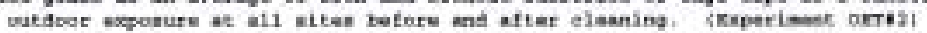

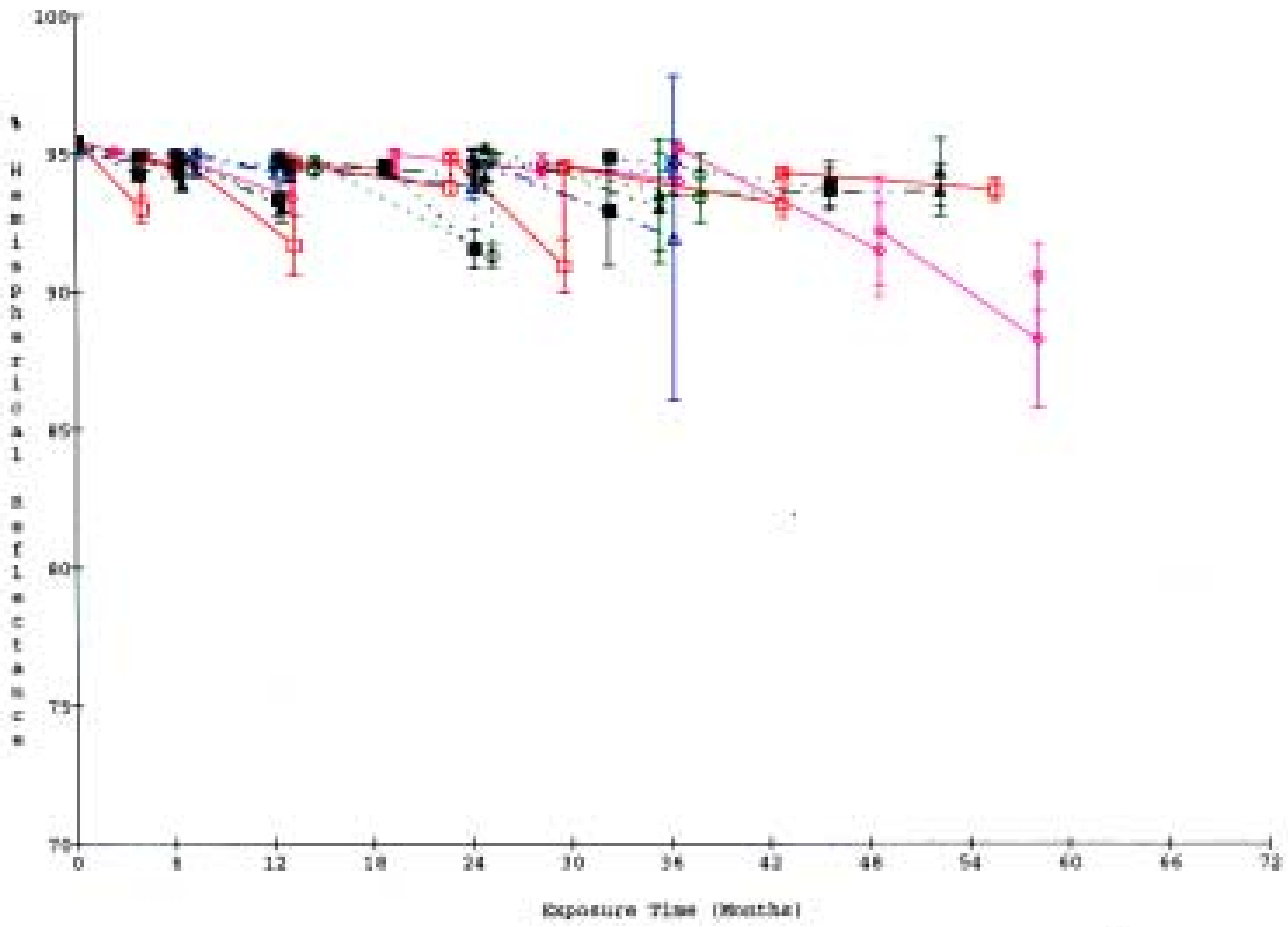




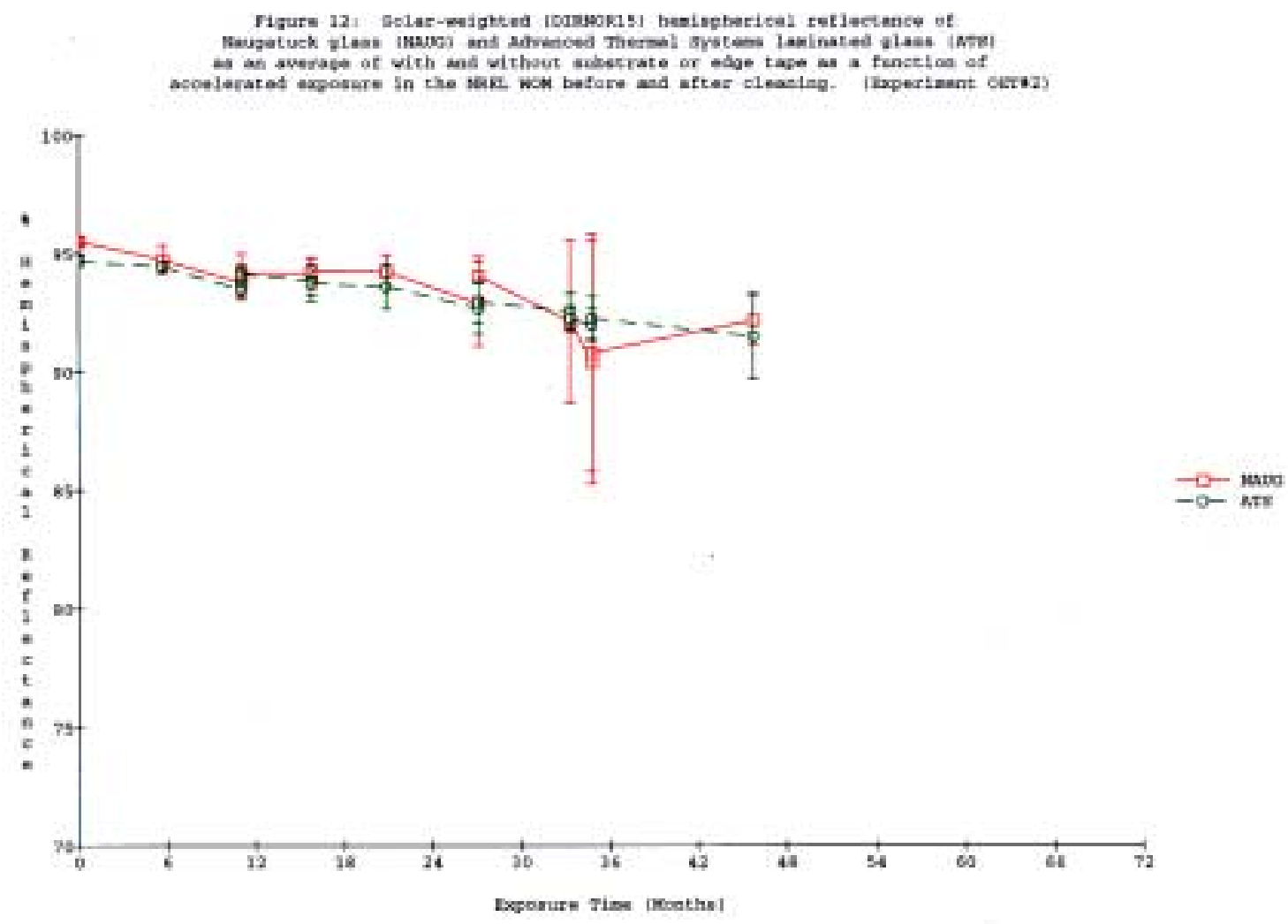

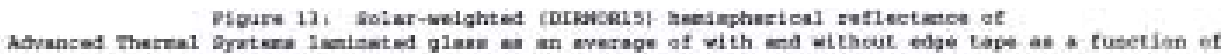

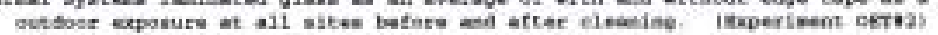

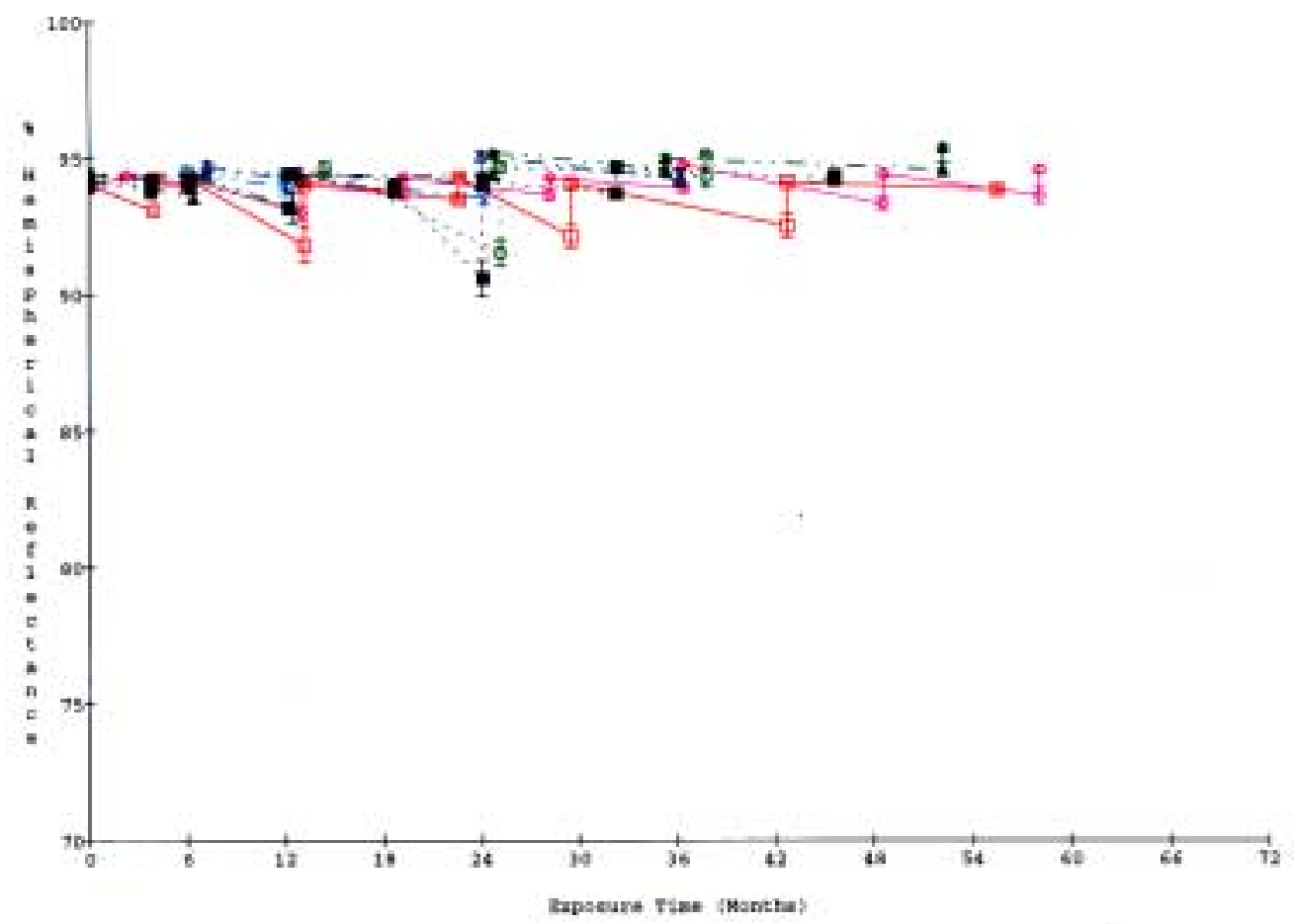




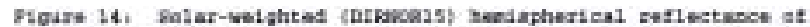

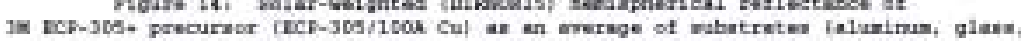

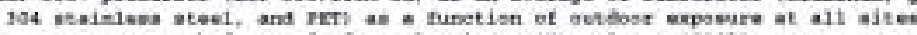
betest atod atter eleaning. imgerinent corvis!

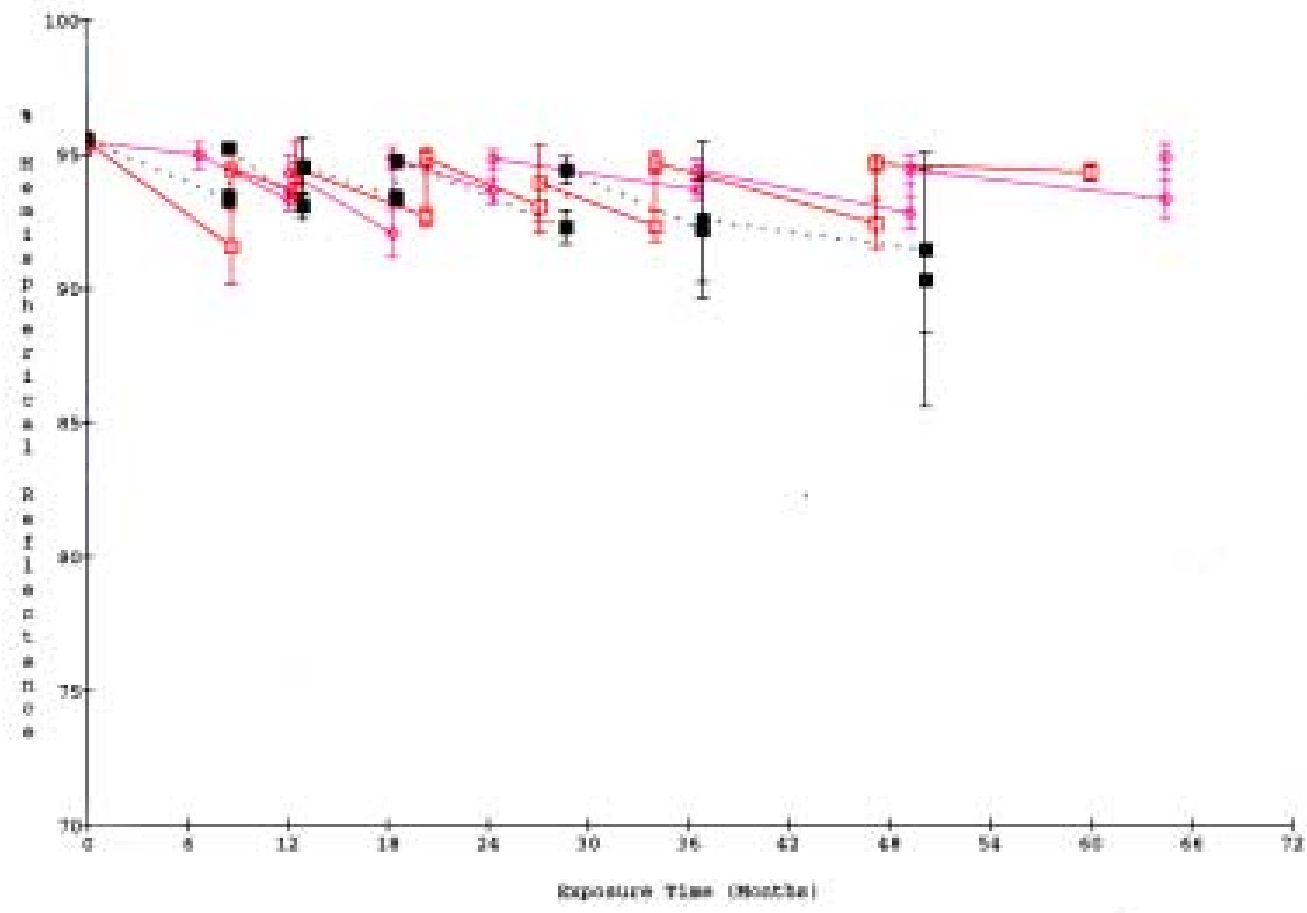

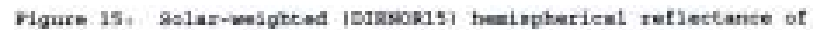

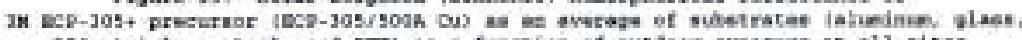

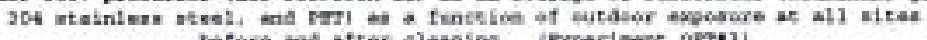

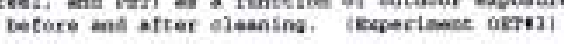

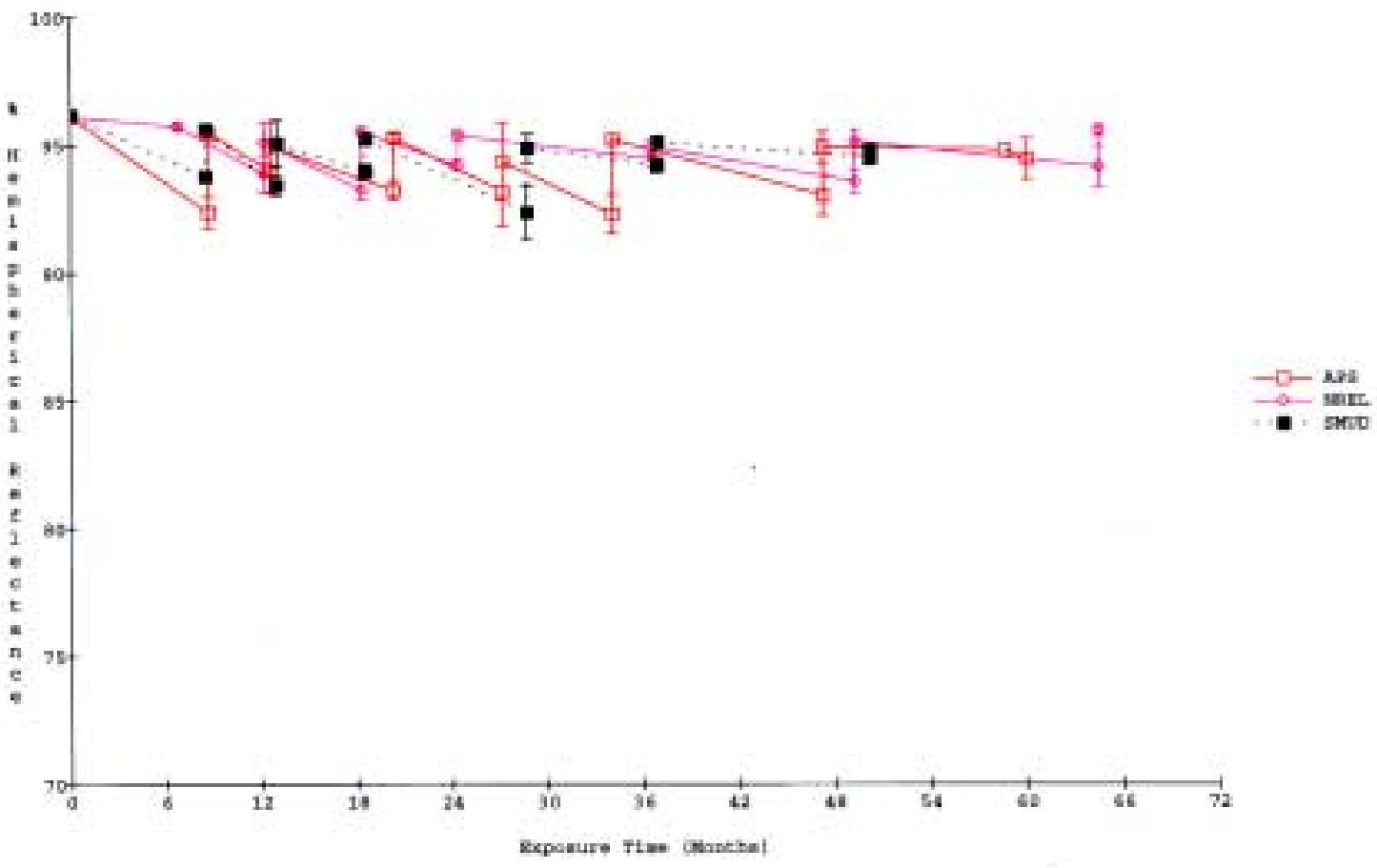



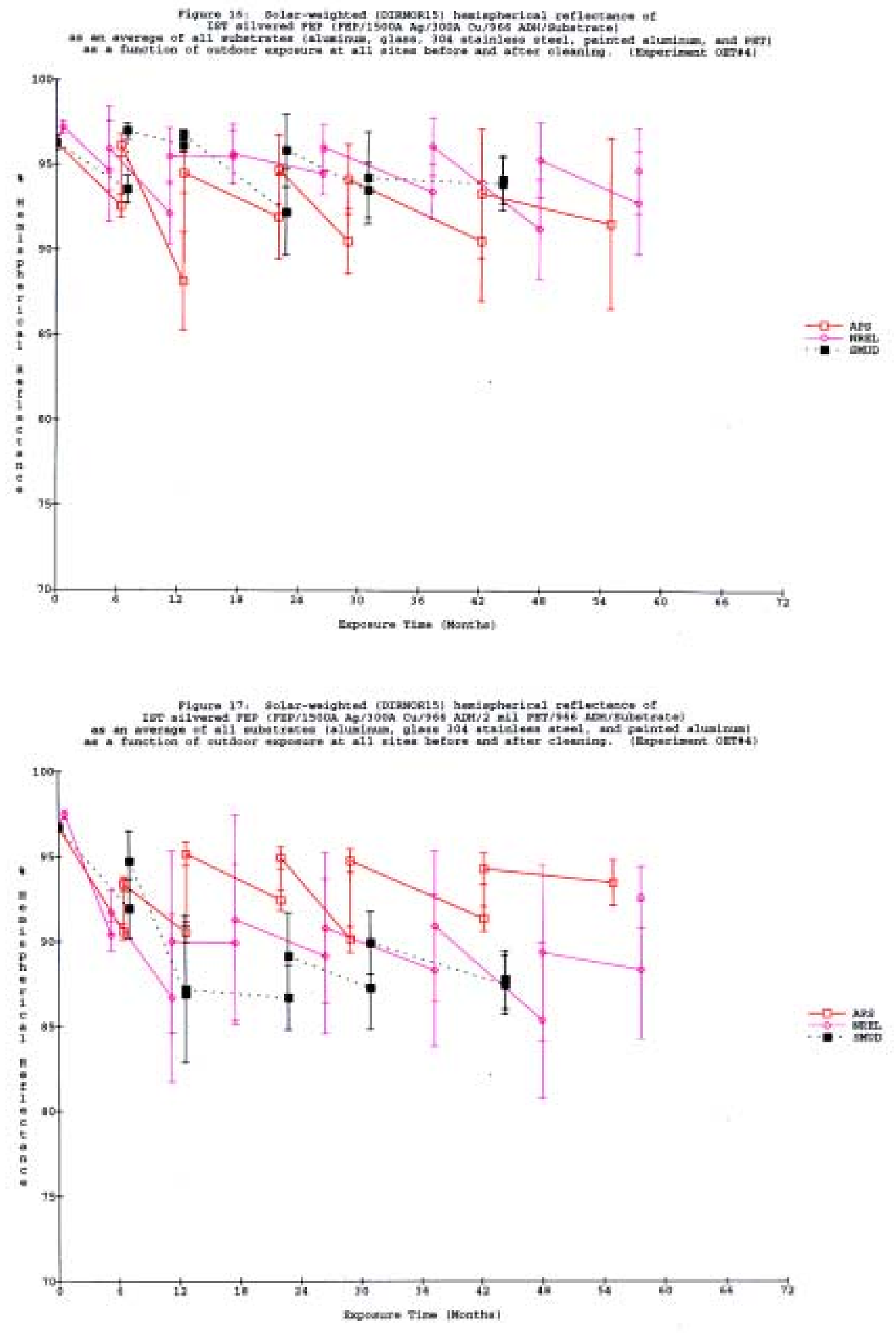


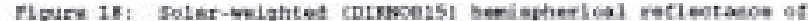
per [rasf

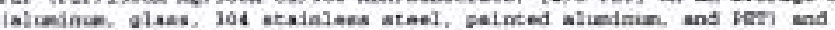

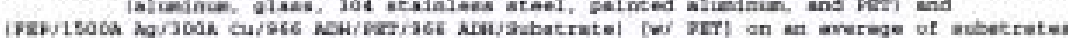

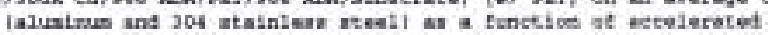

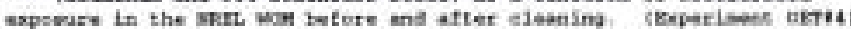

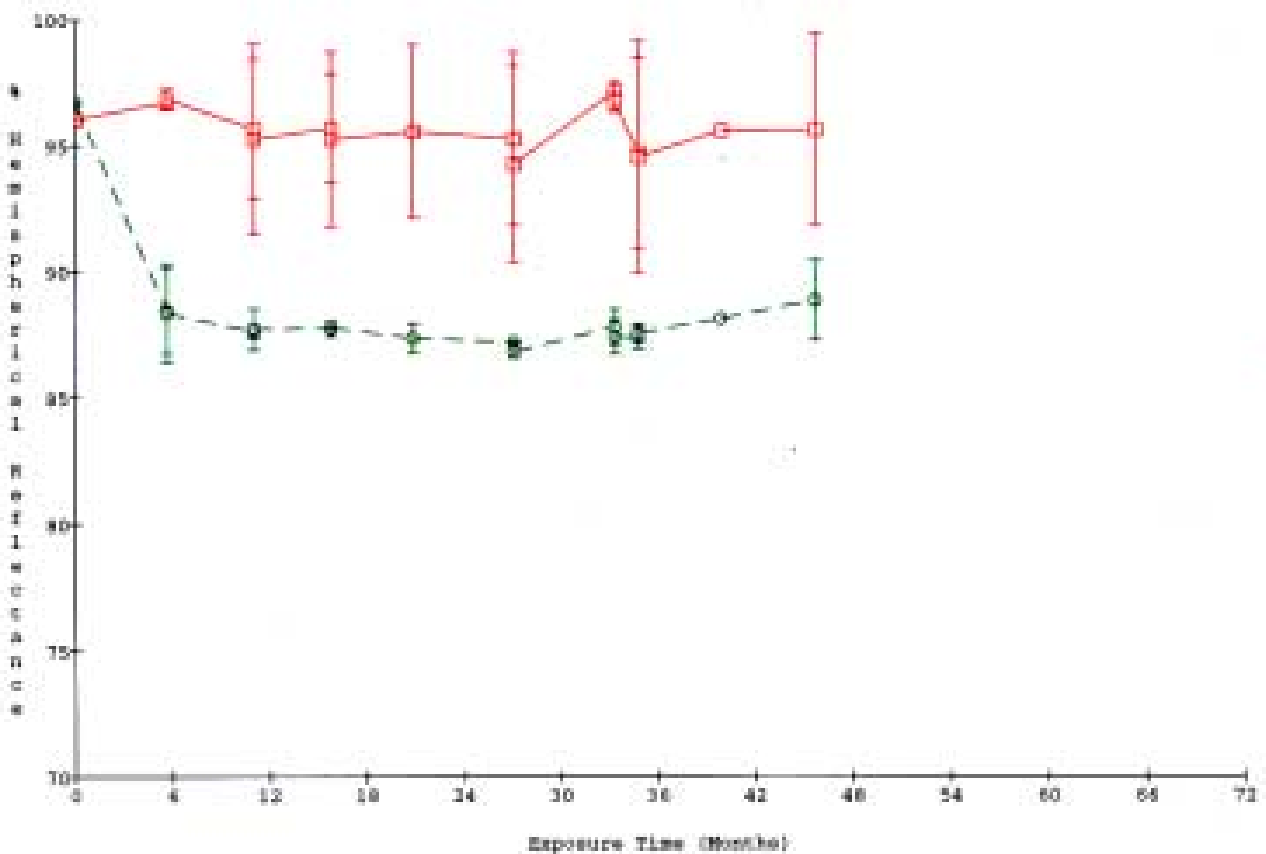

$-0-7 i s$ bes:

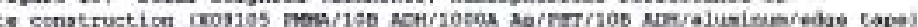

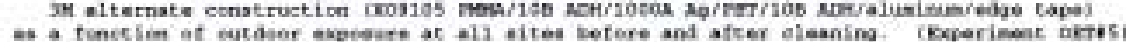

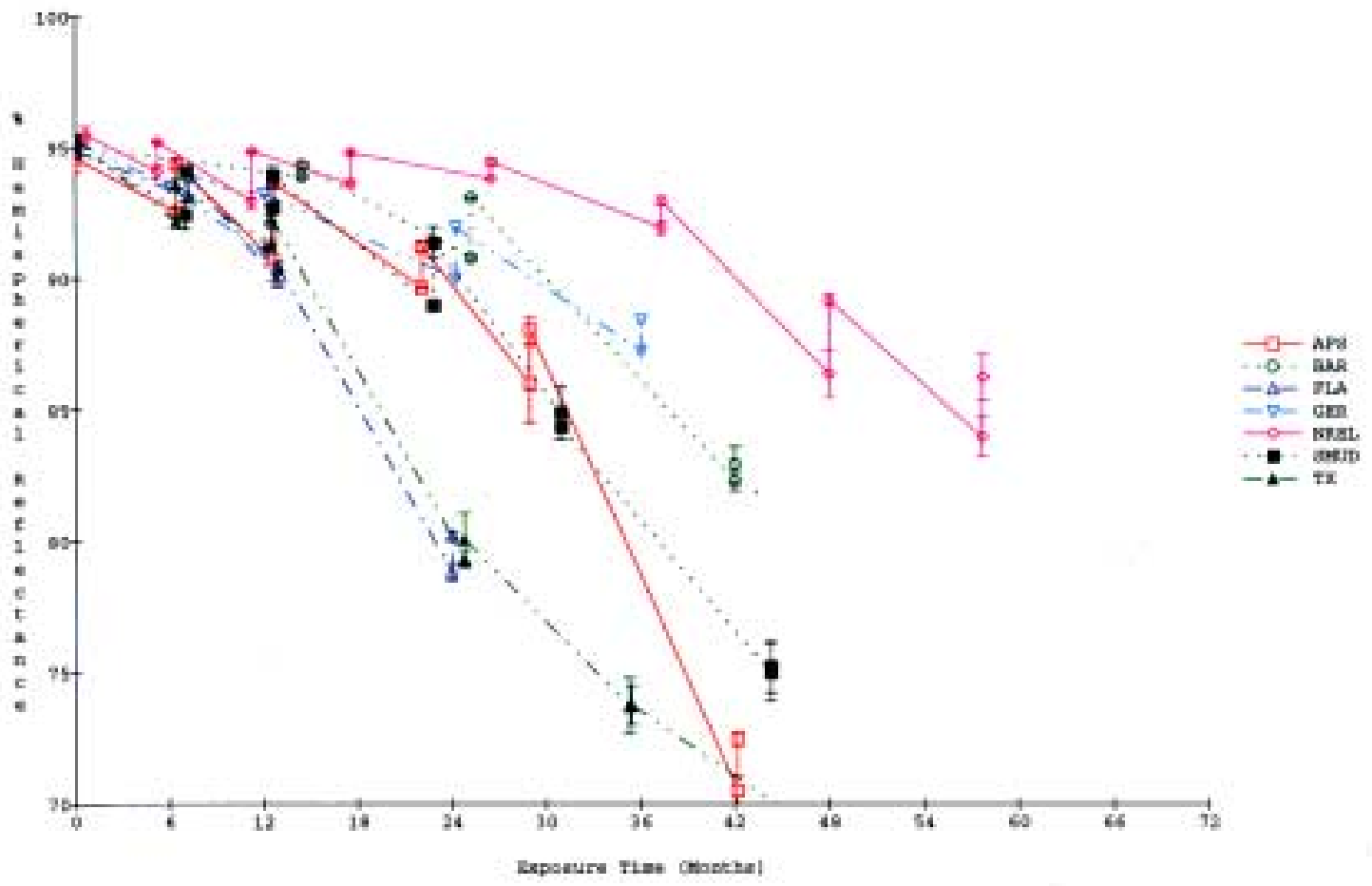


Figure 20. Solsz-weighed (BDigeakis) heatepherisw reflectance of

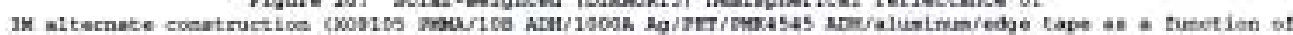

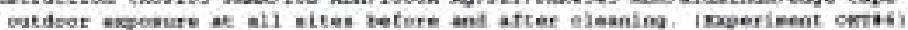
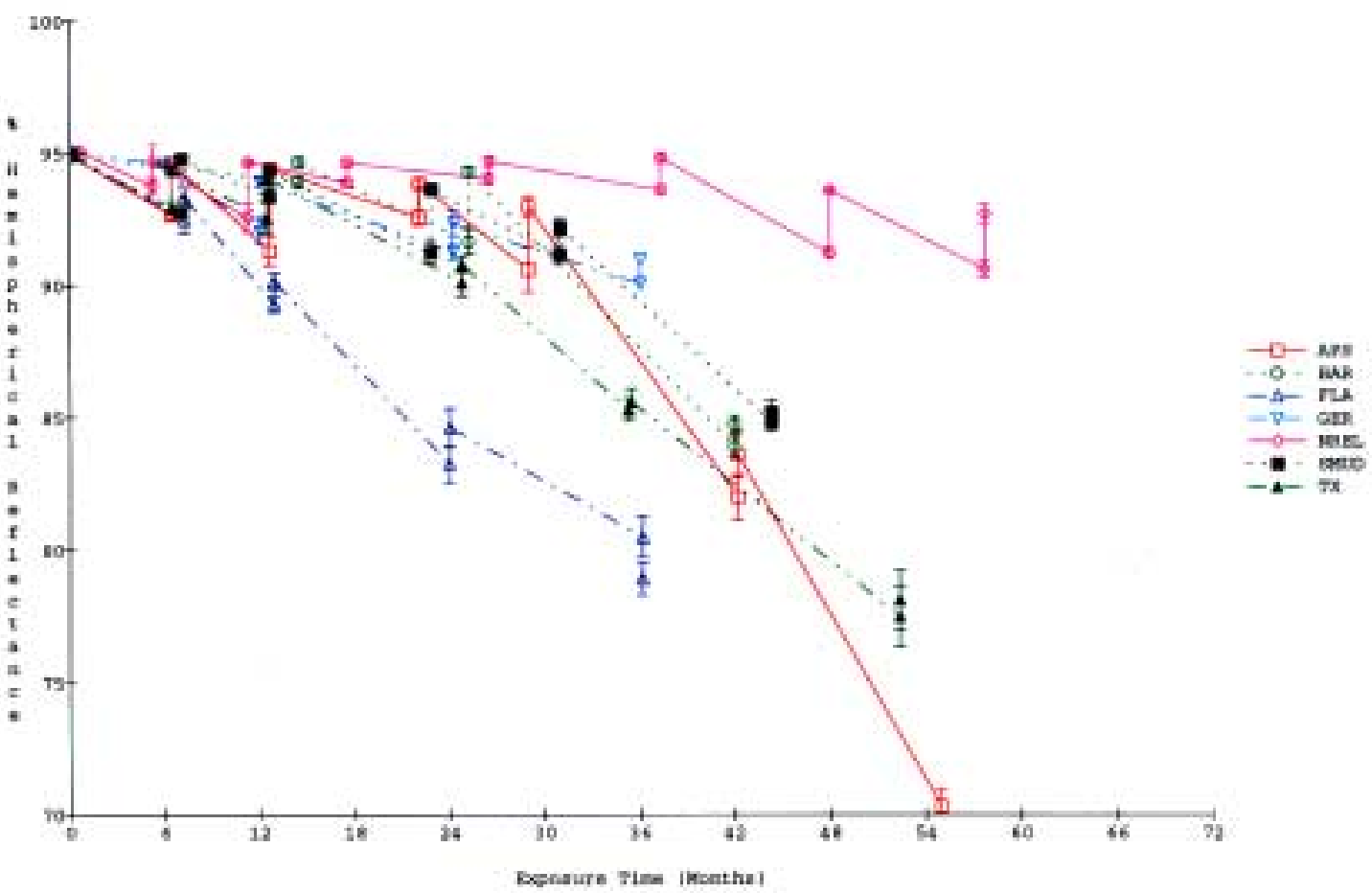

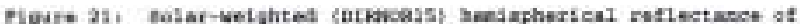

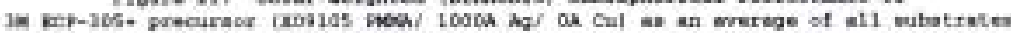

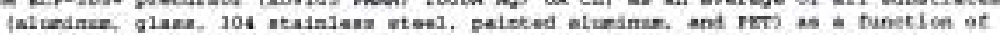

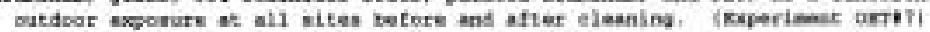

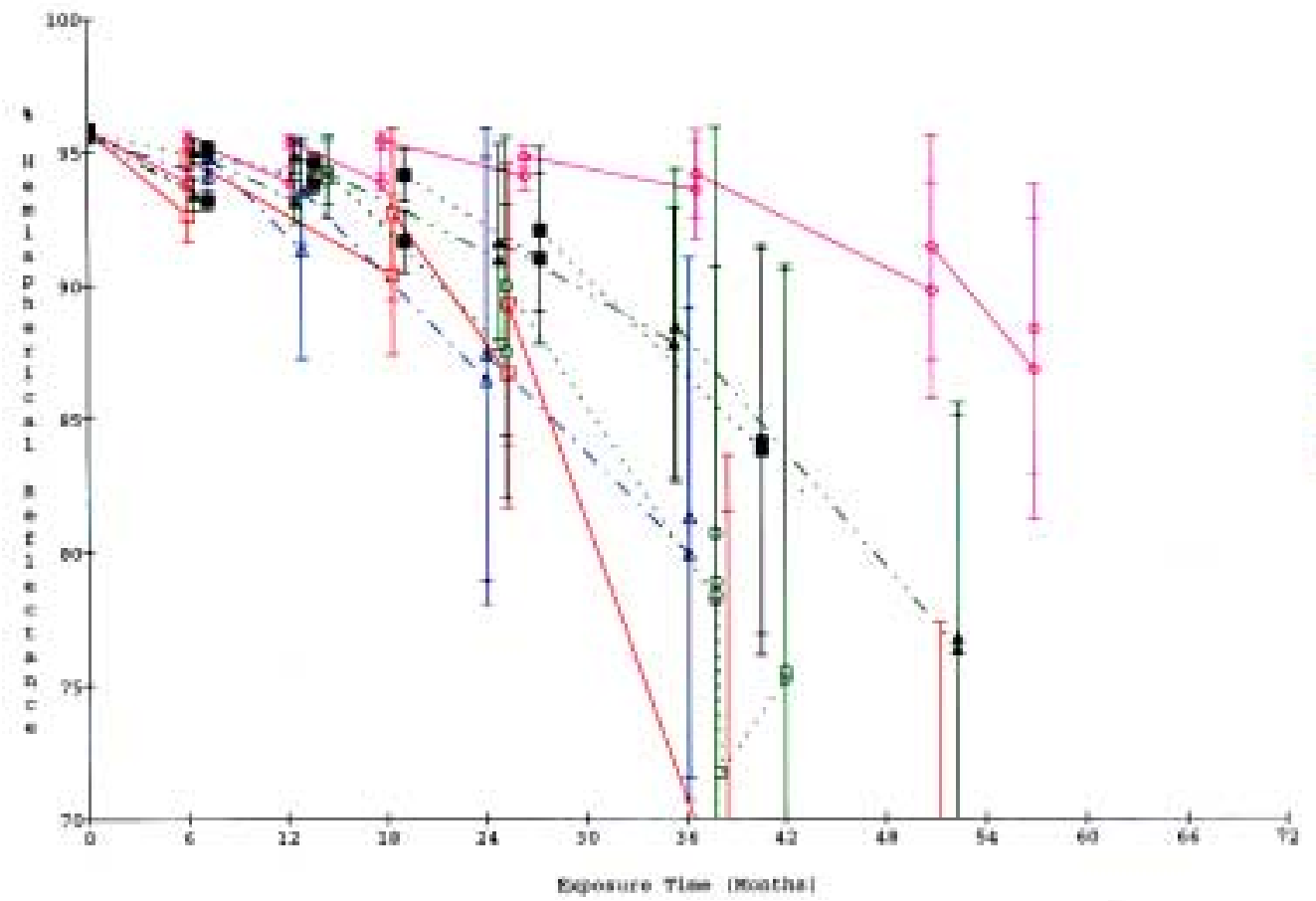




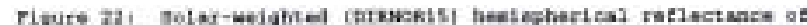

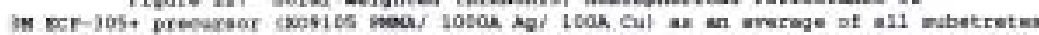

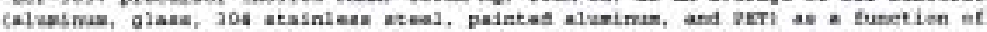

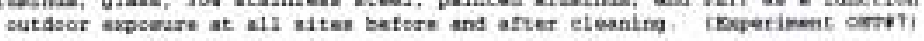

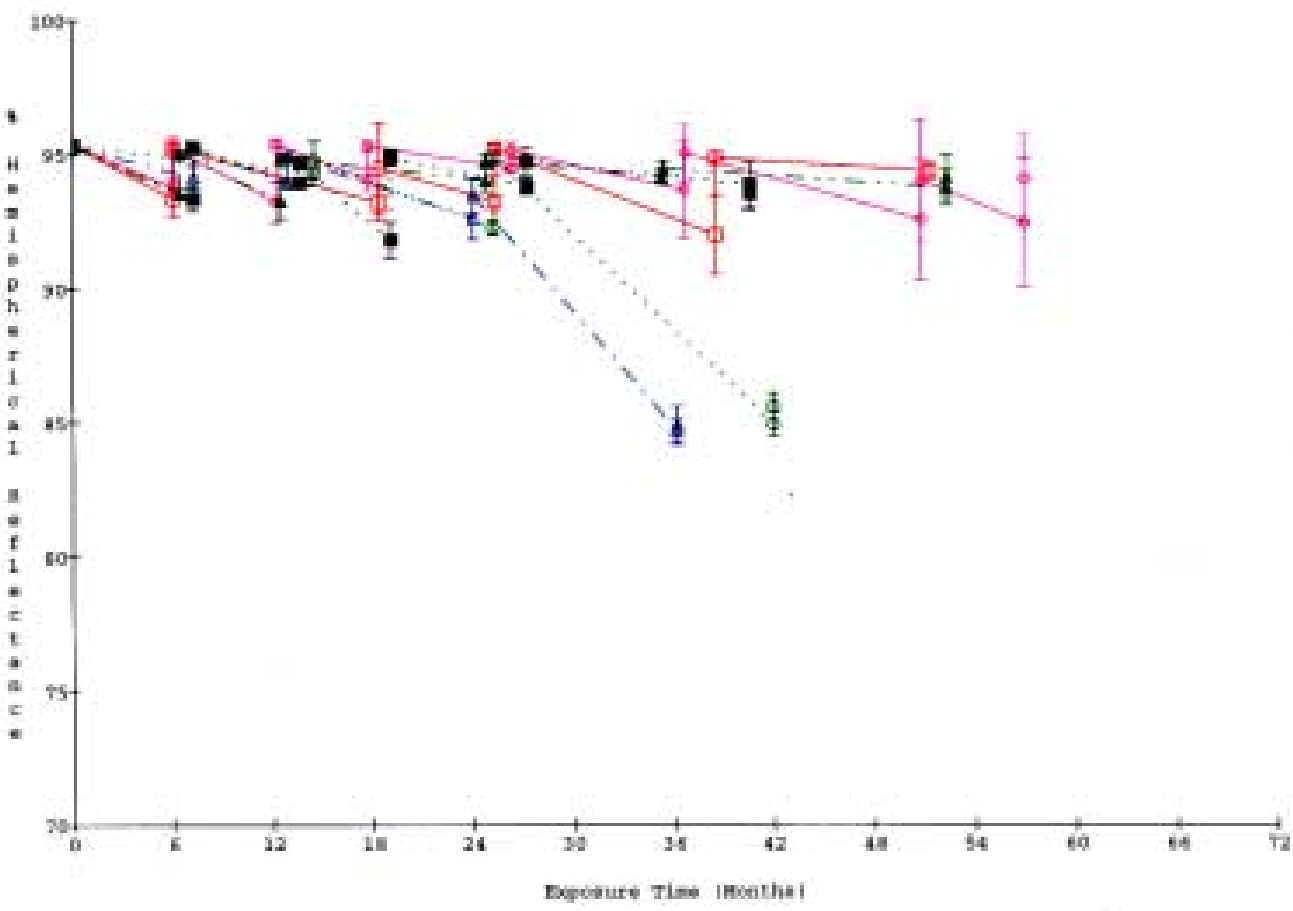

$-7-$ Ara

-0. and

$-\mathrm{s}-\mathrm{rat}$

-

$-\pi x$

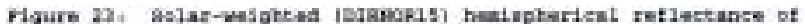

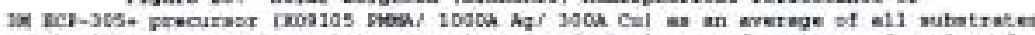

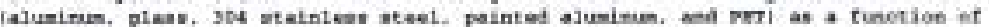

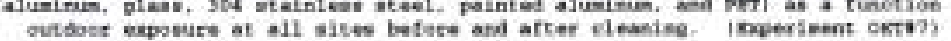

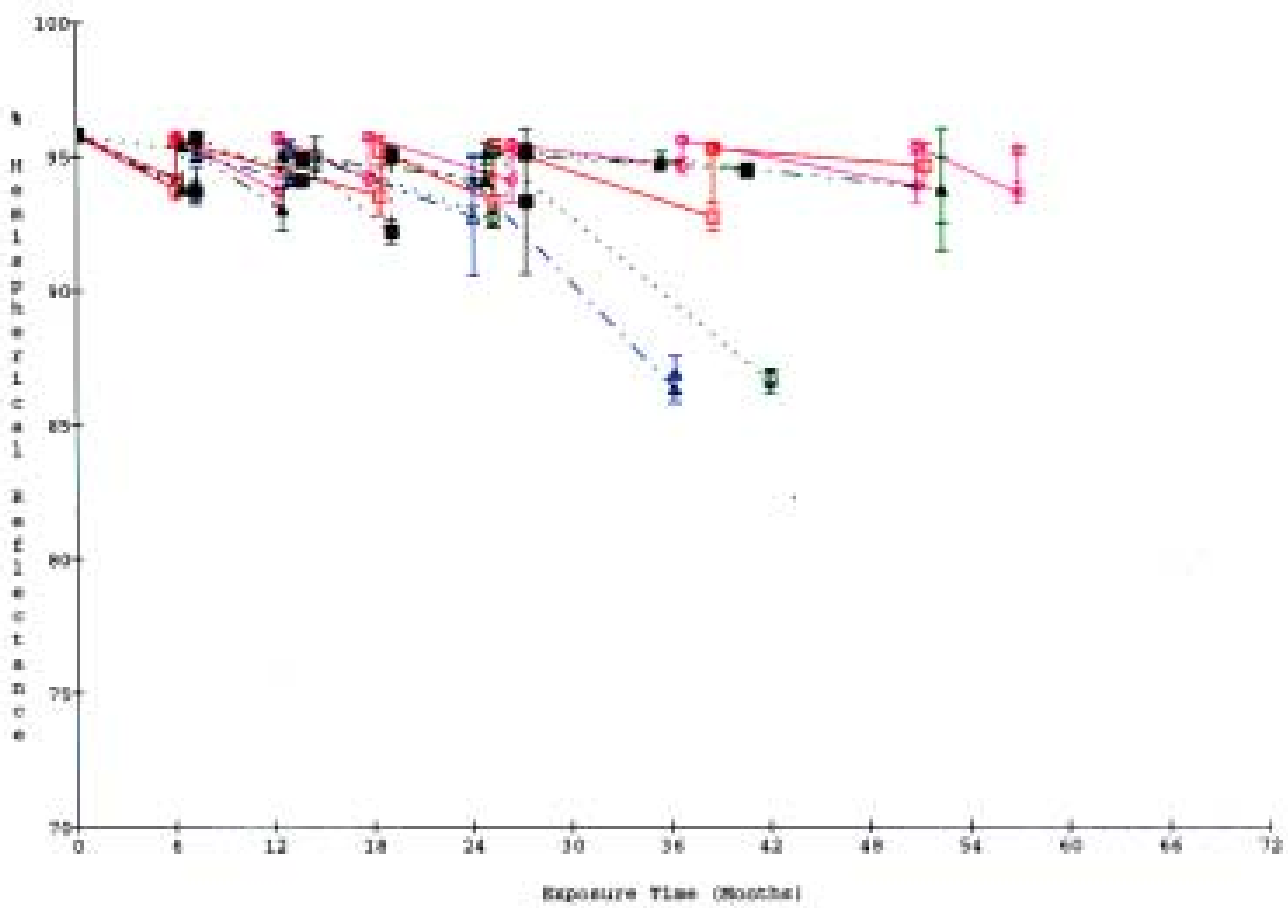




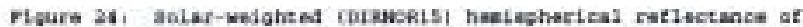

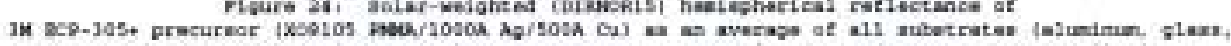

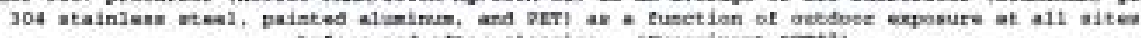
betore and after eleanimg. CDeveriment orsth
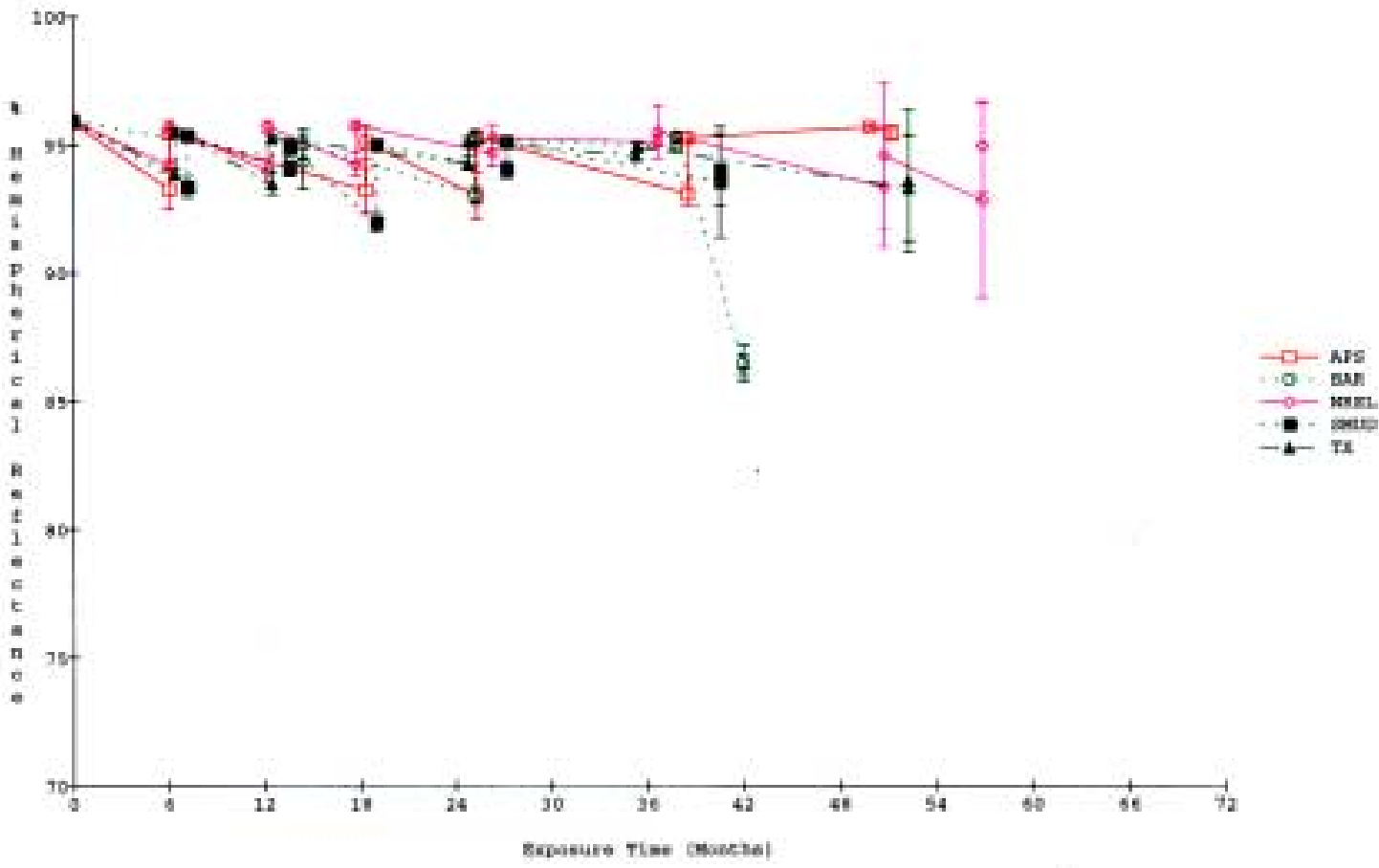

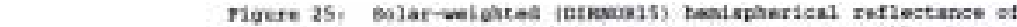

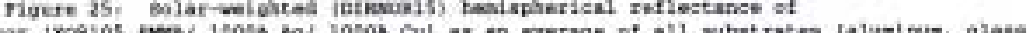

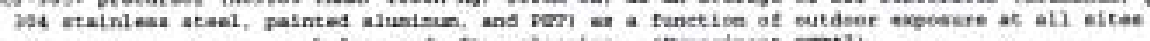

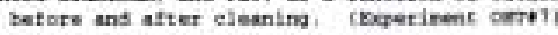

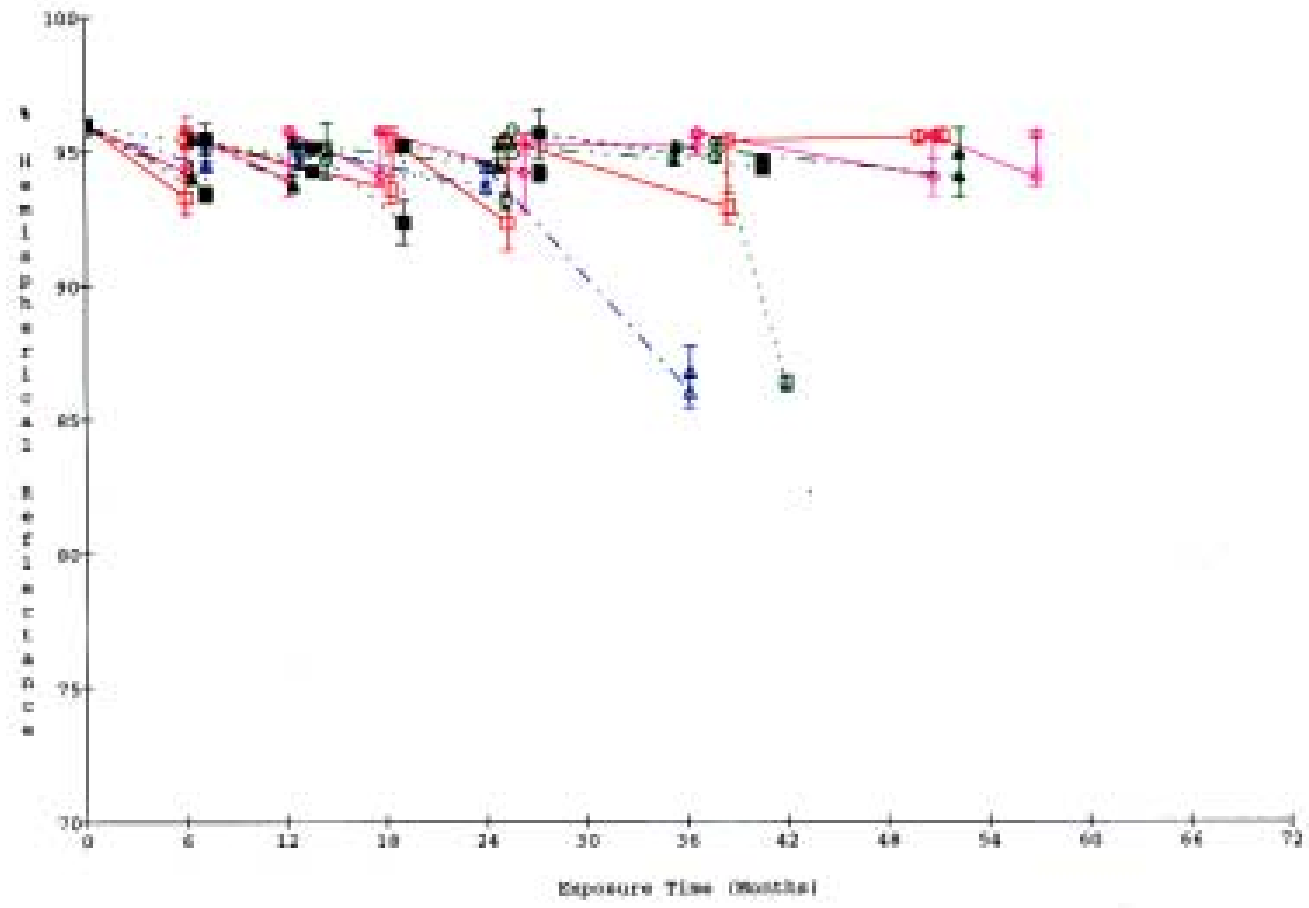



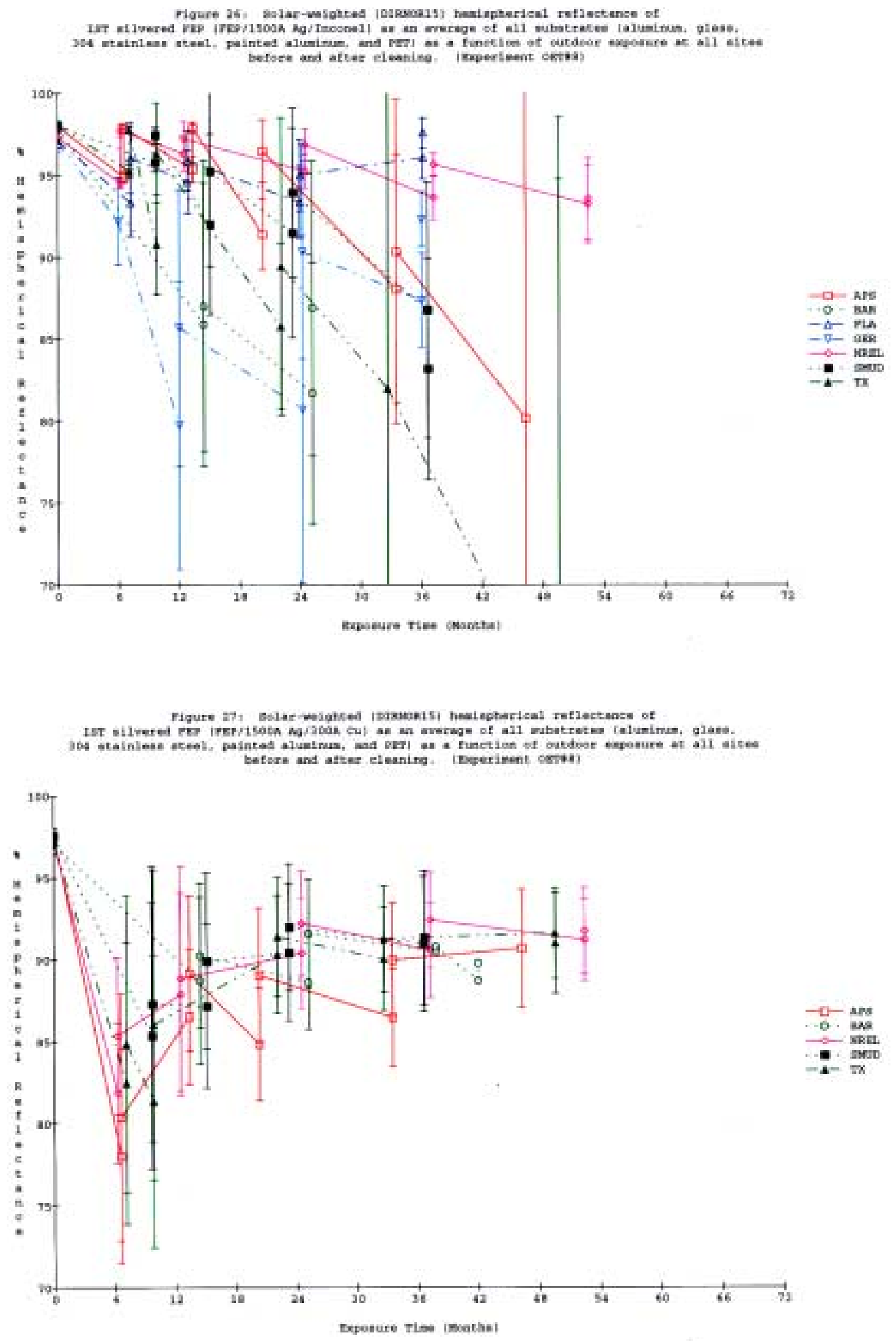


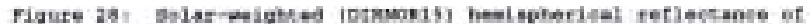

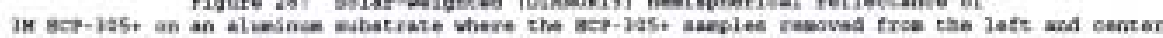

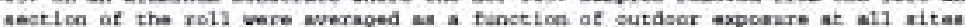

pefore and after eleaniag. (Doperiment cerv?

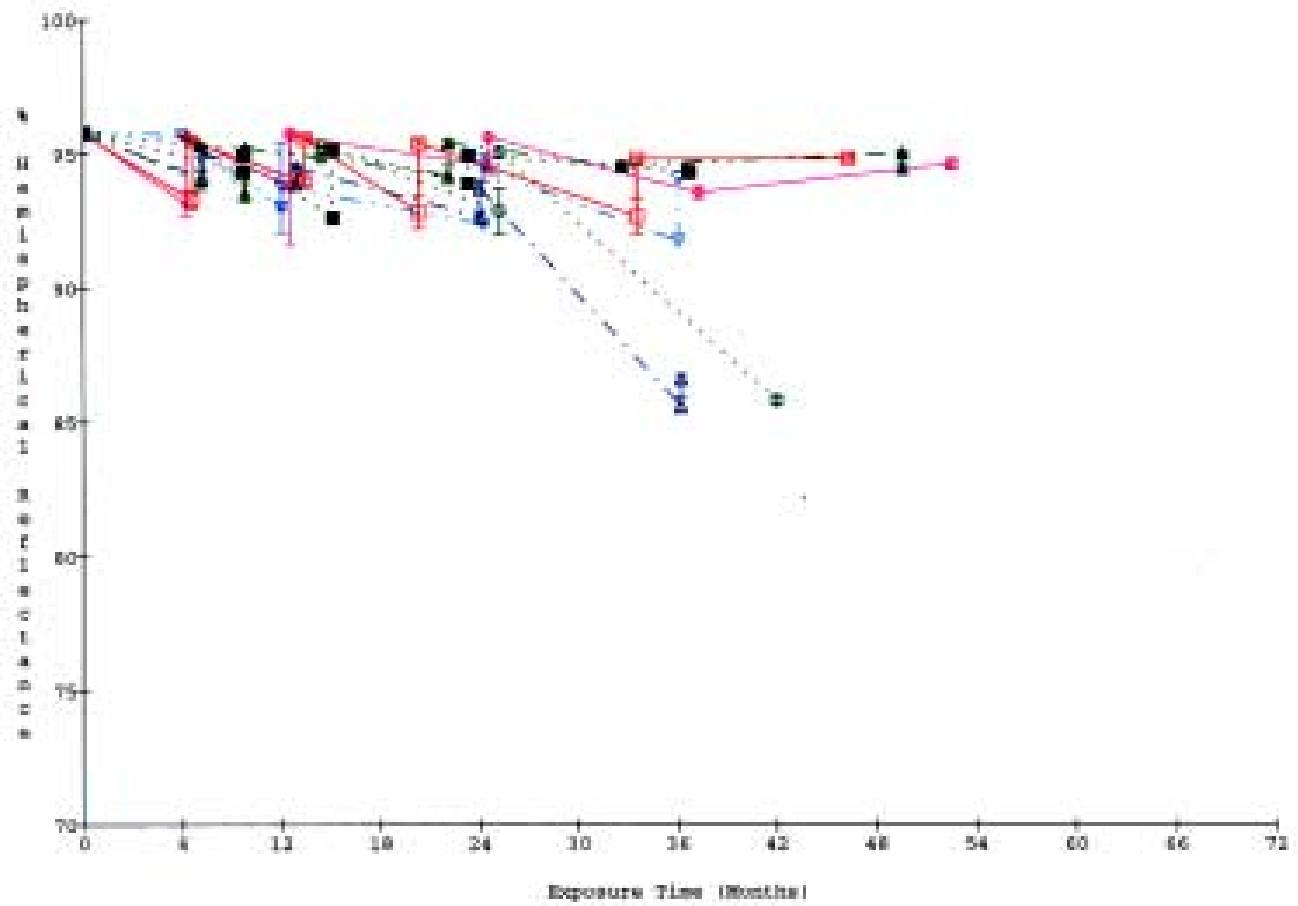

$\rightarrow 0-$ a.r

+9 - whk

$-0-$ VLA

- 100

$-4-21$

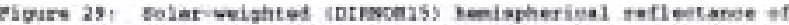

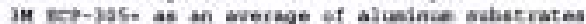

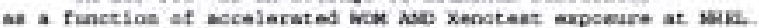
(Deperimant cens)

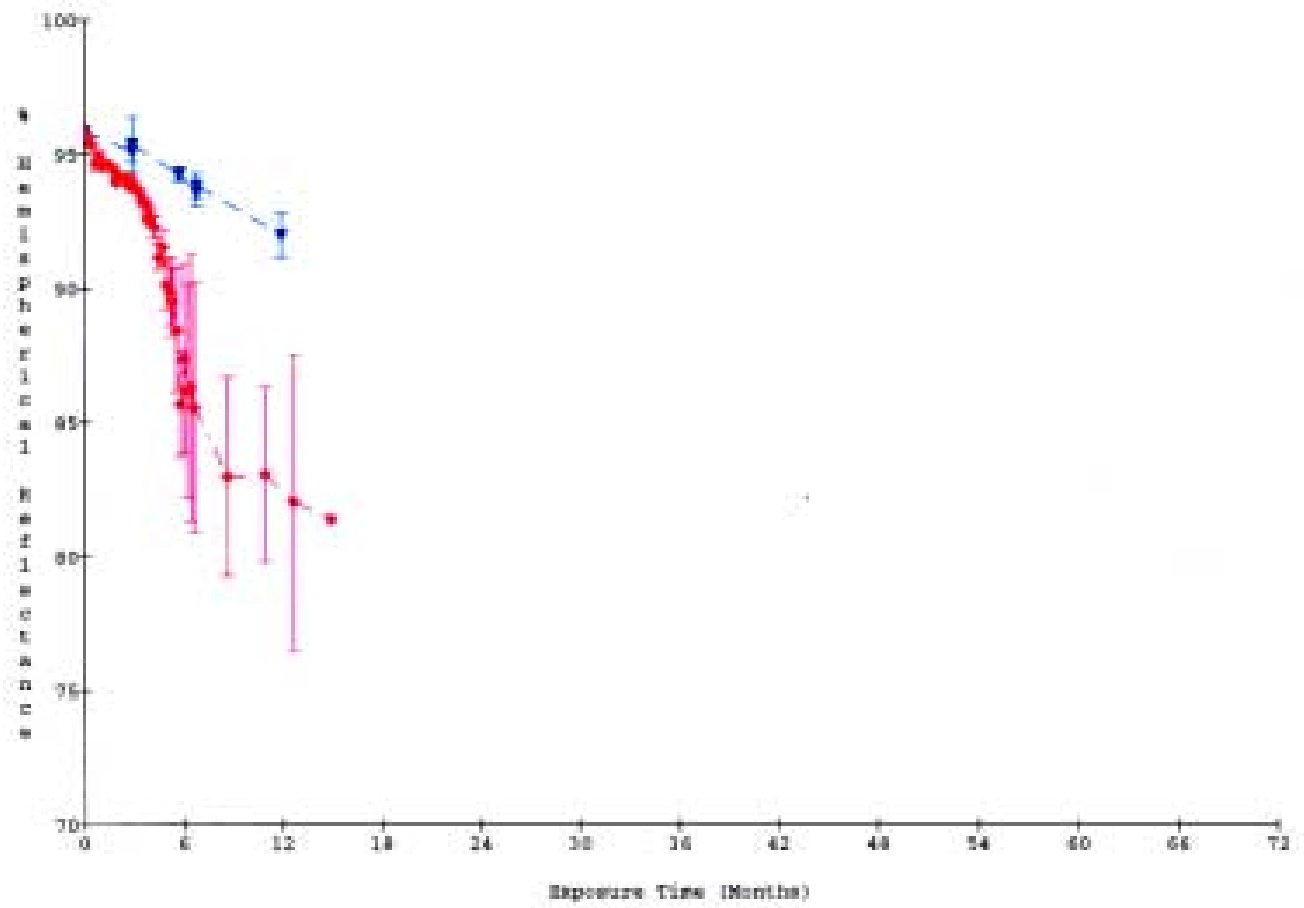




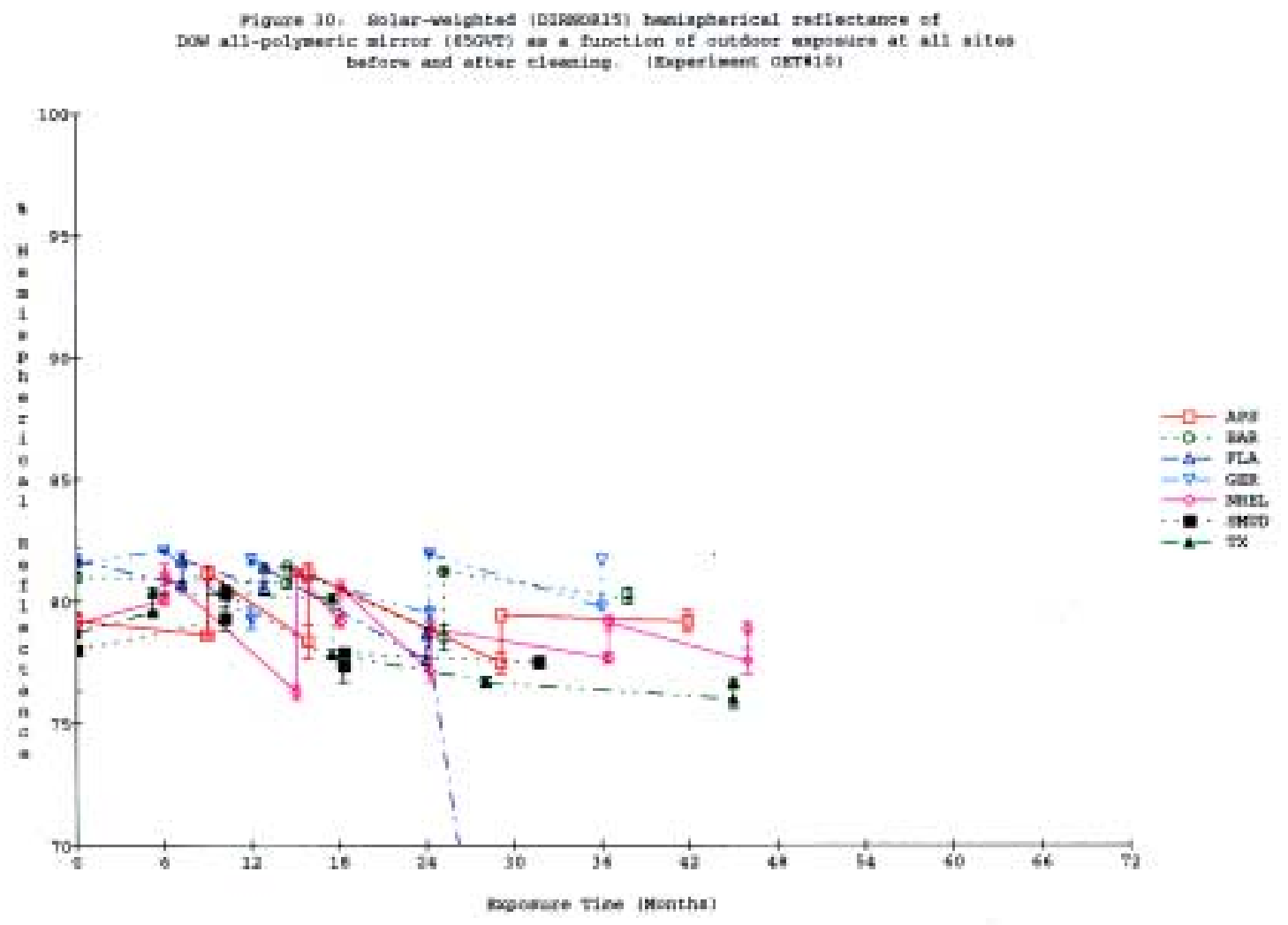

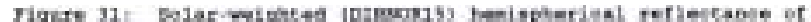

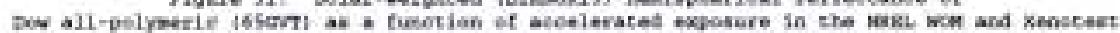
hefors and after eleasiag. Ikaperiment eeroibi

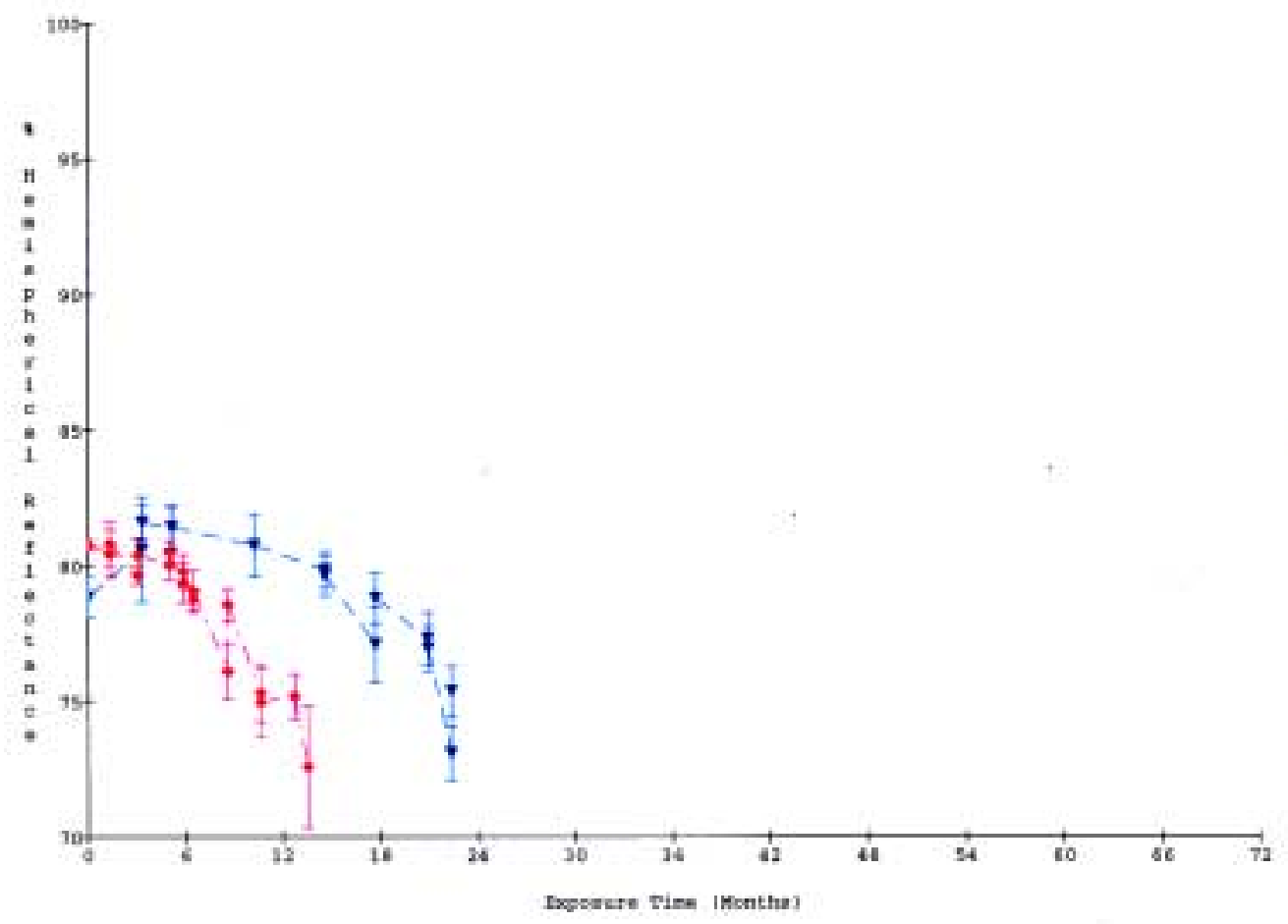




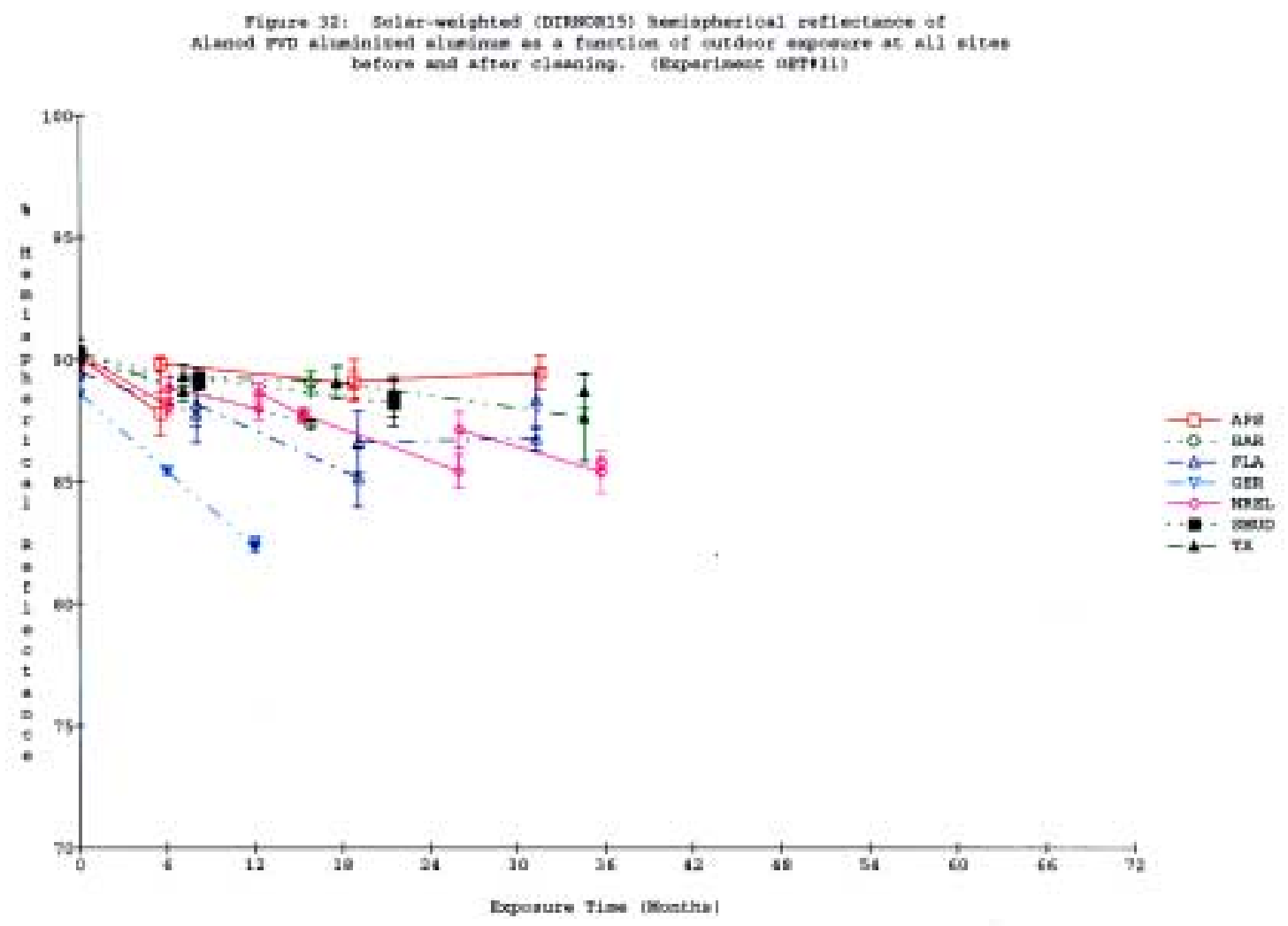

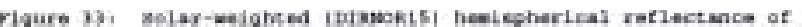

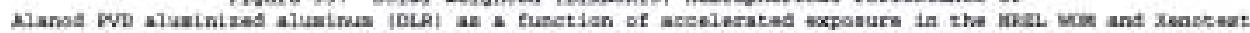
before and after cleaning. [Degeriment oerriz]

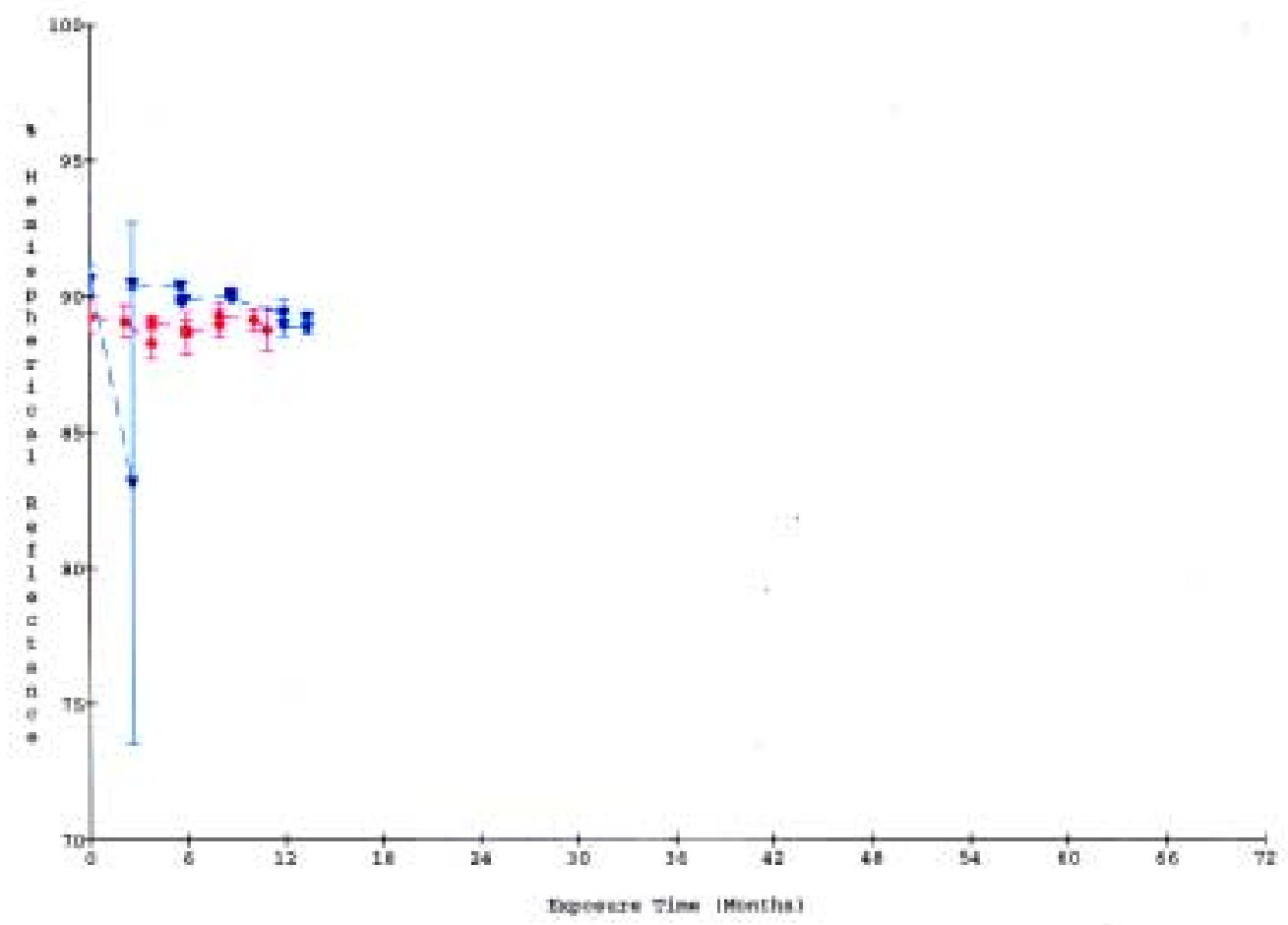




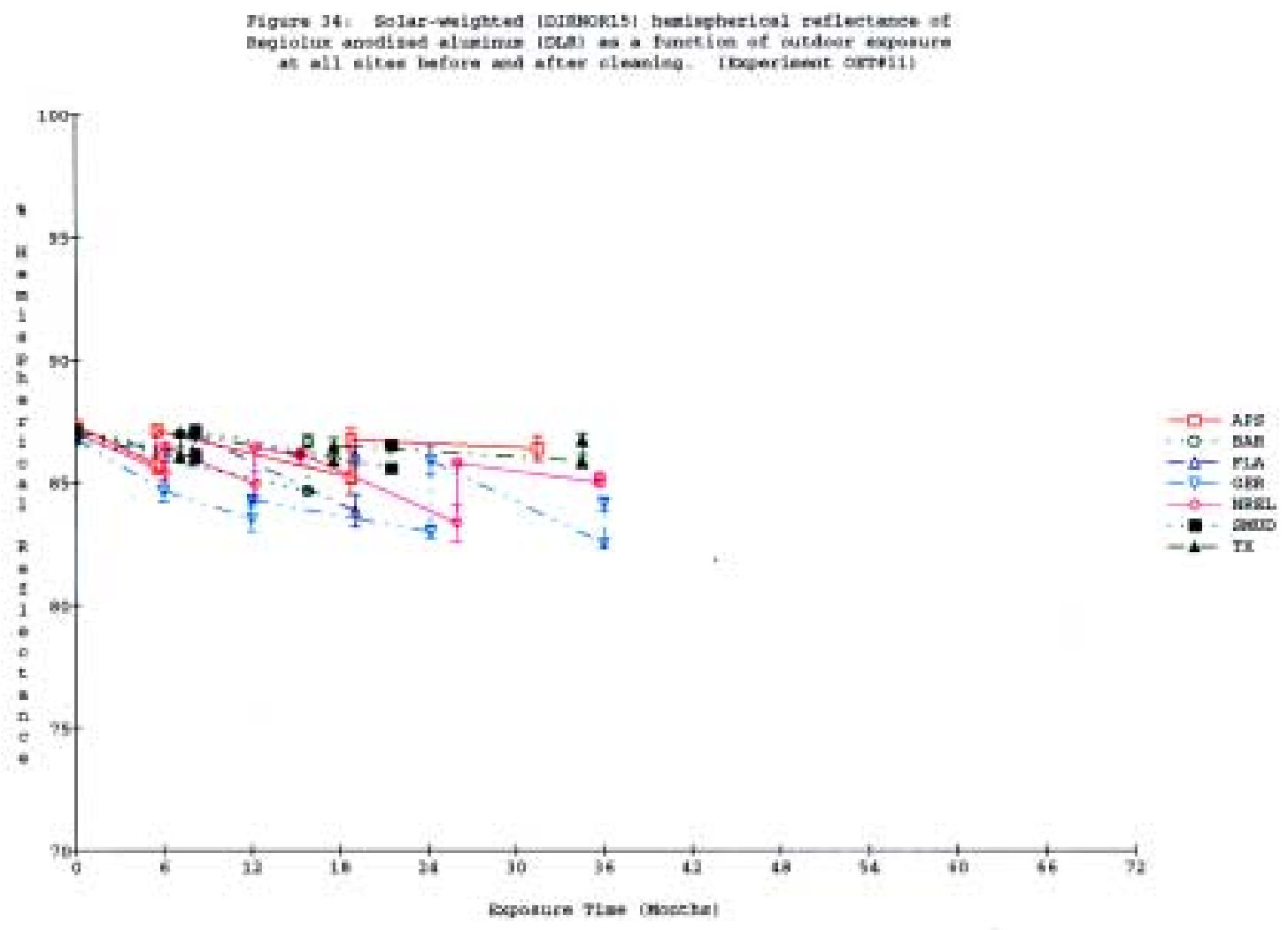

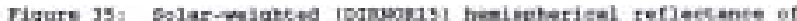

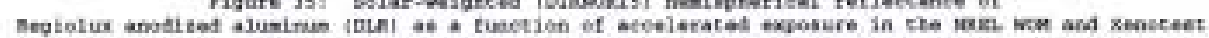
before and afcer eleaning inoperiment cossili!

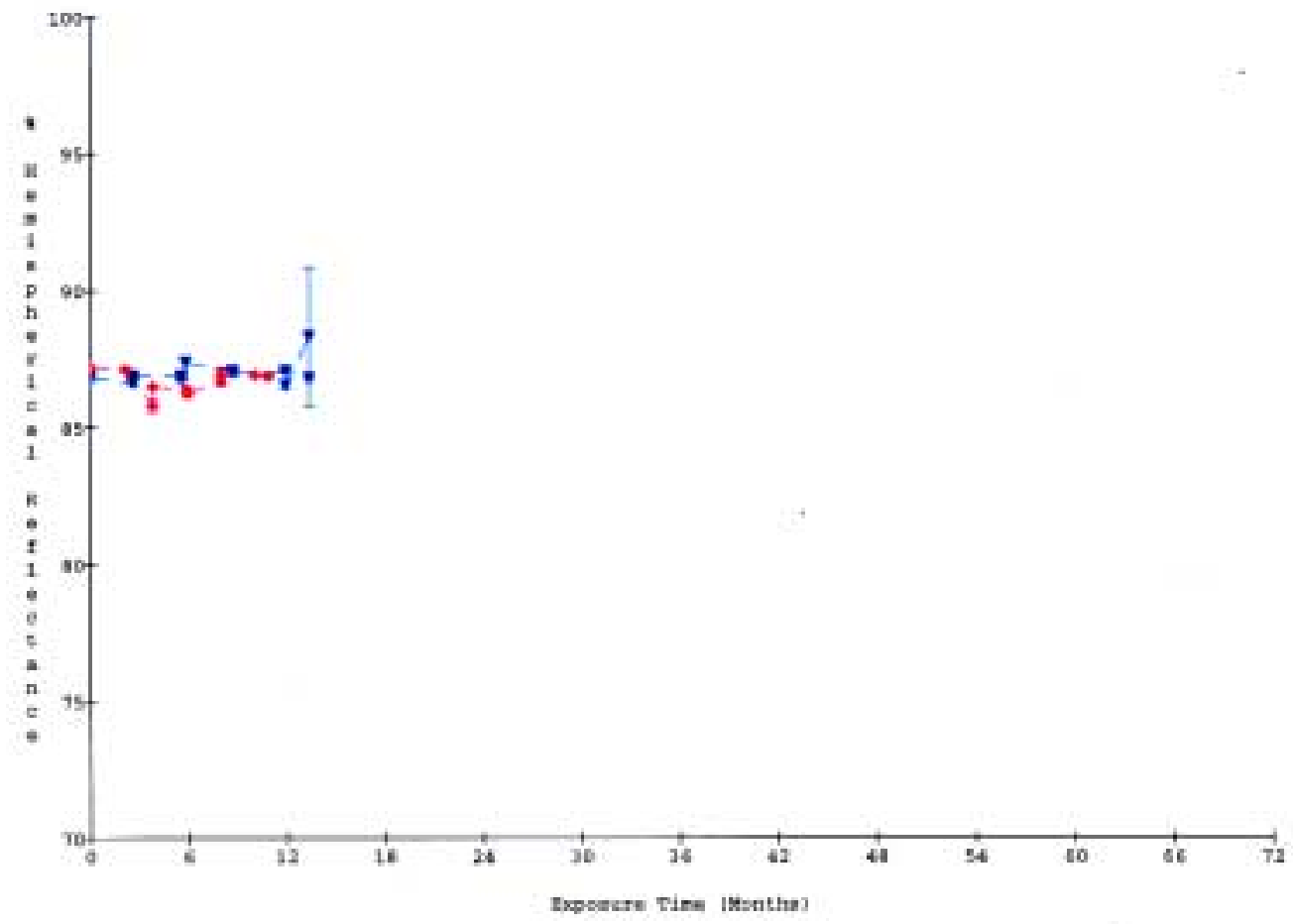




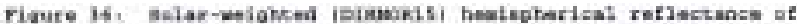

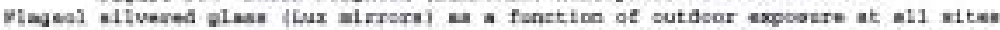
before and aftex eteaning. IDeperiment cervili

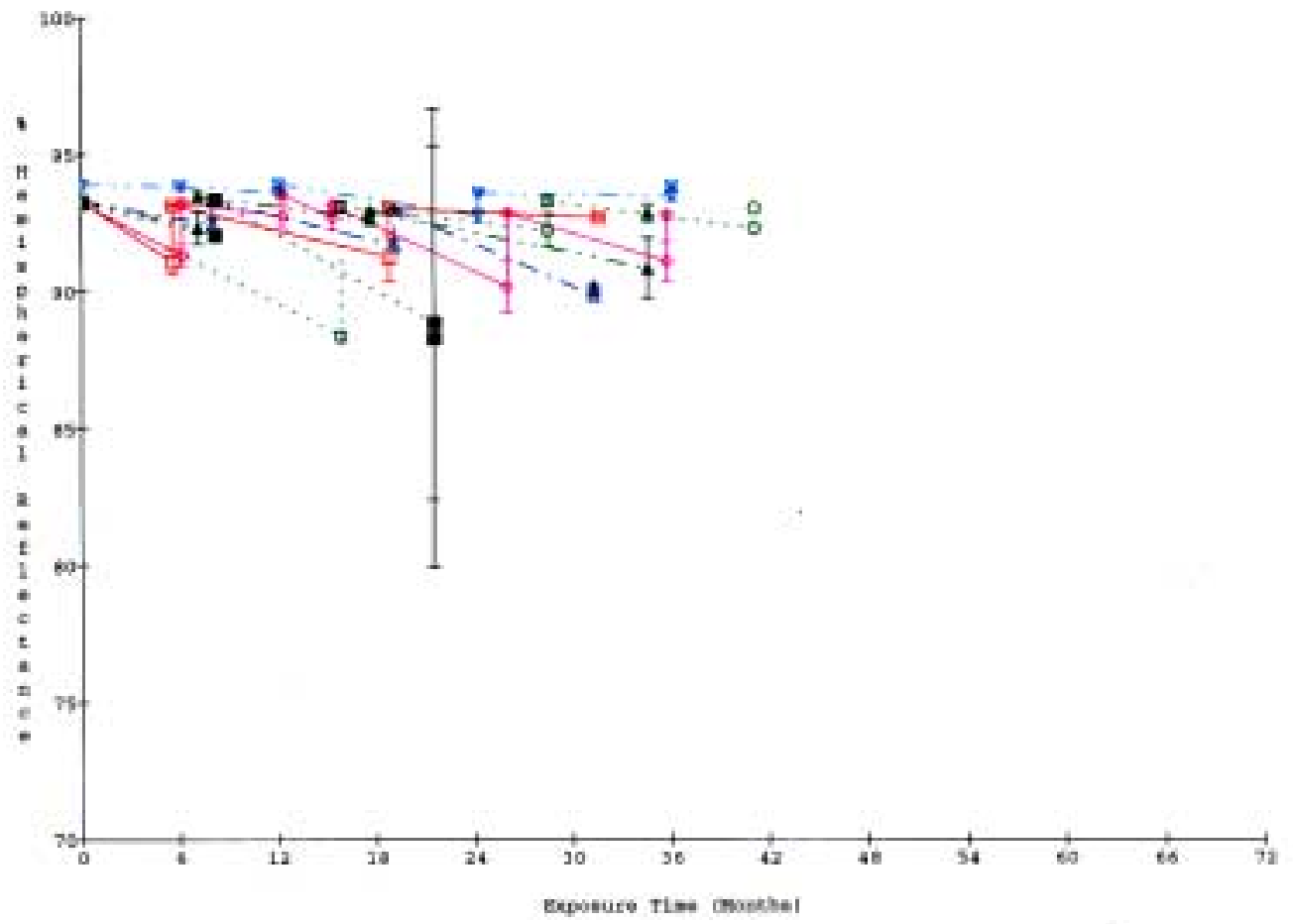

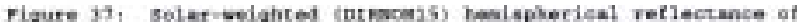

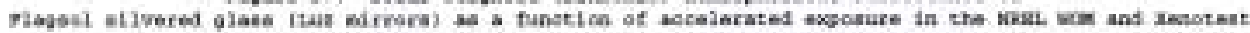

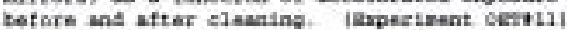

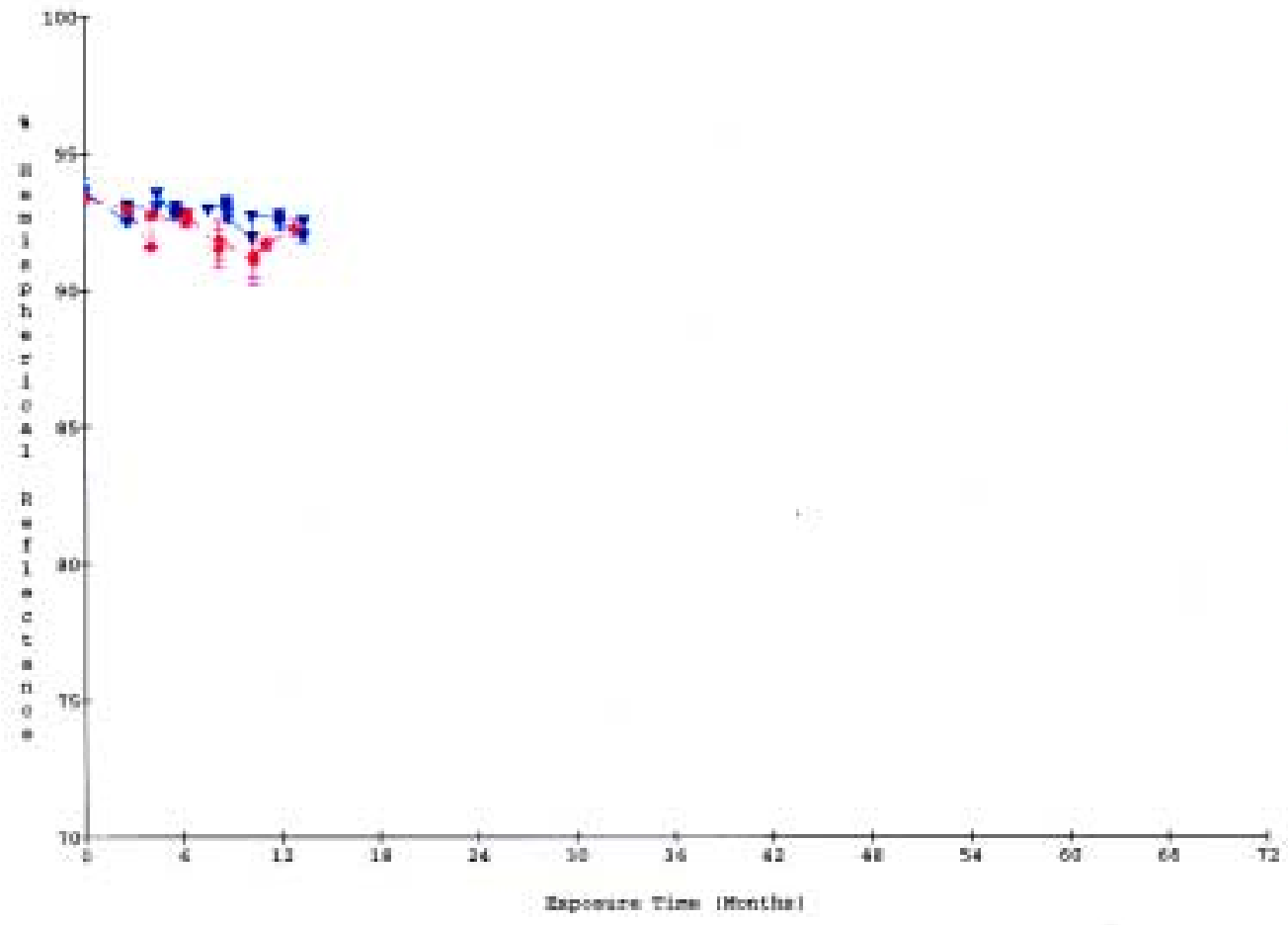




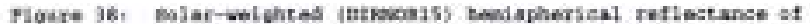

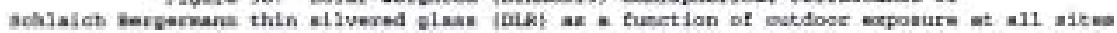
before and aftar elowing. IRrperimant orro117

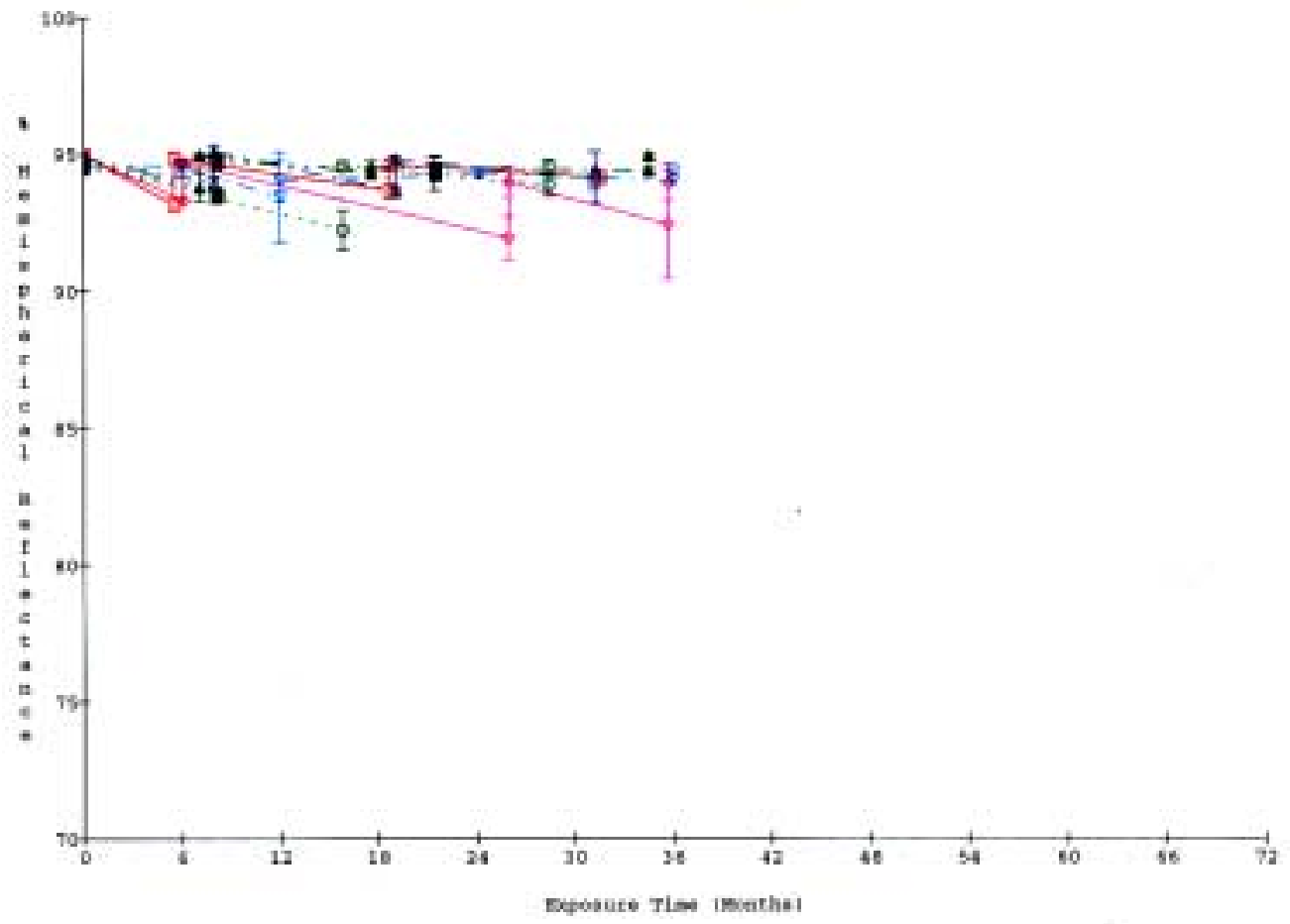

Figure 39, aolar-weightel (erbusas5) healapierical refjectance of

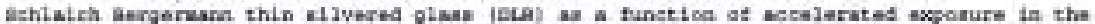

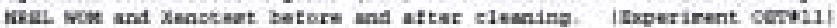

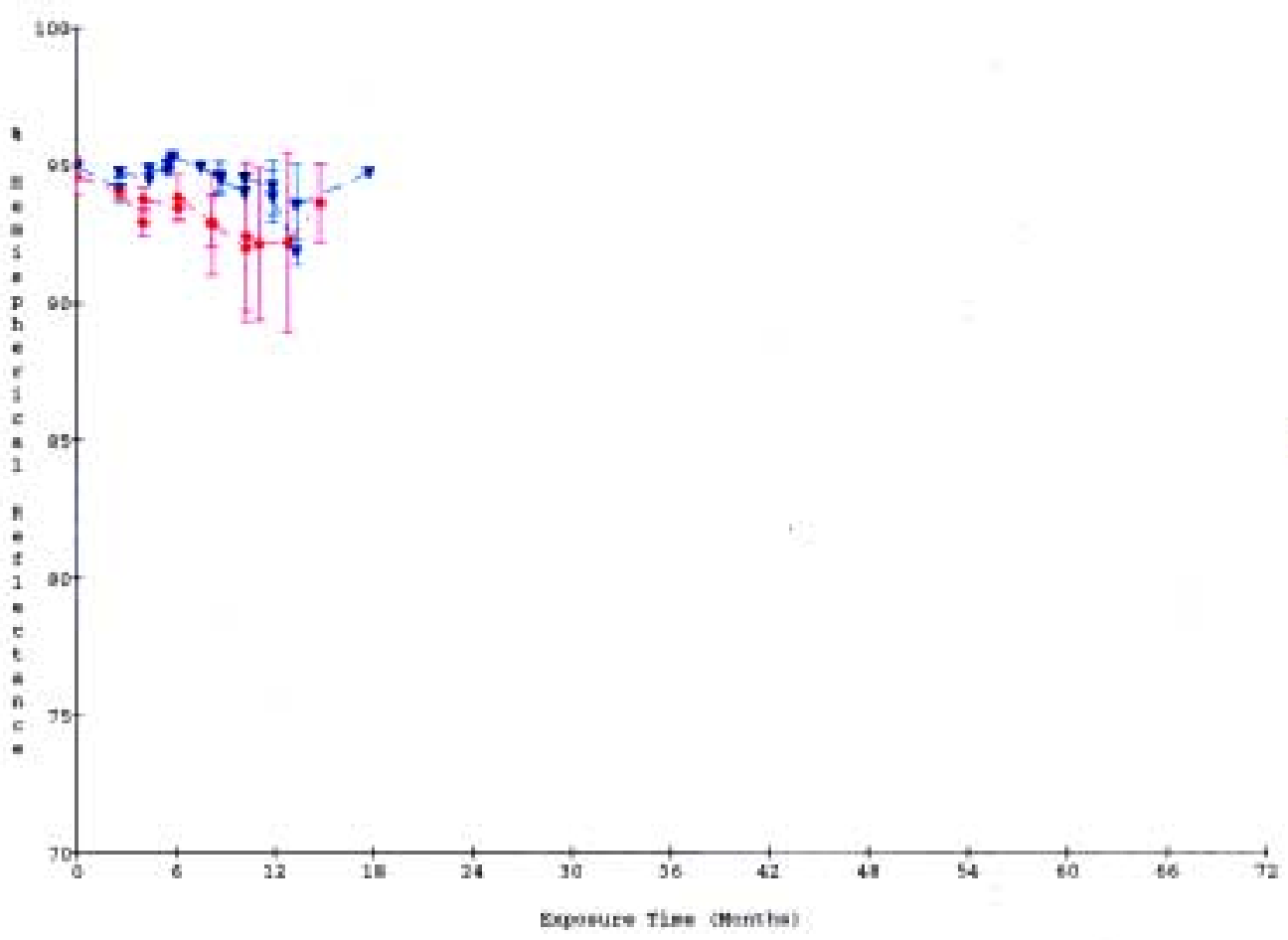




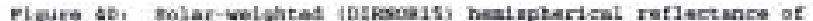

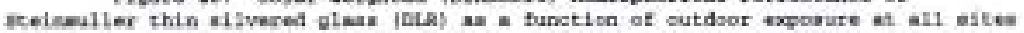

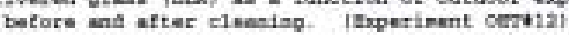
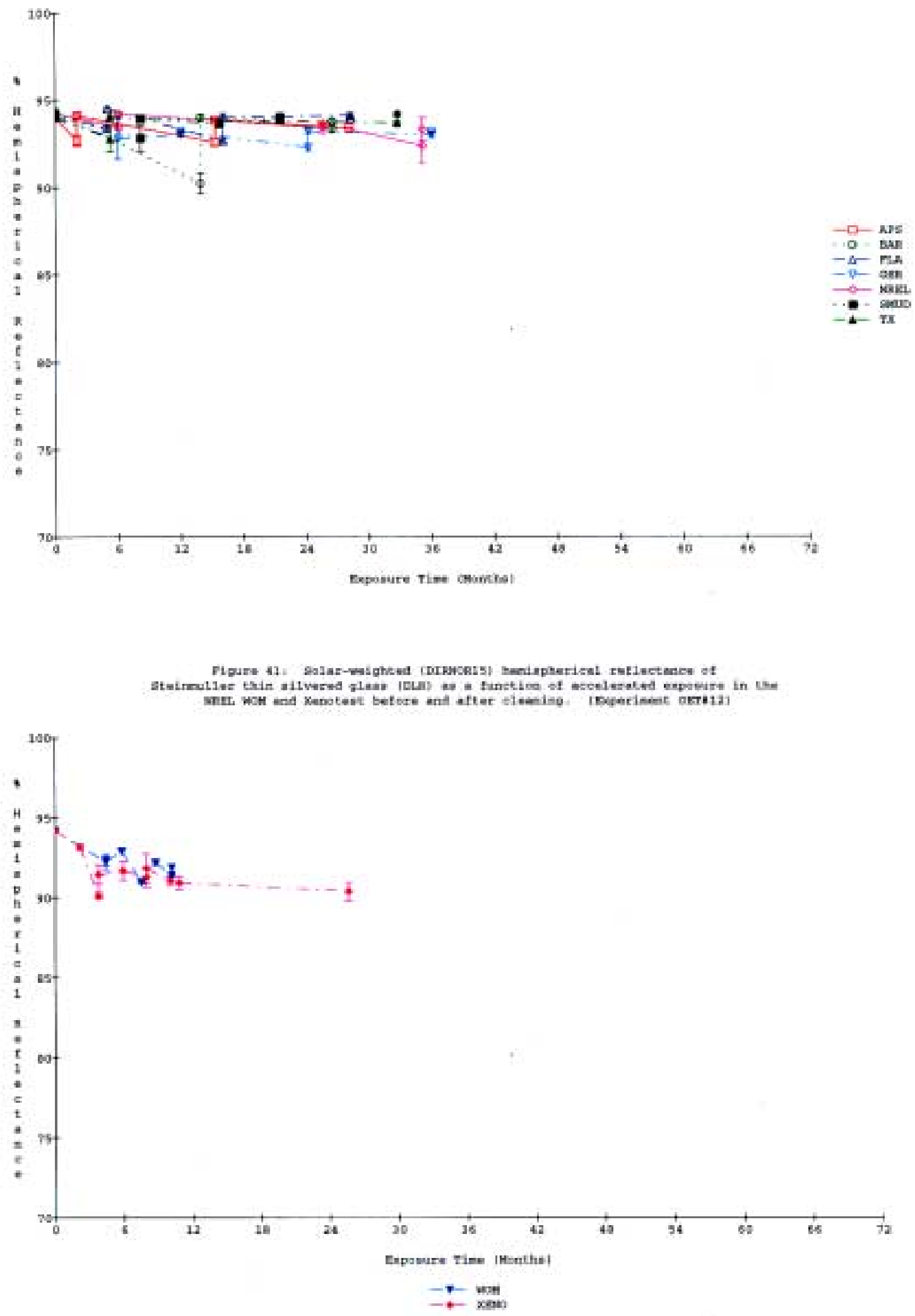


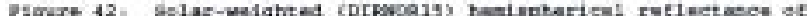

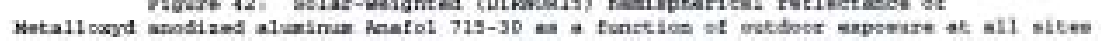
before and atter eleaning. IBoperiment orrtiss

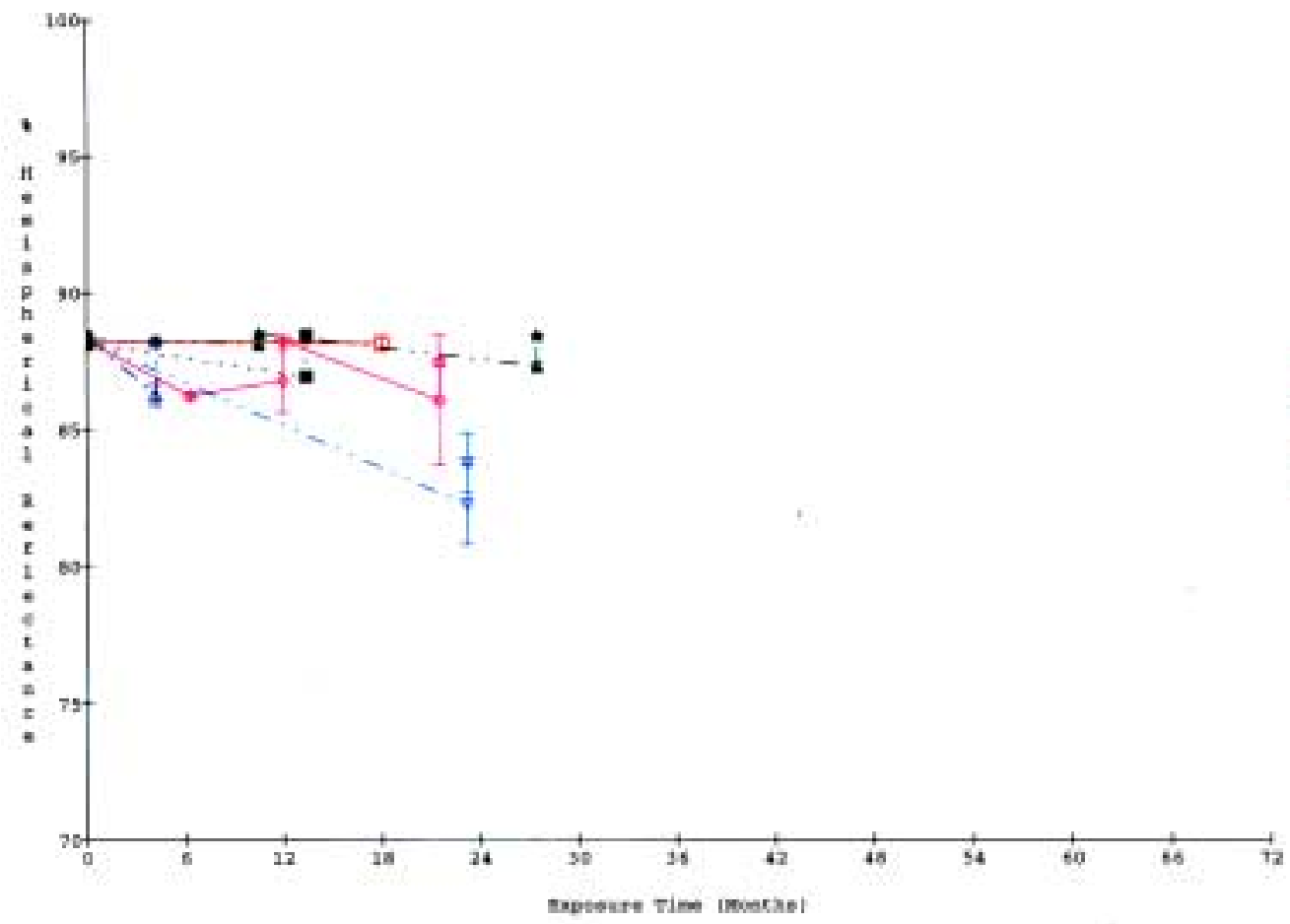

Figure 43, soler weighted tothorsis hemisherieal reflectanes of

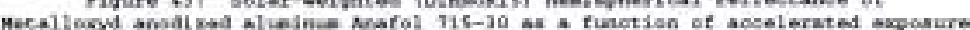

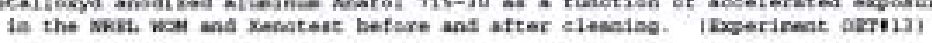

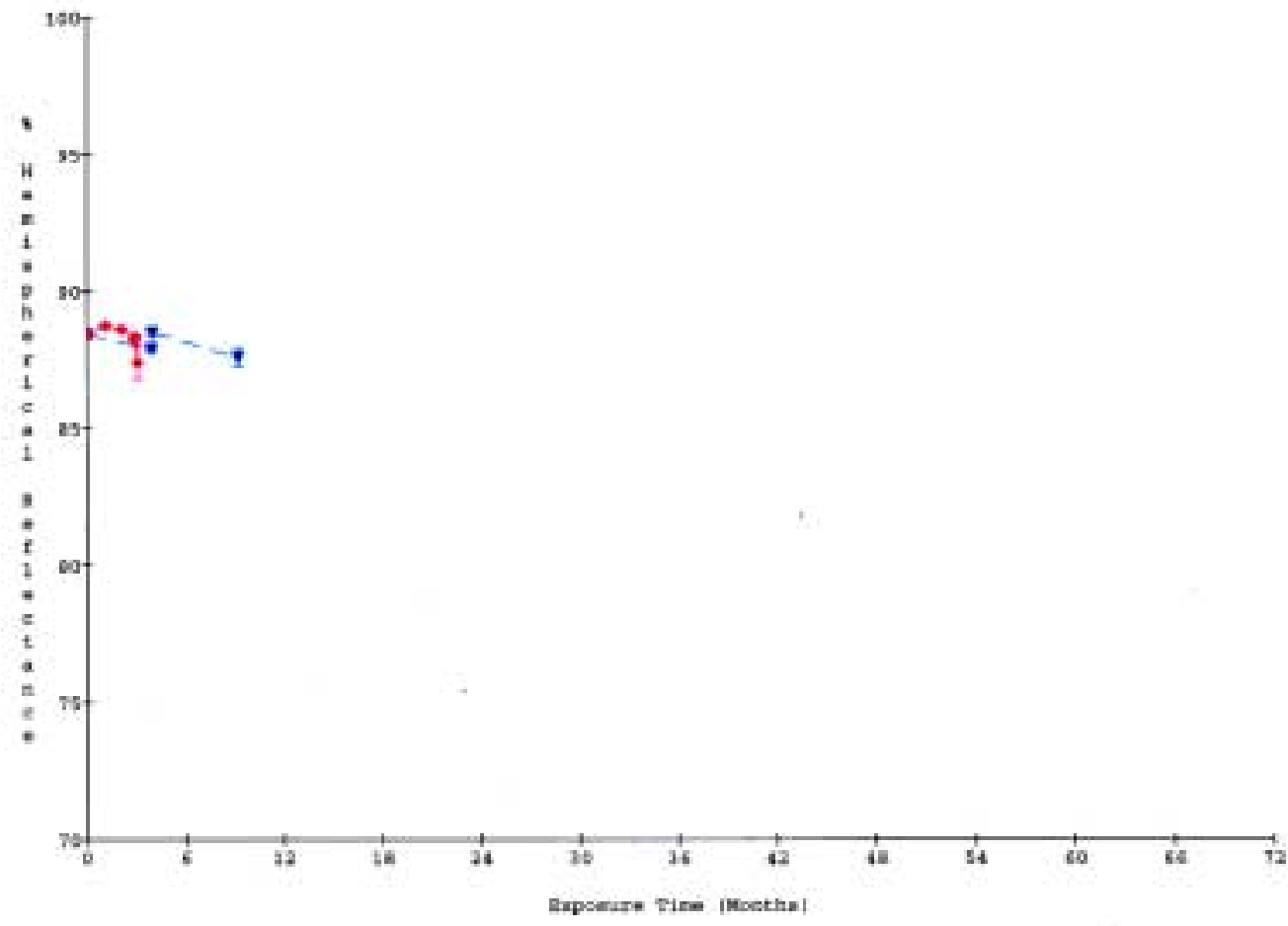




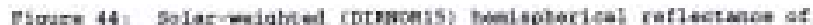

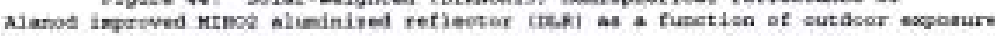
of all sites hefore and after ejaning. (Raperiant oentid
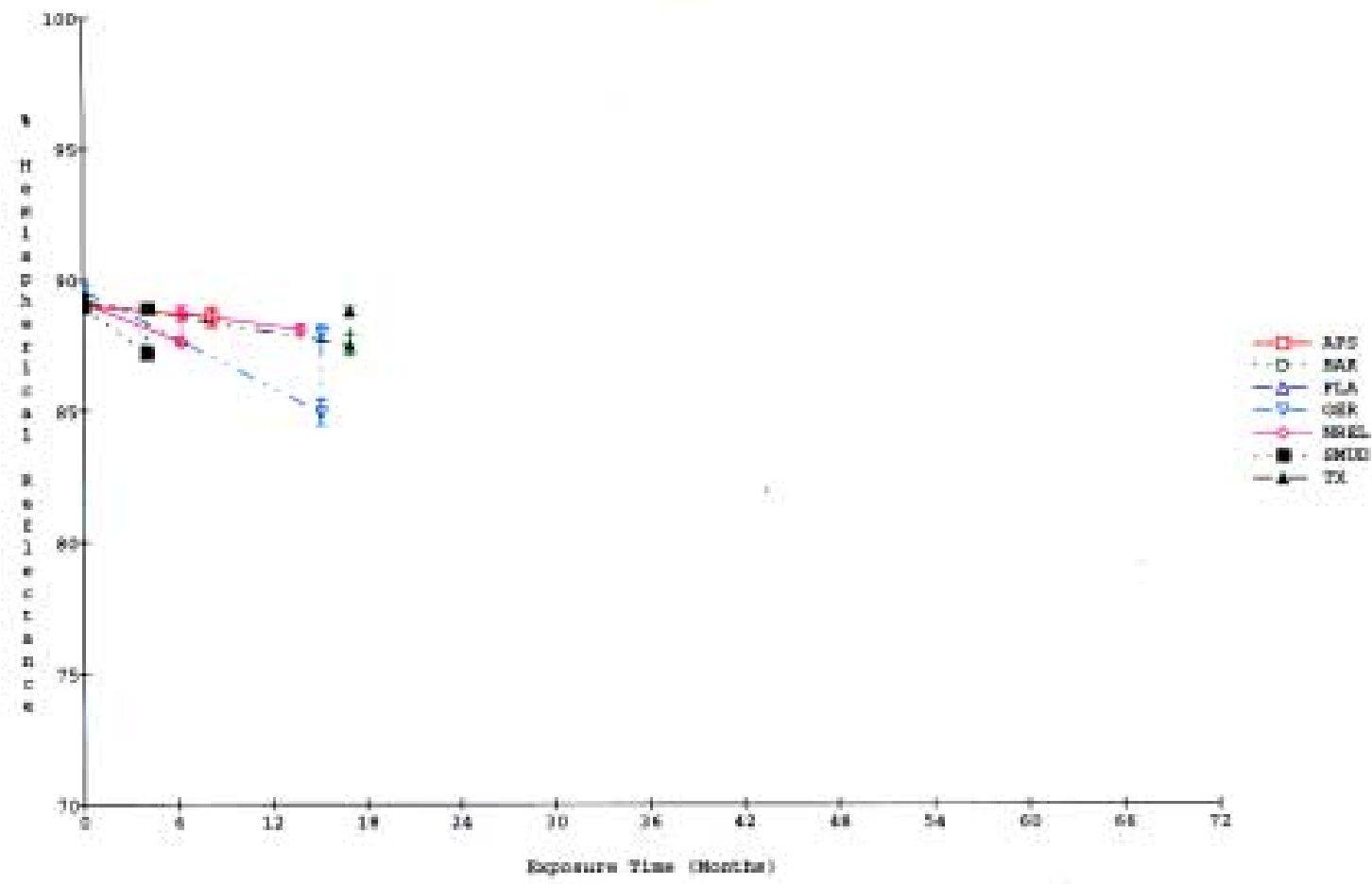

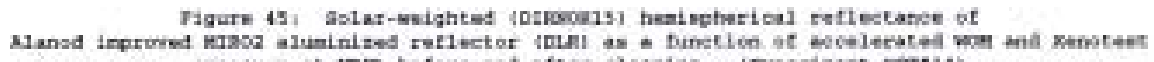

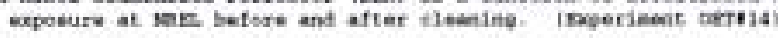

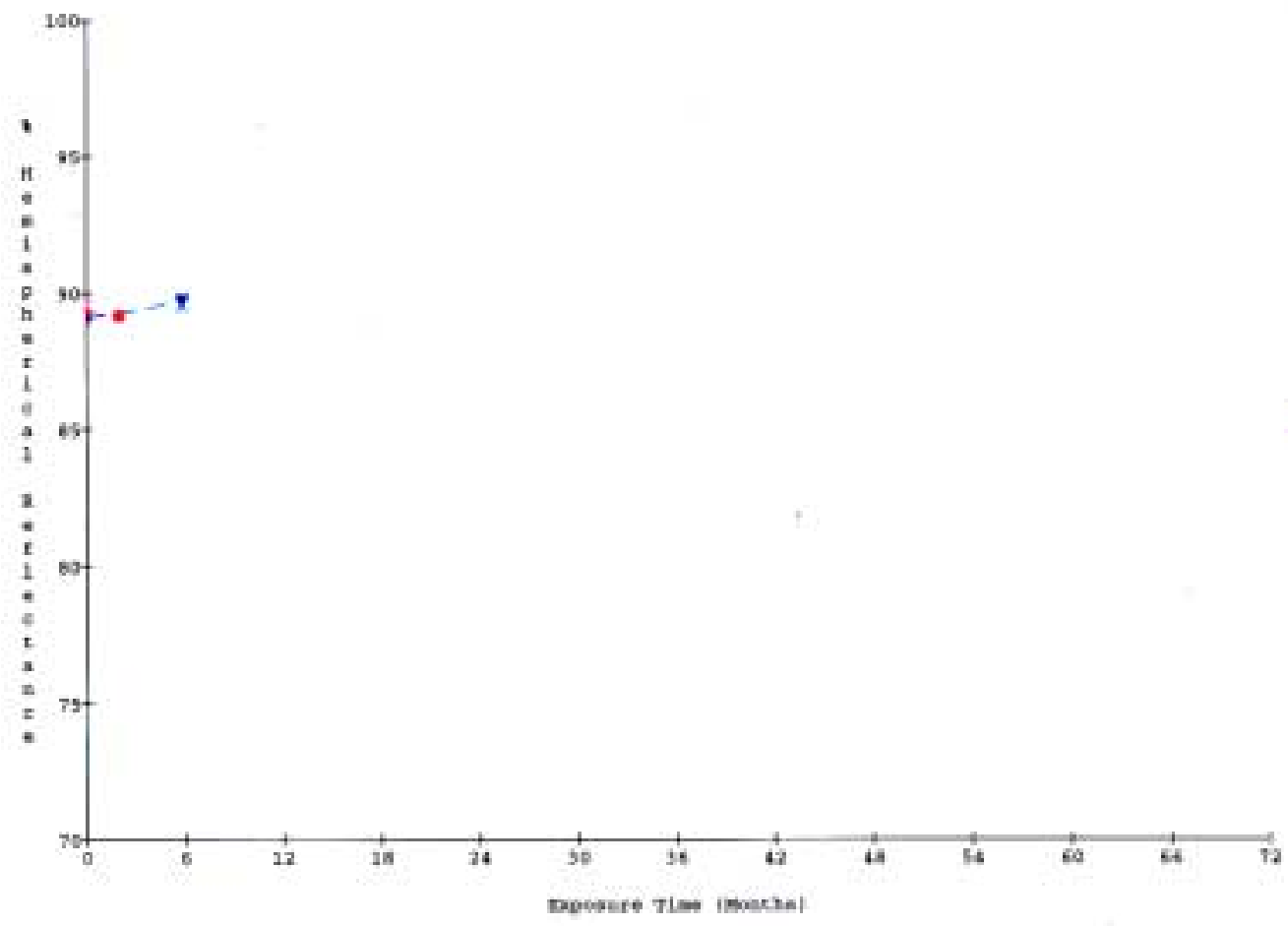




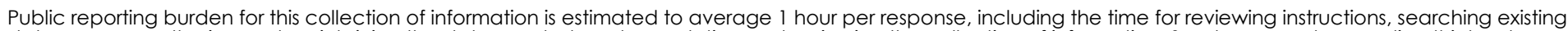

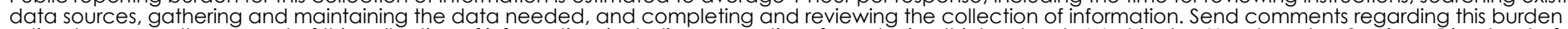

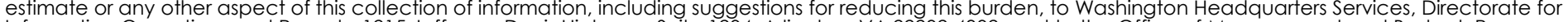

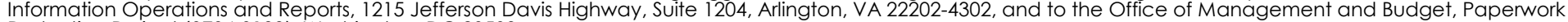
Reduction Project (0704-0188), Washington, DC 20503.
1. AGENCY USE ONLY (Leave blank)
2. REPORT DATE
March 2000
3. REPORT TYPE AND DATES COVERED
Technical Report

4. TITLE AND SUBTITLE

Optical Durability Testing of Candidate Solar Mirrors

6. $\operatorname{AUTHOR}(S)$

G. Jorgensen, C. Kennedy, D. King, K. Terwilliger

7. PERFORMING ORGANIZATION NAME(S) AND ADDRESS(ES)

\section{PERTORMING ORGANIZAIION NAME(S) AND ADDRESS(ES)}

9. SPONSORING/MONITORING AGENCY NAME(S) AND ADDRESS(ES)

National Renewable Energy Laboratory

1617 Cole Blvd.

Golden, CO 80401-3393

5. FUNDING NUMBERS

$\mathrm{C}:$

TA: CP013200

8. PERFORMING ORGANIZATION REPORT NUMBER

10. SPONSORING/MONITORING AGENCY REPORT NUMBER

1. SUPPLEMENTARY NOTES

12a. DISTRIBUTION/AVAILABILITY STATEMENT

National Technical Information Service

12b. DISTRIBUTION CODE

U.S. Department of Commerce

5285 Port Royal Road

Springfield, VA 22161

13. ABSTRACT (Maximum 200 words)

Durability testing of a variety of candidate solar reflector materials at outdoor test sites and in laboratory accelerated weathering chambers is the main activity within the Advanced Materials task of the Concentrated Solar Power (CSP) Program. Outdoor exposure testing (OET) at up to eight outdoor, worldwide exposure sites has been underway for several years. This includes collaboration under the auspices of the International Energy Agency (IEA) Solar Power and Chemical Energy Systems (SolarPACES) agreement. Outdoor sites are fully instrumented in terms of monitoring meteorological conditions and solar irradiance. Candidate materials are optically characterized prior to being subjected to exposure in real and simulated weathering environments. Optical durability is quantified by periodically remeasuring hemispherical and specular reflectance as a function of exposure time. By closely monitoring the site- and time-dependent environmental stress conditions experienced by the material samples, site-dependent loss of performance may be quantified. In addition, accelerated exposure testing (AET) of these materials in parallel under laboratory-controlled conditions may permit correlating the outdoor results with AET, and subsequently predicting service lifetimes. Test results to date for a large number of candidate solar reflector materials are presented in this report. Acronyms are defined in Table 1. Based upon OET and AET results to date, conclusions can be drawn about the optical durability of the candidate reflector materials. The optical durability of thin glass (from Naugatuck, Schlaich, Bergermann und Partner, or Steinmüller), thick glass (from ATS or Flagsol), and two metallized polymers (SA-85, ECP-305+) can be characterized as excellent. The all-polymeric construction, several of the aluminized reflectors (Alanod's improved product, materials from Metalloxyd), and a metallized polymer (ECP-305) can be characterized as having intermediate durability and require further improvement, testing and evaluation, or both. A metallized polymer (SS-95), metallized fluoropolymers (until specularity can be sufficiently improved), and constructions in which adhesives are in direct contact with a silver reflective layer can be characterized as poor and do not warrant further consideration for solar applications. Recently, a number of new promising constructions have been identified including: several front-surface mirrors under an ongoing Sun $\downarrow$ Lab subcontract and prepared by Sun $\bullet$ Lab staff; a new all-polymeric construction using improved interlayer resins and incorporating UV screens; a newly available commercial solar reflector material called SolarBrite 95; and a novel commercial laminate construction co-invented by Sun $\downarrow$ Lab staff and industry collaborators.
14. SUBJECT TERMS

\section{NUMBER OF PAGES}

concentrating solar power ; optical durability ; solar mirrors ; optical materials ; reflector durability ; accelerated exposure testing ; outdoor exposure testing

\begin{tabular}{l|l|l}
\hline 17. SECURITY CLASSIFICATION & $\begin{array}{l}\text { 18. SECURITY } \\
\text { OF REPORT } \\
\begin{array}{l}\text { CLASSIFICATION } \\
\text { OF THIS PAGE } \\
\text { Unclassified }\end{array}\end{array}$ & $\begin{array}{l}\text { 19. SECURITY CLASSIFICATION } \\
\text { OF ABSTRACT } \\
\text { Unclassified }\end{array}$ \\
\hline
\end{tabular}
16. PRICE CODE

20. LIMITATION OF ABSTRACT

UL 